Vol 21 - No $1 \cdot$ March 2013

Investigating past interglacials: An integrative approach

Editors:

Dorthe Dahl-Jensen, Emilie Capron, Emma Stone, Lucien von Gunten and Thorsten Kiefer

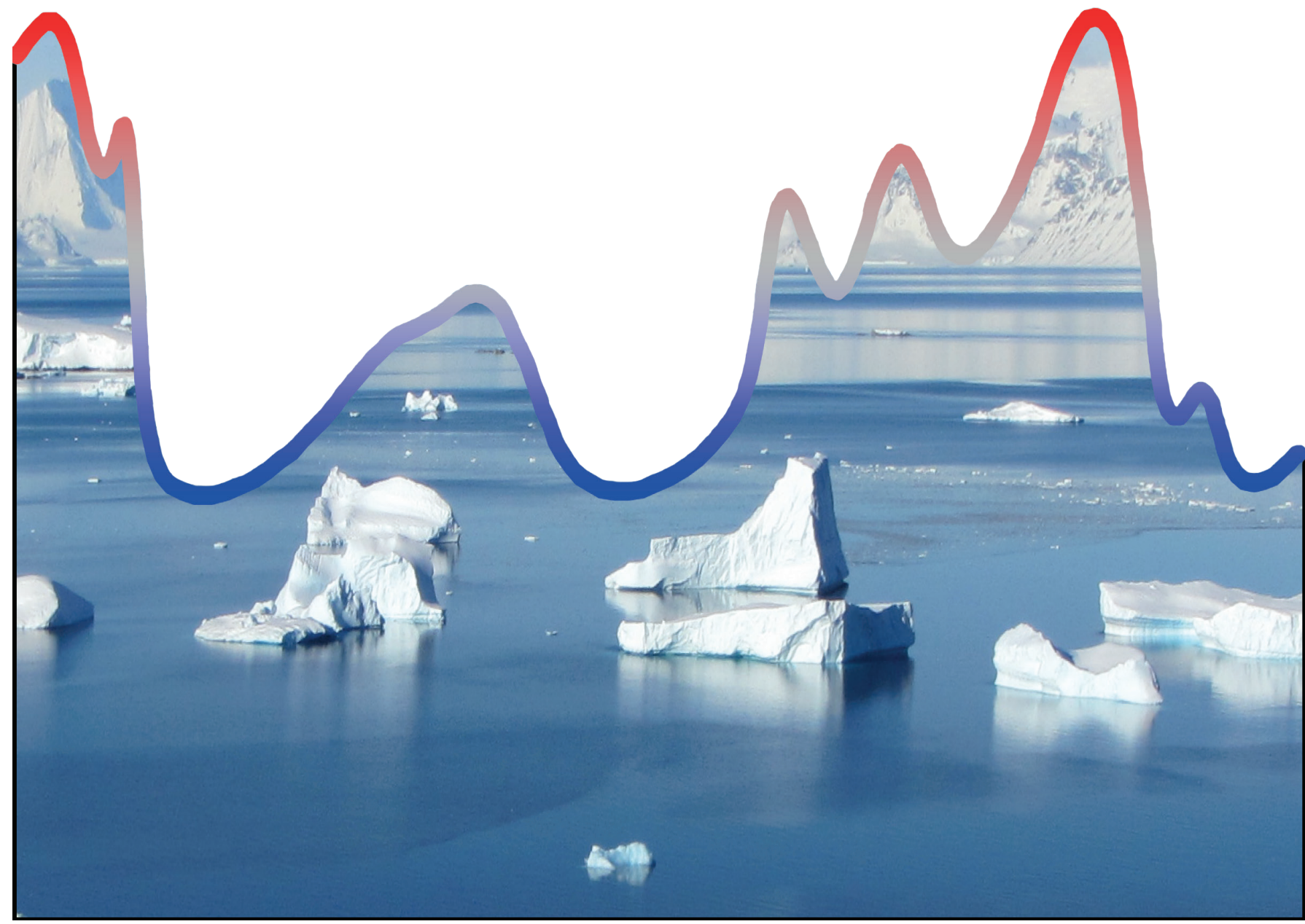

The work of Cesare Emiliani in the 1950s paved the way for research on glacial-interglacial cycles. His composite temperature curve derived from the Caribbean deep sea is displayed here, highlighting, in red, the present (left, last $10 \mathrm{ka}$ ) and the last (right, 128-116 ka) interglacials. Studying past interglacial climates provides unique insights on how natural climate changes interact with anthropogenic global warming. This PAGES newsletter highlights Past4Future project research, which aims at improving our understanding of the climate during the last two interglacials by combining paleoclimatic records with climate model simulations. 


\section{New SSC members}

PAGES is pleased to introduce three new members of its Scientific Steering Committee (SSC). Collectively they will strengthen the committee's modeling and sea level expertise.

Pascale Braconnot from heads the Climate Modeling team at Laboratoire des Sciences du Climat et de I'Environnement in Gifsur-Yvette, France. Her scientific interest con-

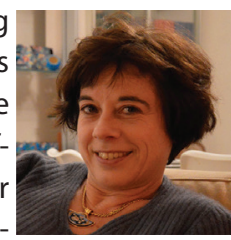
cerns the role of the ocean in climate and changes in the tropical hydrological cycle, focusing on the Afro-Asian monsoon and the El Niño-Southern Oscillation.

Hugues Goosse is a climate modeler at the Université catholique de

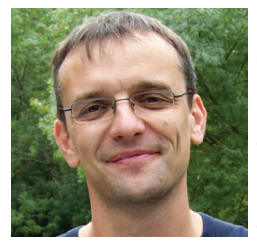
Louvain in Belgium, with a strong interest in decadal to multi-centennial climate variability and on the application of data assimilation methods in paleoclimatology.

Yusuke Yokoyama is Associate Professor at the Atmosphere and Ocean Research Institute of the University of Tokyo, Japan. His research is on proxybased sea-level change and the development of dating methods to interpret sea-level and other palaeoclimate records.

We'd like to take this opportunity to thank the members who recently rotated off the SSC, Takeshi Nakatsuka, Pierre Francus and José Carriquiri, for their invaluable support and contributions during their time on the PAGES SSC.

\section{Goa meetings}

The $4^{\text {th }}$ PAGES Open Science Meeting (OSM) and $2^{\text {nd }}$ Young Scientists Meeting (YSM), which were held in February 2013 in Goa, India, fostered scientific exchange and collaboration amongst participants from around the world. If you weren't amongst those attending, you may still participate retrospectively in the events: View sessions and abstracts on the website, and stay tuned for presentation, poster, photo and video uploads (www.pages-osm.org).

\section{PAGES umbrella programs}

In April, PAGES, the Forum for Climate and Global Change ProClim, and the Oeschger Centre for Climate Change Research, will jointly host the annual meeting of the Scientific Committee of the International Geosphere-Biosphere Programme in Bern, Switzerland. The dominating topic will be the shaping of and transitioning to the Future Earth super-program (see Program
News, PAGES news 20(2)), which may become the "next big thing" in terms of Global Change science organization.

\section{Support for meetings}

During its meeting in February, the PAGES SSC granted support for a total of nine scientific and educational meetings. The next deadline for applying for PAGES meeting support is 1 May 2013. Support can be sought for workshop-style meetings relevant to PAGES Foci and Cross Cutting Themes. The three eligible categories are PAGES Working Group meetings, workshops with a design towards training or education, and an open call for other PAGES-relevant workshops. Application guidelines and forms can be found on the PAGES website (My PAGES > Meeting Support).

\section{Next newsletter issues}

The next two issues of PAGESnews will focus on ENSO and Dust. While the ENSO issue is closed, suitable articles for the Dust issue may still be included. Contact Ute Merkel (umerkel@marum.de) before 30 April 2013. As always, you are invited to submit Science Highlights, Program News, and Workshop Reports for the Open Section of PAGESnews. Find author guidelines on the PAGES website (My PAGES > Newsletter).

\section{Editorial: Past4Future - learning from interglacials}

The EU Framework Programme 7 Collaborative Project Past4Future aims to generate knowledge from climate change during past interglacials that can improve our ability to predict the future.

\section{Dorthe Dahl-Jensen ${ }^{1}$, Emilie Capron ${ }^{2}$ and Emma Stone ${ }^{3}$}

${ }^{1}$ Centre for Ice and Climate, Niels Bohrs Institute, University of Copenhagen, Denmark; ddj@gfy.ku.dk ${ }^{2}$ British Antarctic Survey, Cambridge, UK; ${ }^{3}$ School of Geographical Sciences, University of Bristol, UK

lobal warming strongly influences the future prospects of both citizens and policy makers. The change of climate calls for innovative decisions on food production, risk management, and energy policy. Uncertainties concerning the interplay between natural climatic and environmental variations and man-made changes remain a major obstacle for defining plausible trajectories of climate change in the coming decades. This is important for decisions on mitigation, adaptation, and risk reduction and our capability to monitor the efficiency of climate policy frameworks to reach desired climate targets.

By studying past climate changes when the Earth was as warm or warmer than at present we can gain knowledge about natural climatic and environmental variability on decadal to multi-millennial timescales and relate them to the recent changes originating from anthropogenic influences.
Paleorecords show that the climate system has changed abruptly in the past (e.g. Alley et al. 1997; Dansgaard et al. 1993; Steffensen et al. 2008), but the extent of such changes during warm periods has still to be fully investigated. Understanding the climate dynamics and variability during warm time periods, and the likelihood of abrupt changes within the system, requires improved insight into interactions between forcings such as freshwater 
discharge, changes in solar irradiance, volcanic eruptions and greenhouse gas concentration, and sensitive components of the climate system such as monsoon patterns, thermohaline circulation, sea ice extent, and ice sheets (IPCC AR4 report 2007).

In this context, "Past4Future", a Collaborative Project launched in January 2010 under the $7^{\text {th }}$ Framework Programme of the European Commission, aims at improving our understanding of the processes involved in the climatic variations over the last two interglacial periods. PAGES is a project partner charged with project outreach through the PAGES newsletter and a website. Moreover, Past4Future science is internationally interwoven with several PAGES activities, such as the PAGES working groups on sea level (PALSEA), past interglacials (PIGS), paleofire (GPWG), and sea ice (SIP). This special issue of the PAGES newsletter is accordingly sponsored by Past4Future. It illustrates the research undertaken until now in the framework of the project and reports about recent PAGES related activities.

\section{The Past4Future project}

The Past4Future project uses existing and new paleoclimate records from ice cores (e.g. Dahl-Jensen et al.; Masson-Delmotte et al. this issue), marine cores (e.g. Gersonde and de Vernal; Andresen et al. this issue), speleothems (e.g. Genty et al. this issue), and pollen amongst others. Combining the globally distributed records from these archives enables us to reconstruct climatic and environmental changes during the present interglacial (the Holocene) and the last interglacial (hereafter, LIG). In addition to providing the highest resolved and most comprehensive datasets available for studying past interglacials, these two time periods constitute distinct case studies to explore climate feedbacks in response to orbital forcing. The LIG also appears to be exceptionally warm in the context of the past 800 ka (e.g. Jouzel et al. 2007; Lang and Wolff 2011; NEEM community members 2013). As a consequence, it provides insights for future climate change driven by anthropogenic greenhouse gas emissions (e.g. Otto-Bliesner et al. 2006; Turney and Jones 2010). The paleoclimatic records are combined in integrated analyses with climate models of various degrees of complexity (Stone et al. this issue a), proxy modeling (Sime et al. this issue) and data assimilation (Mairesse et al. this issue).

As such, the Past4Future project is focused around the following four key questions:

\section{What is the risk of abrupt changes in interglacials?}

Abrupt changes during interglacials are caused by poorly understood complex interactions of internal and external forcings. Investigation of the forcings, reaction of the climate system, and impacts on the environment are carried out through integration of synchronized observations and model output. Results aim to inform on the risk of abrupt changes in the next century when man-made forcings such as increasing greenhouse gases add a dimension to the complexity of the system (Sapart et al. 2012).

\section{Can we understand the greenhouse gas records of the interglacial periods?}

On orbital timescales greenhouse gases mirror climate changes with lower concentrations in cold periods and higher concentrations in warmer periods (e.g. Lüthi et al. 2008). Studying greenhouse gas changes across past interglacials offers insights into the dynamics of greenhouse gas budgets and fluxes, e.g. through variations in the capacity of the ocean and terrestrial biosphere to absorb atmospheric $\mathrm{CO}_{2}$, and the possibility of methane release in response to warming. Understanding the biogeochemical cycle in the past is therefore crucial for predicting the future (see Brücher and Brovkin, this issue).

\section{What is the risk of rapid collapse of polar ice sheets?}

Sea level changes are one serious risk that strongly influences the living conditions for the large populations in close proximity to the sea (e.g. Bangladesh). The IPCC Fourth Assessment Report (AR4) estimates a sea level rise between 18 and $59 \mathrm{~cm}$ by the year 2100 . This estimate range, however, did not include the full effect of possible changes in ice sheet dynamics. Therefore, the AR4 probably underestimates the upper bound for sea level rise. The LIG has experienced sea level highstands several meters above today (Kopp et al. 2009; Dutton and Lambeck 2012) attributed, in part, to a reduction in ice sheet volume in both polar regions. Thus studying the LIG can advance our ability to predict reaction times and thresholds for the ice sheets (Siddall et al.; Masson Delmotte et al. this issue).

\section{Did ocean circulation change significantly during previous interglacials?}

Ocean circulation strongly influences the climate of Europe, especially through the warm surface currents in the North Atlantic Ocean (e.g. Jacob et al. 2005). During glacial periods the ocean circulation has abruptly changed resulting in dramatic climate changes. The interglacial periods offer an opportunity to see to what degree shutdowns or slowdowns of the thermohaline circulation occurred in previous warm periods (e.g. Bakker et al. 2012; Govin et al. 2012).

The content of this PAGES newsletter strongly reflects the cross-disciplinary nature of the Past4Future work packages which focus both on data and modeling targets. The newsletter begins by giving a flavor of how to collect paleodata in the field including the logistics and challenges involved (Genty et al.; Gersonde and Seidenkrantz; Steffensen et al. this issue). In addition, it highlights the challenges encountered by the climate modelers in the computer lab (Stone et al. this issue b). The Science Highlights report on a diverse range of topics: reviews of previous research (e.g. Capron et al. this issue), collaborative modeling efforts, new methodological approaches (e.g. Kerhwald et al. this issue), data compilation etc. Indeed, one product of the Past4Future project, aside from new research results, is the integration of the different research groups to successfully address the challenge of model-data comparison.

The Past4Future project is ongoing until 2015. The results are already significant but they also show the challenges ahead in providing a coherent story of climate interactions in the past and how this might be used to inform on future climate.

\section{Selected references}

Full reference list online under:

http://www.pages-igbp.org/products/newsletters/ref2013_1.pdf

\section{Alley RB et al. (1997) Geology 25: 483-486}

Bakker P, Van Meerbeeck CJ, Renssen (2012) Climate of the Past 8: 995 1009

Govin A et al. (2012) Climate of the Past 8: 483-507

Lang N, WolffEW (2011) Climate of the Past 7, 361-380

Turney CSM, Jones RT (2010) Journal of Quaternary Science 25: 839-843 


\section{Past4Future stakeholder survey}

Henning Thing

Centre for Ice and Climate, Niels Bohr Institute, University of Copenhagen; thing@gfy.ku.dk

$T^{n}$ he European Union-funded Past4Future project aims at improving our knowledge of the climate system and the occurrence of abrupt climate changes during the last two interglacials, thereby paving the road for reducing the uncertainties in predicting future climate. The outcome of the project will eventually be globally disseminated and so far we have focused on the best way to communicate our results with citizens and policy-makers of the European Union.

For this purpose, we have (1) identified Past4Future stakeholders, (2) established a dialogue with them, using an online questionnaire, and (3) produced an assessment of their formulated needs and opinions. The online form presented 14 questions with a total of 78 multiple-choice options for answers as well as additional fields for entering detailed information. It took 10 to 12 minutes to complete the questionnaire.

\section{Past4Future Stakeholders}

We defined a Past4Future stakeholder as follows: an organization, a government agency, a commercial company or a community that has a direct or indirect stake in future climate change because it impacts its activities positively or negatively at a local, regional or global scale.

The aim was to receive feedback from at least 20 stakeholders. We identified and approached a total of 141 potential participants in very diverse positions, representing 22 European Union countries, Norway and the USA. The stakeholders were all contacted individually via targeted emails and friendly reminders. Unfortunately, we received feedback from only a few stakeholders: 18 people responded, but only 13 actually completed the questionnaire. Therefore, the opinions and comments expressed by the stakeholders in the review are based on these 13 feedbacks. A response rate of $9 \%$ illustrates how difficult it is to get the attention of the stakeholders although they have been individually approached and tended to. Our method obviously has not been successful; a personal face-to-face briefing with each stakeholder immediately before a paper-based questionnaire was scheduled would likely have produced a much higher response rate.

From the 13 stakeholders, seven come from the public sector (including politician, consultant, agency advisor), three are active in the private sector (e.g. consultant, media) and three are in the field of academia. Around half of the stakeholders operate in the strategic sphere, $30 \%$ conduct research and about $15 \%$ are in education fields.

\section{Interests and opinions of the Past4Future stakeholders}

However small the sample size is, the answers to the questionnaire form the foundation for assessing how to best present and disseminate the results and conclusions of the Past4Future project. This assessment is a first step to help the project partners to appraise stakeholders' interests and needs, the communication pitfalls and the recommended ways in which project activities and results must be communicated widely to the science community, among policymakers, other stakeholders, and to citizens of Europe and beyond.

Here are the main outcomes gathered from the 13 stakeholders:

Firstly, we consider their views on climate change projections: (1) These projections are most often used in a scientific context but stakeholders active in the public sector also use the projections for policy development (Fig. 1). (2) It is important for the stakeholders to know the exact information source, the assumptions made and the associated uncertainties. Stakeholders require projections on climate change risks to be founded in peer-reviewed sources or other sources of high credibility.

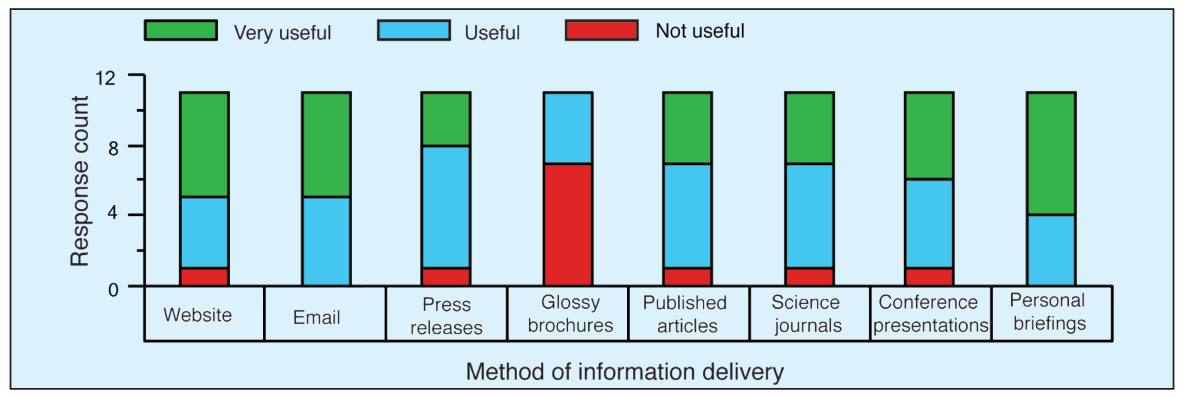

Figure 2: An excerpt from the stakeholder survey: feedback to the question "How useful to you are the following methods of information delivery?" 11 of the 13 stakeholders responded to whether they found the different methods of delivery very useful, useful or not useful. The remaining two stakeholders provided written feedback.

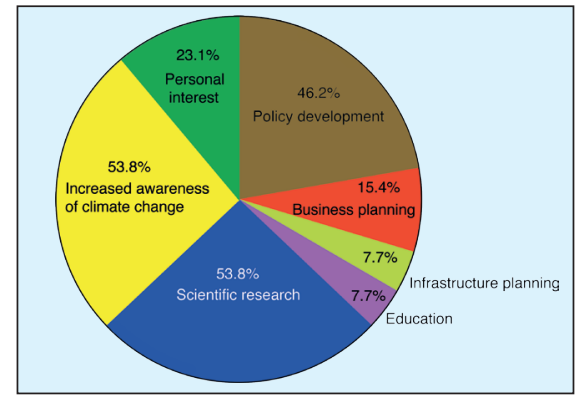

Figure 1:Anexcerptfrom thestakeholder survey: Feedback to the question "In which contexts do you use projections aboutfuture climate change?" Stakeholders were allowed to select multiple answers since they can use future climate change projections in more than one context.

Secondly, their main scientific interests are in: (1) the anthropogenic increase of atmospheric greenhouse gas concentrations and (2) air and ocean temperature changes as well as sea level changes. The stakeholders are less interested in changes caused by solar and volcanic activity.

Thirdly, we consider their views on how to deliver the Past4Future project results (Fig. 2): (1) A personal briefing is preferred as the most useful method, supplemented by targeted information via email and website. (2) Press releases as well as written articles and conference presentations are considered useful means of delivering project results and conclusions. (3) Glossy brochures are deemed a waste of resources. In addition, most stakeholders estimate that information should be updated regularly.

Finally, in terms of the content, results should be delivered with an associated uncertainty. The stakeholder preference for this is an uncertainty that is expressed in "IPCC style" as they understand this concept. Again, they insist on the need to know the sources of uncertainty in the climate change projections.

\section{Outlook}

The delivery of Past4Future results into policy forums cannot be assumed and must be approached in a proactive manner. We will use forms, means and modes that will target the European perspective and impact our stakeholders. This will be achieved through various communicative products (including personal briefings, conference presentations, science journals, press releases, and public addresses) during the next two years, thereby enhancing Europe's ability to act timely and prudently while facing the challenges of the future climate. 


\section{Lifting the veil on speleothem sampling}

Sophie Verheyden ${ }^{1}$ and Dominique Genty ${ }^{2}$

'Geological Survey, Royal Belgian Institute of Natural Sciences, Belgium; sophie.verheyden@naturalsciences.be

¿Laboratoire des Sciences du Climat et de l'Environnement, CEA Saclay, Gif-sur-Yvette, France

\section{We provide insights on speleothem sampling and describe the fieldwork involved in the retrieval campaigns of two calcite speleothems in the framework of the Past4Future project.}

$\mathrm{D}$ uring the last decade, speleothem studies have enhanced our understanding of the evolution of continental climate thanks to the acquisition of high-resolution welldated time-series (Cruz et al. 2005; Drysdale et al. 2009; Fleitmann et al. 2009; Genty et al. 2003; Genty et al. this issue; Wang et al. 2008). Speleothems can be precisely dated to up to 600 ka BP with the Uranium-Thorium method and potentially even further back in time if datable with the Uranium-Lead method.

\section{Preparing for speleothem retrieval}

Access to a cave for sampling is generally the result of long collaborations and much investment of time in order to build a trusting relationship with local cavers, cave owners, and cave managers. Also, speleothem sampling raises ethical issues related to their environmental, esthetical, and economic (touristic) significance. For this reason, sampling is usually conducted with respect to the few existing codes of ethics that provide specific guidelines for scientific work (UIS 1997, 2001; SSS-SGH 2004) (see FFS 2005 for an overview of the existing codes of ethics). Since the number of speleothem studies - and thus sampling - are rapidly increasing (Fleitmann and Spötl 2008), an enhanced exchange of already sampled speleothems through published literature or via internationally referenced museum collections is increasingly needed. This will help minimize the impact of speleothem research on cave environments.

To select the most appropriate speleothems to sample, cave monitoring (e.g. Genty 2008; Mattey et al. 2008; Verheyden et al. 2008) and preliminary dating is performed (Spötl and Mattey 2012). These first steps provide basic information on both the climatic response and growth period enclosed in the selected sample before its removal from the cave. Ongoing technical developments using portable in-situ imagery (Favalli et al. 2011; Hajri et al. 2009) and in-situ chemical analyses (Cuñat et al. 2005; Dandurand et al. 2011) will provide, in the future, information on the Uranium content and internal structure of speleothems, ensuring that scientists select the most appropriate in-situ samples without the need for preliminary laboratory work.

\section{Retrieving speleothems}

In the framework of the Past4Future project, scientists have collected new speleothem data covering the last interglacial

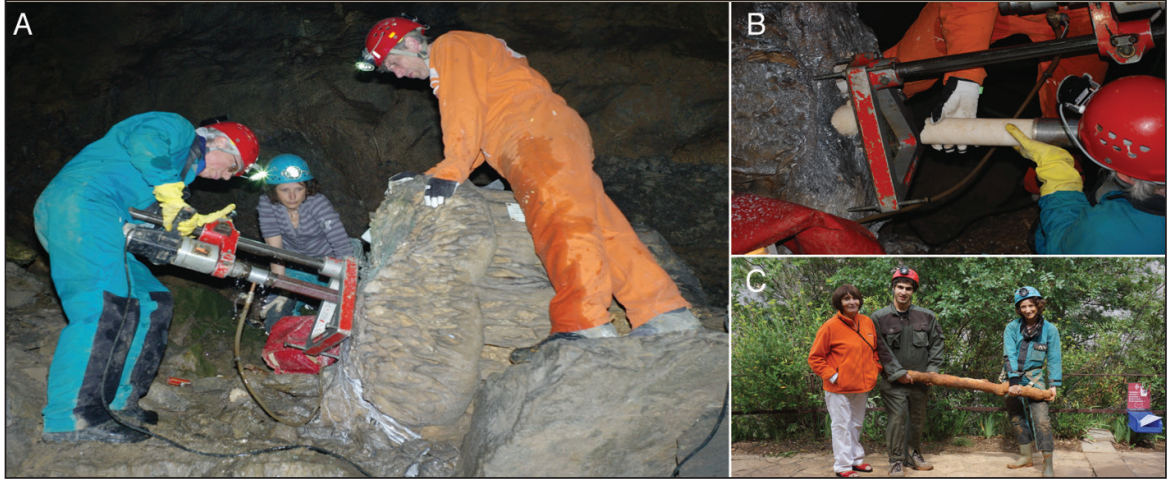

Figure 1: Speleothem samples taken in the framework of the Past4Future project. A) Core drilling of the RSM 17 stalagmite in the Remouchamps Cave, Belgium. The photo shows the drilling device used and the base of the stalagmite. B) Retrieval of a speleothem core. C) The stalagmite taken from Clamouse Cave, France. Photos: $E$. Zaremba, S. Verheyden, and D. Genty.

period (LIG) and the penultimate deglaciation (Termination II). Among the new samples is RSM17, a broken stalagmite approximately 3-m-long and 1-m in diameter, from the Remouchamps Cave in southeast Belgium (BiSpEem project, Belspo 20122016). Preliminary Uranium-series dates indicate that the stalagmite was deposited between $126[-11,+14]$ and $95.3[-8,+9] \mathrm{ka}$ $\mathrm{BP}$ with an overall growth-rate of $0.1 \mathrm{~mm} \mathrm{yr}^{1}$ (Gewelt 1985). A team of seven people cored the stalagmite in May 2012. Since the stalagmite is located in a section of the cave open to tourists and close to the underground river, electricity and cooling water were available, facilitating the operation. However, the drilling was often interrupted by tourist visits. After six hours, 11 cores of $\sim 30-\mathrm{cm}$-long and $8-\mathrm{cm}$-diameter were retrieved from the stalagmite (Fig. 1A-B). Sub-samples are currently at the University of Minnesota waiting to be Uranium dated.

In June 2012, a 1.4-m-long and 10$\mathrm{cm}$ in diameter stalagmite was found broken on the floor of the Clamouse Cave (southern France), where other spelethems have already been sampled (McMillan et al. 2005; Plagnes et al. 2002; Quinif 1992) (Fig. 1C). The stalagmite was removed from the cave and ongoing dating is now needed to confirm that this stalagmite covers the LIG time period. The southern part of France benefits from optimal climate conditions enabling continuous speleothem growth during Termination periods, while speleothem growth further north generally only starts when full interglacial conditions are present.

Such a thin "take-away" stalagmite is ideal for studying the entire section, while drilled cores such as those from the Remouchamps Cave only reveal part of the internal section of the stalagmite. However, core drilling provides the possibility of sampling large stalagmites and flowstones. Importantly, drilling provides a unique opportunity to sample with minimal impact on the cave environment (Spötl and Mattey 2012).

\section{Outlook}

The speleothems sampled in the Remouchamps and Clamouse Caves in the framework of the Past4Future project are currently being analyzed. They will provide new chronological constraints on the onset of the LIG time period. They will also complement the existing speleothem dataset compiled by Genty et al. (this issue) with the aim of improving our understanding of the continental climate variability in Western Europe during Termination II and the LIG.

\section{Acknowledgements}

We thank the Remouchamps cave owners and managers, Y. Quinif, C. Ek, M. Gewelt, S. Delaby, cavers, Nicole Dubois and her team.

\section{Selected references}

Full reference list online under:

http://www.pages-igbp.org/products/newsletters/ref2013_1.pdf

BiSpEem Project - Belspo (2012 2016). Available at: www.naturalsciences.be/geology/research/environment/bispeem

Drysdale, RN et al. (2009) Science 325: 15271531

Spötl C, Mattey D (2012) Journal of Speleology 41: 2934

UIS (1997) Available at: http://www.uis-speleo.org/

Wang Y et al. (2008) Nature 451: 10901093 


\section{Drilling a deep ice core at the NEEM site in Greenland}

JøRGEN P. StefFEnSEN

Centre for Ice and Climate, Niels Bohr Institute, University of Copenhagen; jps@gfy.ku.dk

\section{We summarize the different approaches and logistical requirements for completing an ice core drilling. We also present the recent North Greenland Eemian Ice Drilling (NEEM) international project.}

ce cores are drilled in glaciers and on ice sheets on all of Earth's continents. Whilst mountain glacier "shallow" ice core drilling reaches depths of $\sim 300$ $\mathrm{m}$, "deep" drilling of several kilometers can be achieved on the Greenland and Antarctic ice sheets.

\section{Drilling an ice core}

Specialized drills are used to drill ice cores. They range in length from $3.5 \mathrm{~m}$ to $15 \mathrm{~m}$. The devices hang on a steel cable with electrical wires inside allowing remote control from the surface. The cable runs from a winch over a top wheel on a vertical tower during drilling. Ice core drills can be either electromechanical or thermal.

An electromechanical drill is simply a rotating pipe (core tube) with cutters at the head (Fig. 1A). During rotation, the cutters incise a circle around the ice to be cored until the core tube is filled with ice. The cuttings (also referred to as ice chips) are transported to a chip chamber in the drill. Rotation of the drill head is achieved by anchoring the motor section to the wall of the borehole with knife springs that allow sliding up and down but prevent any rotation. When the drill tube is full, the ice core is broken by a pull in the cable. Several barbs inside the core tube grab the core and break it. The drill is subsequently hoisted to the surface and in the case of most intermediate and deep-sized drills the drill and tower are tilted horizontally for easy removal of the core.
In the thermal drill, a ring-shaped heating element melts a circle around the ice to be cored and the melt water is stored in a tank in the drill.

Ice cores have typical diameters of $75 \mathrm{~mm}, 98 \mathrm{~mm}$ or $123 \mathrm{~mm}$. They are usually retrieved in sections that are 1 $\mathrm{m}$ to as much as $4 \mathrm{~m}$ in length (Fig. 1B). As glacier ice deforms under pressure, it is necessary to fill the borehole with a drilling fluid for depths below $\sim 400$ $\mathrm{m}$ to compensate for the increasing hydrostatic pressure of the surrounding ice with depth. This drilling fluid has a density slightly above the density of the glacier ice $\left(920 \mathrm{~kg} \mathrm{~m}^{3}\right)$ and thus prevents plastic deformation of the borehole and constriction of its width.

\section{The logistics of ice core field camps}

A "shallow" drilling for a 100-m-deep ice core can be performed on open snow as the drilling only takes a day or so. However, "intermediate" drilling to several hundred meters in depth may take weeks, and this is normally done in the shelter of a tent or in a covered snow trench (Fig. 2A). "Deep" drilling to more than one kilometer depth take many months and span several summer field seasons. In this case substantial infrastructure, such as a drill shelter, drill fluid supply and handling, electrical installations, campsite facilities, and organized transportation are needed.

The logistics involved in setting up and running a deep ice coring camp are considerable and costly (e.g. the total cost of the NEEM field activities was 7.4 million euros) and so far only 11 cores deeper than $1.5 \mathrm{~km}$ have been drilled worldwide. A substantial part of the costs occur from transportation, either over land by tractor train or, in the case of the NEEM project, by skiequipped LC-130 Hercules air planes. In the past two logistical philosophies have been used:

- One can limit the scientific analyses in the field to an absolute minimum, which in principle reduces the expensive manpower required for this task. The ice cores are then cut and analyzed in cold rooms back home;

- One can do as many analyses in the field as possible, taking advantage of nature's own clean "cold room" in an excavated science trench (Fig. 2B). This approach requires more manpower in the field; the advantages, though, are that scientists can work on the fresh core and that data are available at the end of the field campaign.

The key to a successful ice core drilling is the retrieval and documentation of an unbroken ice core, i.e. the top and bottom of an ice core section have to match up with the previous and subsequent cored sections. The core length (depth) must also be assigned with millimeter precision.

\section{Drilling an ice core}

The NEEM project (2007-2012) is the result of collaboration between 14 international partners and was initiated as an International Polar Year project.

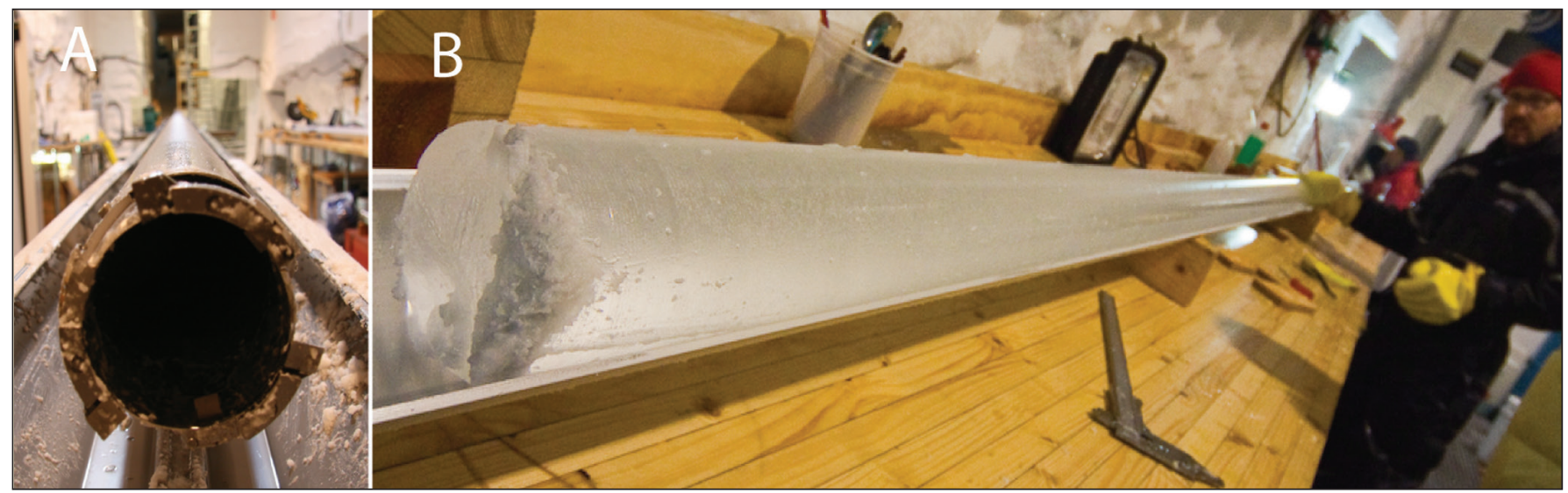

Figure 1: Drilling an ice core. A) The drill head of the NEEM drill (photo: J.P. Steffensen). B) A freshly drilled 3.5-m ice core section at NEEM (photo: T. Burton). 


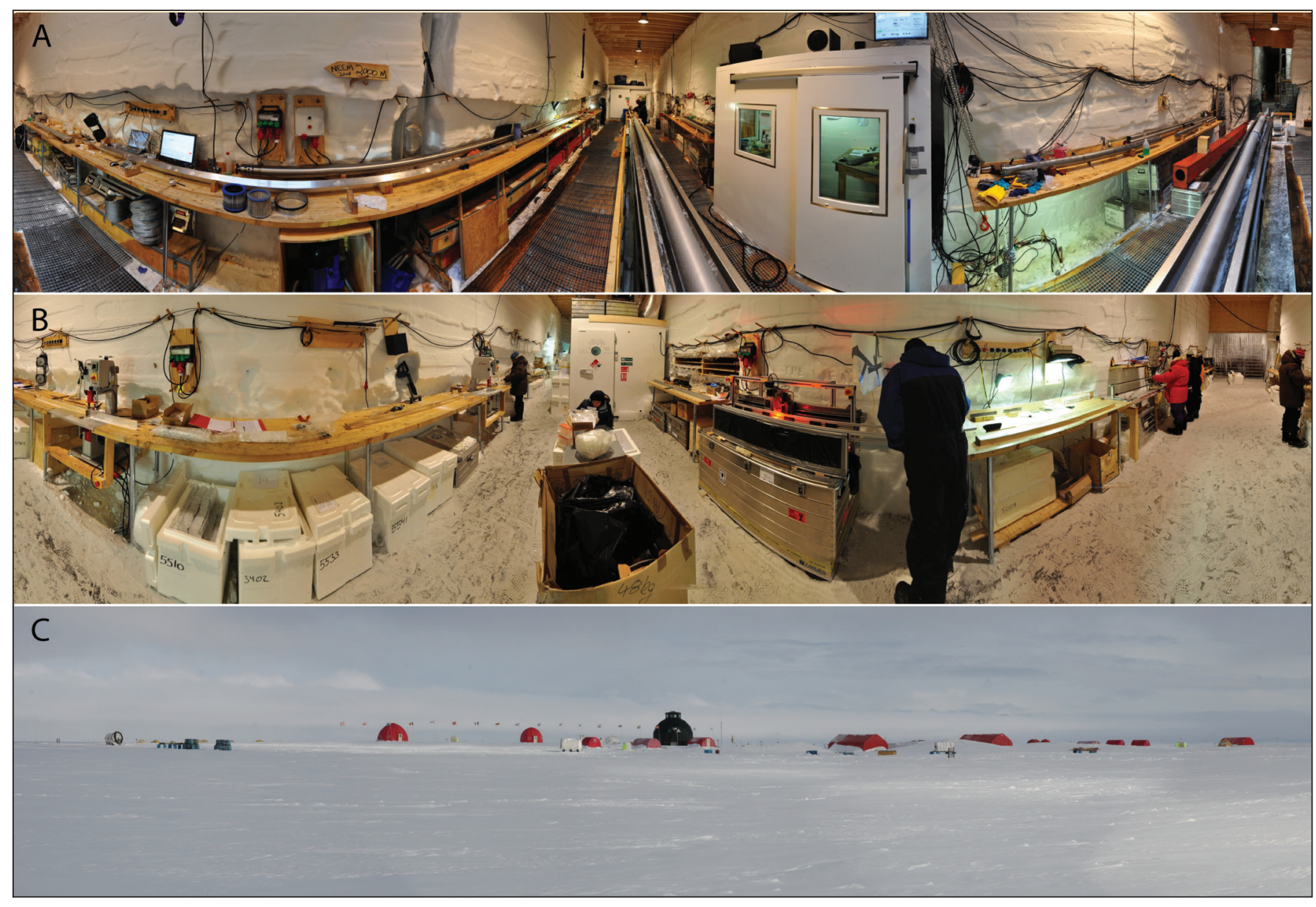

Figure 2: The NEEM ice coring project field camp. A) $360^{\circ}$ view of the NEEM drill trench, $7 \mathrm{~m}$ below the surface (photo: M. Leonhardt and J.P. Steffensen). B) A $360^{\circ}$ view of the NEEM science trench, $7 \mathrm{~m}$ below the surface (photo: M. Leonhardt and J.P. Steffensen). C) Panoramic view of the NEEM camp in the 2010 field season (photo: J.P. Steffensen).

The strategy chosen was to perform as many analyses as possible on site.

Typical NEEM field season began May $1^{\text {st }}$ and ended August $15^{\text {th }}$. A brief synopsis outlines the highlights from each field season during the project:

- 2007: The project team reached the NEEM ice core drilling site $\left(77^{\circ} \mathrm{N}, 51^{\circ} \mathrm{W}\right.$, $2480 \mathrm{~m}$ above sea level) by tractor train from the former NGRIP ice core site some $365 \mathrm{~km}$ away.

- 2008: The team constructed the camp consisting of a four-level geodesic dome, two garage tents, a roofed drill trench and roofed science trench, a powerhouse and six tent buildings (Fig. $2 \mathrm{C})$. The first $110 \mathrm{~m}$ of ice were drilled using a mobile "shallow" drill and the "deep" drill was installed in the drill trench.

- 2009 and 2010: The team completed the ice core drilling and ice core scientific processing. The first ice core with material from the bedrock was drilled in July 2010 at 2535 m depth. During these two seasons the camp population was around 35.

- 2011 and 2012: Special rock drill extensions were mounted on the drill and several meters of debris-laden ice from the base of the ice sheet were drilled.
The NEEM camp was deconstructed in July and August 2012. Most of the camp infrastructure, including the geodesic dome, was designed to be stored on heavy sleds, ready to be towed to a future drilling site.

The drilling of the NEEM ice core was carried out by two shifts of two drillers and one mechanic with $\sim 30 \mathrm{~m}$ of ice drilled per day. An average of 15 scientists were in the science trench to process the drilled ice with the work organized as an assembly line (Fig. 2B). Typical activities in the science trench consisted of documenting and cutting the cores into sections of $55 \mathrm{~cm}$ and performing a large range of measurements such as the Di-Electric Properties (DEP) and electrical conductivity of the ice (solid ice Electrical Conductivity Method, ECM). Thin sections of ice were also prepared to define the physical properties of the ice, and volcanic tephra layers were sampled. In addition, we also conducted on-line Continuous Flow Analysis of the ice for dust, $\mathrm{Na}^{+}$, $\mathrm{Cl}^{-}, \mathrm{SO}_{4}{ }^{2-}, \mathrm{NO}^{3-}, \mathrm{NH}_{4}^{+}$, liquid conductivity, black carbon, formaldehyde, peroxide, and $\mathrm{Ca}^{2+}$. For the first time, water isotope measurements by laser spectrometry and on-line measurements of gas concentrations by laser spectroscopy $\left(\mathrm{CH}_{4}\right.$; see Blunier et al. this issue) were coupled with the main on-line system. The remaining ice core sections (such as those set aside for discrete gas concentration and water isotopes measurements) were then packed in insulated boxes and shipped to cold rooms in Copenhagen for storage.

More than 270 individuals spent a total of 12,520 man-days at NEEM. These persons consisted of $51 \%$ young scientists, $21 \%$ senior scientists, $20 \%$ logistics and $8 \%$ related to associated projects. In this way NEEM has not only been a project fulfilling a scientific objective to retrieve last interglacial ice (NEEM community members 2013; Dahl-Jensen this issue) but it has also been a unique opportunity for young scientists to gain fieldwork experience in the high Arctic. For many of them, a stay at NEEM has laid the foundation for future successful international collaborations in ice core science.

\section{Reference}

NEEM community members (2013) Nature 493: 489-494 


\section{Sampling marine sediment}

Rainer Gersonde ${ }^{1}$ and Marit-Solveig Seidenkrantz ${ }^{2}$

'Alfred-Wegener-Institute Helmholtz Centre for Polar and Marine Research, Bremerhaven, Germany; Rainer.Gersonde@awi.de ${ }^{2}$ Centre for Past Climate Studies, Department of Geoscience, Aarhus University, Denmark

\section{Recovered in ocean basins and marginal seas, marine sediments represent valuable archives to reconstruct global past climate and ocean variability as far back as the Mesozoic time period (150-170 million years). Here, we give a short overview on how to recover sediments from the ocean floor.}

A n important prerequisite for successful sample site selection and the decision for an appropriate drilling strategy or coring device is the acoustic pre-site survey in the target area. To generate high-resolution 3D images of the ocean floor, multi-beam sonar systems are used. Such a system can accurately map the topography of an area with a width of up to five and a half times the water depth below the ship's track. For sediment coring (to a total depth of $70 \mathrm{~m}$ ) sediment echo-sounding systems such as PARASOUND or sub-bottom profilers provide information on the sediment deposition pattern and can register the sedimentary layering as deep as $200 \mathrm{~m}$ below the sea floor (Fig. 1). At sites selected for deep drilling, additional single or multi-channel seismic surveys are required to generate information on the structure and nature of deep sediment (> $100 \mathrm{~m}$ depth) and to prevent the accidental drilling of sediment rich in explosive and polluting hydrocarbons.

\section{Drilling techniques}

The longest and oldest marine records are recovered in the frame of the Integrated Ocean Drilling Program (IODP, www.iodp. org). Within the IODP, launched in 2003, and its predecessors the Deep Sea Drilling Project (DSDP, 1968-1983) and the Ocean Drilling Program (ODP, 1985-2003), a total of more than 3,300 sites have been drilled in all ocean basins. The oldest sediments yet recovered from the ocean are from the West Pacific and were dated to ca. 170 million years (Lancelot et al. 1990). IODP operates the riser-less vessel JOIDES Resolution $(J R)$ for sediment drilling for paleoclimate studies. Additional mission-specific platforms are required for drilling in environments that are not always accessible to the $J R$, such as the sea-ice covered Arctic Ocean and shallow water sites.

The current coring techniques utilized by IODP include:

- The Hydraulic Piston Corer (HPC) and the Advanced Piston Corer (APC), which are push type, non-rotating tools that produce well-preserved, well-oriented and continuous cores from unconsolidated sediment. This makes the recovered sediment cores most suitable for paleoceanographic studies

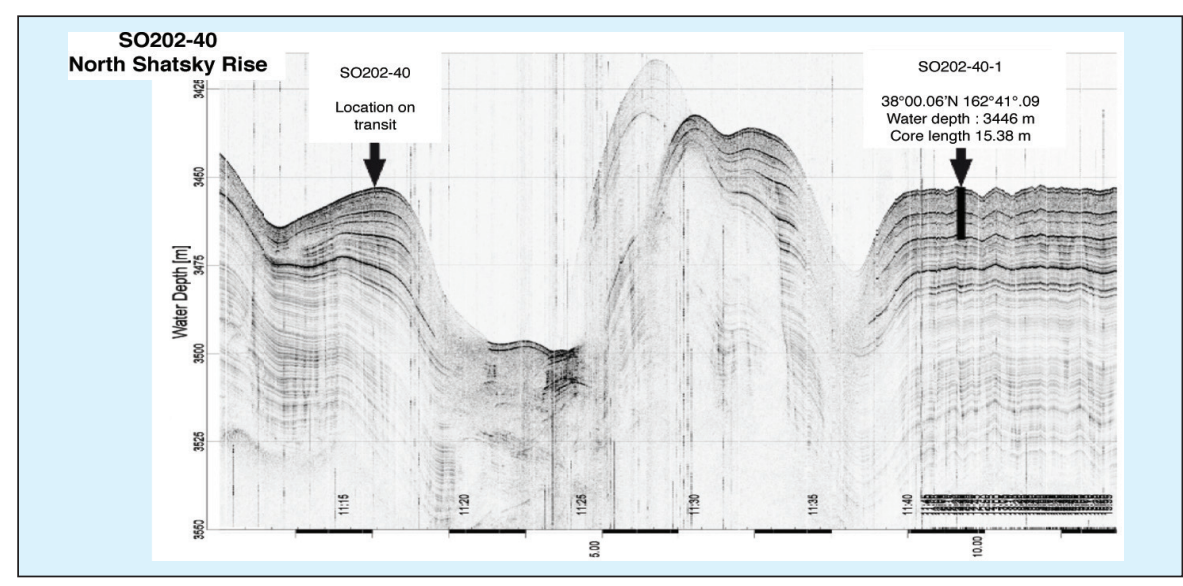

Figure 1: An example of a PARASOUND-survey at Site SO202-40 on the northern Shatsky Rise (from Gersonde 2012). PARASOUND penetration ranges around $75 \mathrm{~m}$. After selection of a sediment-coring site on a survey transit, the ship returned to the chosen location to recover a piston core. The 5-min-spaced time marks (lower panel) indicate that the ship was positioned at the site shortly after 11:40 am. The piston corer recovered the sediment as indicated by the black bar. After core recovery the ship remained at the site for further sampling.

at high resolution. The HPC/APC techniques, however, are generally limited to the upper $200 \mathrm{~m}$ of sediment.

- The Extended Core Barrel (XCB) coring system, which is used to recover deeper and more consolidated sediments.

- The Rotary Core Barrel (RCB) system, the oldest and most basic technique, which is used to retrieve cores from hard sediment and rock.

For all these techniques the sediment is retrieved in plastic liners. This allows the core, which is then cut into $1.5-\mathrm{m}$ segments, to be suitably handled, logged, and sampled on board and on shore. For a detailed compilation of IODP drilling techniques see http://www.iodp.org/iodp-drilling-a-coringtechnology.

Considering that access to drilling vessels is limited, MARUM (University of Bremen) has developed the MEBO sea floor drill rig (Freudenthal and Wefer 2007). MEBO weights 10 tons and can be deployed from standard research vessels. It is operable at water depths up to $2000 \mathrm{~m}$ and drills up to 80 -m-long cores. Thus, this relatively inexpensive drilling technique allows for the recovery of more consolidated sediment that cannot be collected with the available nondrilling methods (Box 1).

\section{Non-drilling techniques}

The paleoceanographic studies in the framework of the Past4Future project and similar research initiatives studying the late Pleistocene use cores drilled with the $J R$.
However, the main body of material is collected using non-drilling systems deployed from conventional research vessels. The basic design of the coring devices consists of one or more steel tubes or boxes attached below a lead weight unit. This set-up is winched to the sea floor and pushed into the sediment to recover a core. Below, we briefly review four main types of coring devices. Additional information and technical details on each device are given in Box 1 .

The simplest design is the gravity corer, consisting of an up to 20-m-long steel tube attached to a lead weight of 1-2 tons (Fig. 2A). Longer cores can, however, be recovered with the piston corer (Fig. 2B). Originally invented in 1947 by B. Kullenberg (Swedish Deep Sea Expedition) the piston corer has been further developed during the last few decades and is one of the most used coring devices within the marine coring community. Attached to the piston corer weight assembly is a trigger arm, which carries a wire with a small weight or a small gravity corer device (trigger corer) extending below the base of the piston corer tube. When the trigger corer penetrates the sea floor to collect the uppermost sediment sequence, the trigger arm is lifted and the piston corer is released falling freely with its own gravity into the sediment. When contact is made with the sediment surface, a piston, located inside the coring tube, is lifted up at the speed of penetration. Such a design reduces the friction inside the tube and allows for the collection of long cores. The Calypso 
Box 1: Comparison of three non-drilling techniques and one drilling technique

\begin{tabular}{|c|c|c|c|c|}
\hline & Gravity Corer & Piston Corer & Kasten Corer & MEBO sea floor drill rig \\
\hline Core diameter & $9-12 \mathrm{~cm}$ & $9-12 \mathrm{~cm}$ & $0.1 \times 0.1-0.3 \times 0.3 \mathrm{~m}^{2}$ & $7.4-8.4 \mathrm{~cm}$ \\
\hline Max. core length & up to $20 \mathrm{~m}$ & up to $60-70 \mathrm{~m}$ & $10-12 \mathrm{~m}$ & up to $80 \mathrm{~m}$ \\
\hline Total weight & $1-5$ tons & $1-10$ tons & $3-7$ tons & $\sim 10$ tons \\
\hline Max. water depth & Limited by ship wire length & Limited by ship wire length & Limited by ship wire length & $2000 \mathrm{~m}$ \\
\hline Advantages & $\begin{array}{l}\text { - Easy and fast handling } \\
\text { - Deployable in rough sea } \\
\text { - Core recovered in liner }\end{array}$ & $\begin{array}{l}\text { - Long core retrieval } \\
\text { - Core recovered in liner }\end{array}$ & $\begin{array}{l}\text { - Large volume of sediment } \\
\text { ideal for multi-proxy studies }\end{array}$ & $\begin{array}{l}\text { - Drills both soft and hard sediments } \\
\text { - Operates from standard research } \\
\text { vessels }\end{array}$ \\
\hline Drawbacks & $\begin{array}{l}\text { - Potential of over-penetration } \\
\text { (i.e. loss of the top sediment) } \\
\text { - Possible compression of } \\
\text { sediment and of non-uniform } \\
\text { recovery of deeper sediment } \\
\text { - Only works in soft sediment }\end{array}$ & $\begin{array}{l}\text { - Time consuming/complex } \\
\text { deployment } \\
\text { - Needs good sea conditions } \\
\text { - Potential sediment inflow } \\
\text { due to piston failure }\end{array}$ & $\begin{array}{l}\text { - Heavy core weight } \\
\text { - Needs good sea conditions } \\
\text { - Liner-less core recovery: } \\
\text { on-board sampling of core } \\
\text { - Only works in soft sediment }\end{array}$ & $\begin{array}{l}\text { - Time consuming/complex } \\
\text { deployment } \\
\text { - Needs good sea conditions } \\
\text { - Core recovery may be } \\
\text { discontinuous in sediment with } \\
\text { alternating composition } \\
\text { - High operation costs }\end{array}$ \\
\hline
\end{tabular}

piston corer operated from the French R/V (Research Vessel) Marion Dufresne and the US R/V Knorr can recover cores as long as 60 to $70 \mathrm{~m}$, depending on the type of sediments penetrated (for more details see http://perso-sdt.univ-brest.fr/ jacdev/uf08/ calypso.html and www.whoi.edu/page. do?pid=19095). Another simpler device is the kasten corer. This coring device also penetrates marine sediments by gravity and consists of long, rectangular boxes with up to 30-cm-edge length (Fig. 2C). Because of the large volume of sediment sampled, this coring technique is beneficial for multiproxy paleoceanographic studies. Gersonde (2012) presents a photo gallery with the

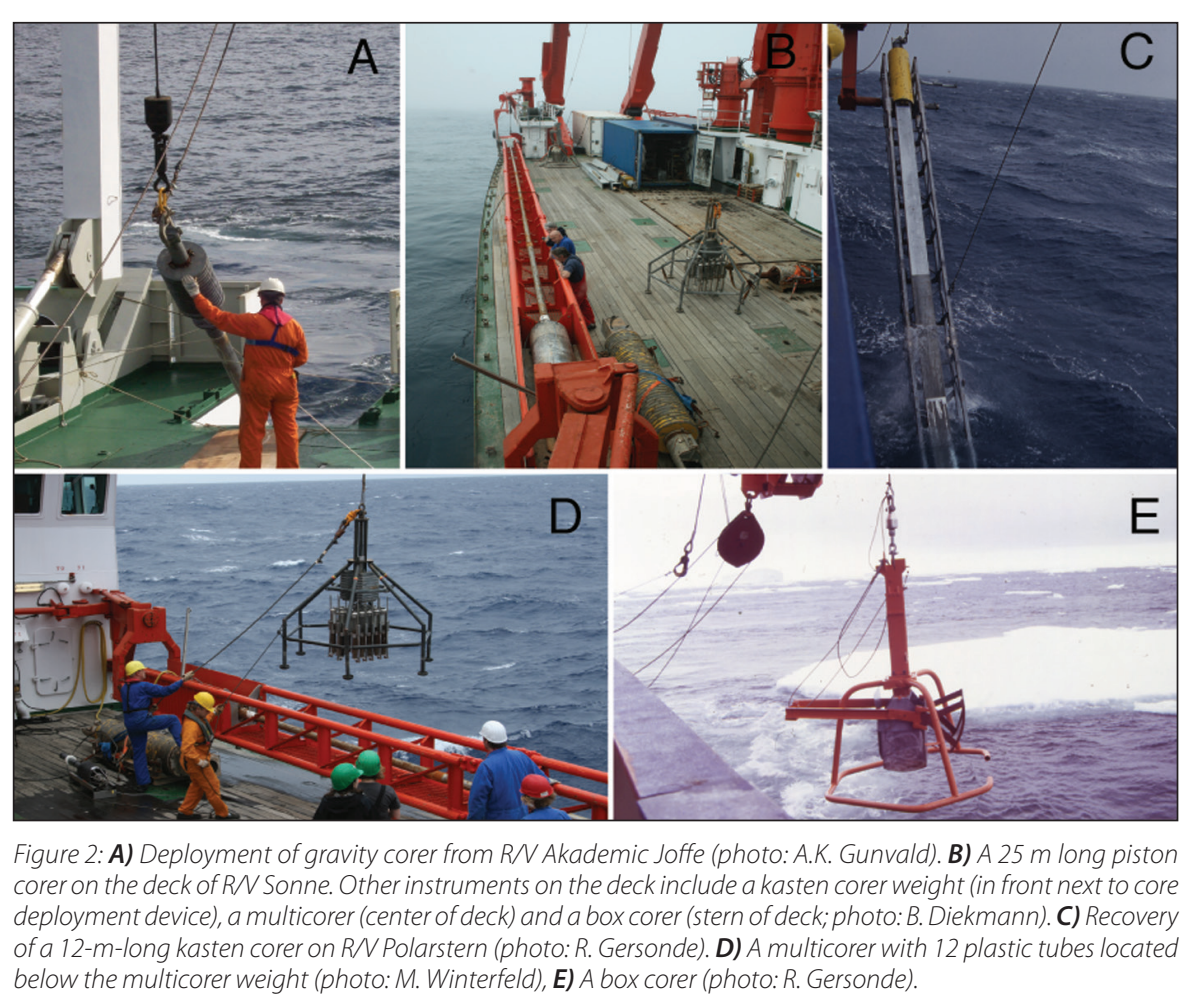

Figure 2: A) Deployment of gravity corer from RN Akademic Joffe (photo: A.K. Gunvald). B) A 25 m long piston corer on the deck of RN Sonne. Other instruments on the deck include a kasten corer weight (in front next to core deployment device), a multicorer (center of deck) and a box corer (stern of deck; photo: B. Diekmann). C) Recovery of a 12-m-long kasten corer on RN Polarstern (photo: R. Gersonde). D) A multicorer with 12 plastic tubes located below the multicorer weight (photo: M. Winterfeld), E) A box corer (photo: R. Gersonde).

set-up and handing of the different coring devices as well as on-board sampling.

Sediment coring is generally accompanied by surface sediment sampling for undisturbed recovery of the sediment/ water interface. This is most often achieved using a multicorer, which samples up to 12 individual cores (up to 50-cm-long; Fig. 2D). Surface sediment samples may also be obtained using different designs of grabs and box corers (Fig. 2E) but generally these do not result in the same quality of sampling as the multicorer. The surface sediment sampling is of importance for understanding modern sediment deposition and the development of reference data sets for paleoceanographic transfer functions. It also provides material for the reconstruction of the most recent ocean history.

\section{Marine sediment core storage}

National and international sediment core repositories assure long-term maintenance and curation of sediment materials under refrigerated conditions around $4^{\circ} \mathrm{C}$. Besides IODP core repositories located at College Station (US), Kochi (Japan) and Bremen (Germany), important repositories are at the Lamont-Doherty Earth Observatory (Columbia University), Scripps Institute of Oceanography, Florida State University (Talahassee), Oregon State University (Corvallis), Alfred Wegener Institute (Germany), MARUM (Bremen), and the British Ocean Sediment Core Research Facility.

Many countries (e.g. the US, Germany, France, Sweden, South Korea, Russia, Japan) operate research vessels that can deploy longer (more than $10 \mathrm{~m}$ ) coring systems. The ships are financed through international and national programs and may stay at sea for as long as 70 days per cruise. Long cruises are especially scheduled to visit remote areas, such as the polar oceans. Depending on the visited ocean basin and the cruise duration, the total recovery may exceed $1000 \mathrm{~m}$ of sediment core collected from up to 60 to 70 sites. Drilling cruises with the $J R$ last around 50 to 55 days and may recover more than $8000 \mathrm{~m}$ of sediment core during one single cruise.

\section{References}

Freudenthal T, Wefer G (2007) Scientific drilling with the sea floor drill rig MEBO, Scientific Drilling 5, doi: 10.22 04/iodp.sd.5.11.2007

Gersonde R (2012) Reports on Polar and Marine Research 643, doi: 10013/ epic.38996

Lancelot et al. (1990) Proceedings of the Ocean Drilling Program, Initial Reports 129, doi:10.2973/odp.proc.ir.129.1990 


\section{Insights into paleoclimate modeling}

\section{Emma J. Stone' ${ }^{1}$, P. Bakker ${ }^{2}$, S. Charbit ${ }^{3}$, S.P. Ritz ${ }^{4}$ and V. VARma ${ }^{5}$}

'School of Geographical Sciences, University of Bristol, UK; emma.j.stone@bristol.ac.uk

Earth \& Climate Cluster, Department of Earth Sciences, Vrije Universiteit Amsterdam, The Netherlands; ${ }^{2}$ Laboratoire des Sciences du Climat et de I'Environnement, CEA Saclay, Gif-sur-Yvette, France; ${ }^{4}$ Climate and Environmental Physics, Physics Institute and Oeschger Centre for Climate Change Research, University of Bern, Switzerland; ${ }^{5}$ Center for Marine Environmental Sciences and Faculty of Geosciences, University of Bremen, Germany

\section{We describe climate modeling in a paleoclimatic context by highlighting the types of models used, the logistics involved and the issues that inherently arise from simulating the climate system on long timescales.}

In contrast to "data paleoclimatologists" who encounter experimental challenges, and challenges linked to archive sampling and working in remote and/or difficult environments (e.g. Gersonde and Seidenkrantz; Steffensen; Verheyden and Genty, this issue) we give a perspective on the challenges encountered by the "computer modeling paleoclimatologist".

Simulating the physical interactions between atmosphere, ocean, biosphere, and cryosphere to explain climate dynamics is achieved through a large range of computer tools, from simple box models to complex three-dimensional (3D) fully coupled atmosphere-ocean general circulation models (GCMs) (see Box 1 for some examples).

Investigating the climate forcing and feedbacks that occurred during the past requires performing simulations on the order of thousands to tens of thousands of model years and due to computational time this is not easily achievable with a GCM. Therefore, compromises are required in terms of model resolution, complexity, number of Earth system components and the timescale of the simulation.

A suite of models referred to as Earth Models of Intermediate Complexity (EMICs) can effectively bridge the gap between computationally intensive GCMs and the box models (Claussen et al. 2002). These EMICs enable one to efficiently perform large ensembles and multi-millennial simulations whilst still retaining much of the behavior of a higher complexity model (e.g. Menviel et al. 2012; Ritz et al. 2011; Robinson et al. 2011). Although computing advancements have allowed transient climate experiments to be realized on long timescales, performing snapshot simulations with EMICs or GCMs is still frequent and useful (see Lunt et al. 2012).

\section{Climate modeling by Past4Future} Within the Past4Future project numerous questions are addressed by modelers such as the sensitivity of climate to enhanced freshwater forcing, ice sheet changes and variations in solar and volcanic activity, using a range of EMICs and GCMs. Here, we highlight the implementation of multi-millennial transient simulations for the last interglacial period which include changes in astronomical and/or greenhouse gas concentrations (see Stone et al. this issue) using

\begin{tabular}{|c|c|c|c|c|c|}
\hline Model & Type & Components & Resolution & $\begin{array}{l}\text { Time to run } \\
10 \mathrm{ka}\end{array}$ & Main references \\
\hline CLIMBER-2 & EMIC & At; Oc; Si; Is; Ve & $\begin{array}{l}10^{\circ} \times 51^{\circ}, 1 \text { level (atm + land) } \\
2.5^{\circ} \times 20 \text { levels (latitude-depth) } \\
\text { Ice sheets: } 40 \mathrm{~km} \times 40 \mathrm{~km}\end{array}$ & $\sim 3$ hours & $\begin{array}{l}\text { Petoukhov et al. (2000); } \\
\text { Bonelli et al. (2009) }\end{array}$ \\
\hline Bern3D & EMIC & At; Oc; Si; Ve; Cc; Se & $\begin{array}{l}\sim 5^{\circ} \times 10^{\circ}, 1 \text { level (atm+land) } \\
\sim 5^{\circ} \times 10^{\circ}, 32 \text { levels (ocn }+ \text { sea ice) }\end{array}$ & $\sim 2-12$ hours & $\begin{array}{l}\text { Müller et al. (2006); } \\
\text { Ritz et al. (2011) }\end{array}$ \\
\hline LOVECLIM & EMIC & $\mathrm{At} ; \mathrm{Oc} ; \mathrm{Si} ; \mathrm{Ve}$ & $\begin{array}{l}\sim 5.6^{\circ} \times 5.6^{\circ}, 3 \text { levels (atm + land) } \\
\sim 3^{\circ} \times 3^{\circ}, 20 \text { levels (ocn }+ \text { sea ice) }\end{array}$ & $\sim 15$ days & Goosse et al. (2010) \\
\hline FAMOUS & Low resol. GCM & At; Oc; Si; Ve; Cc & $\begin{array}{l}5.0^{\circ} \times 7.5^{\circ}, 11 \text { levels (atm + land) } \\
2.5^{\circ} \times 3.75^{\circ}, 20 \text { levels (ocn +sea ice) }\end{array}$ & $\sim 2$ months & $\begin{array}{l}\text { Smith (2012); Smith et al. (2008); } \\
\text { Williams et al. (2013) }\end{array}$ \\
\hline CCSM3 & GCM & At; Oc; Si; Ve & $\begin{array}{l}\sim 3.75^{\circ} \times 3.75^{\circ}, 26 \text { levels (atm + land) } \\
\sim 3.6^{\circ} \times 1.6^{\circ}, 25 \text { levels (ocn + sea ice) }\end{array}$ & 〜-5 months & $\begin{array}{l}\text { Collins et al. (2006); } \\
\text { Yeager et al. (2006) }\end{array}$ \\
\hline
\end{tabular}

Box 1: Description of some of the types of climate models used in the Past4Future project. The following components are available in the models: Atmosphere (At), Ocean (Oc), Sea ice (Si), Ice sheet (Is), land surface with dynamic Vegetation (Ve), Carbon cycle (Cc) and marine sediment (Se). The At, Oc and Si components are used in the last interglacial model inter-comparison described in Bakker et al. (2013) but dynamic vegetation is switched off. Note that the models, which have approximate resolutions, use non-regular grids. 
five climate models of varying degrees of complexity (see Box 1): CLIMBER-2 is a zonally-averaged model that permits basin-wide analysis, Bern3D includes a $3 \mathrm{D}$ ocean but a simple 2D atmosphere, LOVECLIM is of higher resolution (see Box 1), includes a low resolution GCM ocean but a simple three-layer dynamical atmosphere, FAMOUS is a low-resolution version of the UK Meteorological Office GCM (Gordon et al. 2000), and CCSM3 includes a fully dynamic atmosphere with the ability to be run at different resolutions (in this example the lowest resolution is used).

Although EMICs allow long time integrations to be easily realized, they parameterize a large number of processes (e.g. winds are fixed in Bern3D). The two GCMs, FAMOUS and CCSM3, have the advantage of including less parameterizations than the EMICs but they take months to run and generate large amounts of data. For instance, EMICs such as CLIMBER-2 and Bern3D have been able to simulate more than $800 \mathrm{ka}$ in a few weeks. This is currently not achievable by models such as FAMOUS and CCSM3, which take several months to simulate only $10 \mathrm{ka}$.

Not only should the computational time be considered but also the ability to actually run the model code on a computer in terms of the power and the financial expense involved. Typically, climate models are written in numerically efficient computing code (e.g. FORTRAN), which can be implemented on a local desktop computer, as is the case for the EMICs given in Box 1. Otherwise, computationally intensive codes are run using high performance computing facilities such as the German HLRN supercomputer (used by CCSM3) or the "BlueCrystal" cluster at the University of Bristol (used by FAMOUS), which has the ability to carry out at least 37 trillion calculations a second (Fig. 1). These supercomputers are inherently expensive to implement, e.g. the BlueCrystal facility initially cost seven million pounds, with ongoing developments, and continuous maintenance incurring future costs.

\section{Maintaining and managing a climate model}

Most model code is maintained centrally and in many cases can be downloaded freely by everyone. For example, the National Centre for Atmospheric Science looks after the FAMOUS model code in the United Kingdom and CCSM3 is maintained by the National Center for Atmospheric Research in the USA.

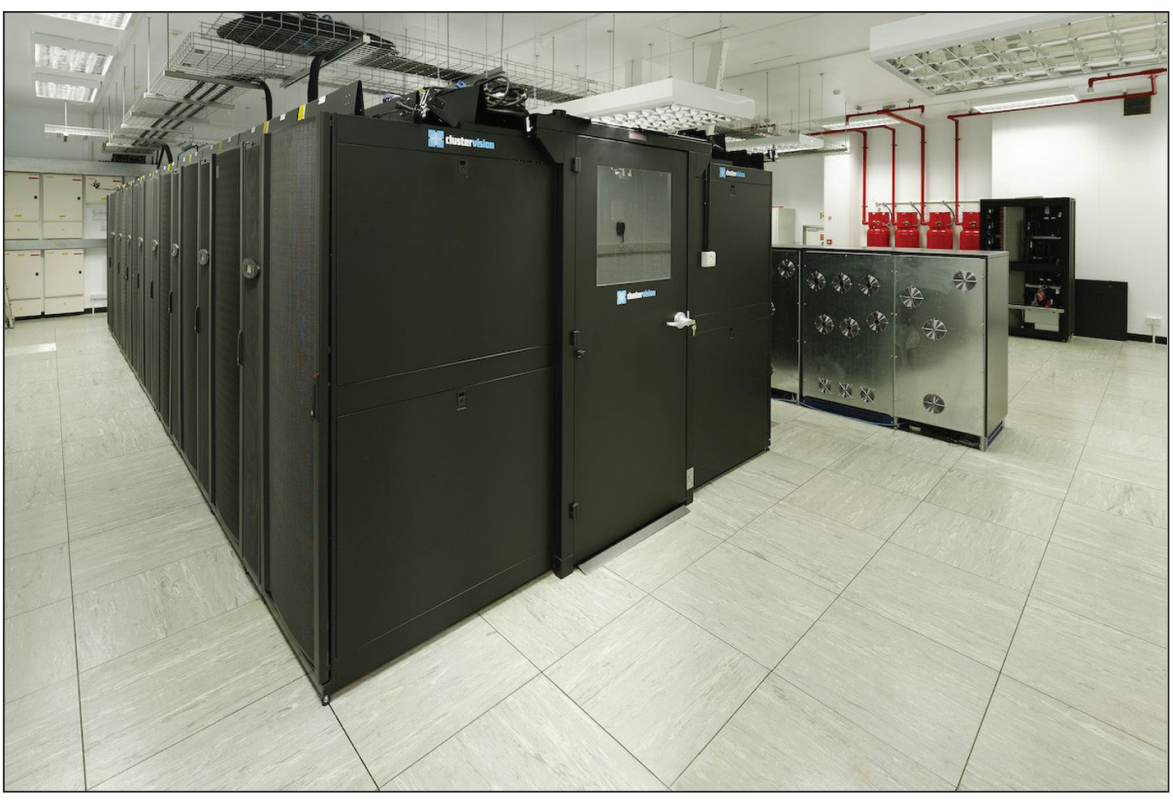

Figure 1: The machine room hosting the BlueCrystal supercomputer located in the Advanced Computing Research Centre (www.acrc.bris.ac.uk), University of Bristol (UK). Photo: Timo Kunkel.

Modelers from remote locations can submit new code but this needs to be peerreviewed before being implemented into the next model version.

The EMIC models given in Box 1 comprise tens of thousands of lines of code while the GCMs contain more than half a million lines (see Easterbrook (2009) for details on the UK Meteorological Office model). Many individuals are involved in ongoing code modification and development, so version control is required to ensure errors are not inadvertently inserted. Good code development is also needed to ensure that any updates include clear and concise comments for users.

The technological development of increasing computer power, allowing climate researchers to run these multi-millennial simulations, large ensembles and GCM experiments, has presented a challenge with regard to what data should be written out and how it should be securely stored. The efficiency of some models such as CLIMBER-2, Bern3D and to an extent LOVECLIM, allows experiments to be repeated if more variables and different temporal resolutions (e.g. daily, monthly etc.) are required. This is not easily achievable with models such as FAMOUS and CCSM3. As such, careful decisions on what output would be useful are needed, not only for answering current research questions but also for long term future analyses, before the experiments are implemented.

The size of the output generated by the models in Box 1 varies greatly for a 10 ka simulation (depending on spatial and temporal resolution) from $\sim 400$ $M B$ to 6 TB. Normally, a sub-set of this data is stored on a storage facility that guarantees longevity and is ideally freely accessible. For example, the PANGAEA database (Data Publisher for Earth and Environmental Science; www.pangaea. de) is not only used for the secure storage of paleodata but also paleoclimate model results.

\section{Closing remarks}

The choice of a climate model has to be carefully considered in terms of included processes, the required spatial resolution, computational time and cost, the ability to obtain and run the model code and the storage space required for the model data. Although models are an incomplete representation of the Earth System, the advances in model development and computing technology over the last few decades have allowed researchers to consider more complex physical processes including a better understanding and consideration of the uncertainty in their model predictions (Hargreaves 2010). In the context of paleoclimatology this has greatly improved our understanding of the processes and feedbacks in the climate system.

\section{Selected references}

Full reference list online under:

http://www.pages-igbp.org/products/newsletters/ref2013_1.pdf

Bakker P et al. (2013) Climate of the Past 9: 605-619

Claussen M et al. (2002) Climate Dynamics 18: 579-586

Easterbrook SM (2009) Computing in Science and Engineering 11(6): 65-74

Hargreaves JC (2010) Wiley Interdisciplinary Reviews: Climate Change 1: 556-564

Robinson A, Calov R, Ganopolski A (2011) Climate of the Past 7: 381-396 


\section{Using marine sediment archives to reconstruct past outlet glacier variability}

Camilla S. Andresen ${ }^{1}$, F. StraneO ${ }^{2}$, M.H. Ribergaard ${ }^{3}$, A.A. Bjørk ${ }^{4}$, A. Kuijpers ${ }^{1}$ and K.H. KJaer ${ }^{4}$

'Geological Survey of Denmark and Greenland, Department of Marine Geology and Glaciology, Denmark; csa@geus.dk 2 Department of Physical Oceanography, Woods Hole Oceanographic Institution, USA; ${ }^{3}$ Danish Meteorological Institute, Centre for Ocean and Ice, Denmark; ${ }^{4}$ Centre for GeoGenetics, Natural History Museum, Denmark

Ice-rafted debris in fjord sediment cores provides information about outlet glacier activity beyond the instrumental time period. It tells us that the Helheim Glacier, Greenland's third most productive glacier, responds rapidly to short-term ( 3 to 10 years) climate changes.

Cea-level rise is one of the major socioSeconomic concerns associated with global warming, since millions of people live within coastal floodplains that are situated less than $1 \mathrm{~m}$ above present sea-level. The latest IPCC report suggested a sea-level rise of 0.18 to $0.59 \mathrm{~m}$ within the next 100 years (IPCC 2007), but emphasized that the contribution from outlet glaciers is the largest source of uncertainty. Since then, several studies (see SWIPA 2011 for references) have suggested that the contribution from outlet glaciers could be $+1 \mathrm{~m}$ or more.

The concern about unexpected glacier dynamical behavior was highlighted when the three largest outlet glaciers in Greenland were observed to suddenly increase their discharge at the onset of this century. Specifically, Jakobshavn Glacier in west Greenland, Kangerdlugssuaq Glacier and Helheim Glacier, both in Southeast Greenland, accelerated, thinned and retreated between 2000 and 2005 (Fig. 1A, Rignot \& Kanagaratnam 2006; Van den Broeke et al. 2009). In the case of Jakobshavn Glacier, researchers proposed that the acceleration was triggered by a warming of the subsurface ocean currents off West Greenland (Holland et al. 2008) consistent with the mid1990s warming of the North Atlantic subpolar gyre, which feeds the waters off West Greenland via the Irminger Current (Buch et al. 2004; Holliday et al. 2008; Stein 2005). The ocean warming, in turn, was attributed to a shift from a positive to a negative North Atlantic Oscillation (NAO; Hurrell 2001) phase and additional changes in the lowpressure systems causing a westerly movement of the subpolar frontal system (Flatau et al. 2003; Hatun et al. 2005). The westward spreading of the warm subpolar waters contributed to a warming of the West Greenland continental shelf and an increase in the rate of submarine melting of the glacier front, thereby increasing iceberg calving rates and mass loss (Rignot et al. 2010).

This hypothesis of glacier melting caused partly by warm subsurface water penetration into the glacial fords has also been suggested to explain the acceleration of outlet glaciers in Southeast Greenland (Christoffersen et al. 2011; Murray et al. 2010; Nick et al. 2009; Straneo et al. 2010). For example, Sermilik Fjord, where the Helheim Glacier terminates, is characterized by a thick layer of $\sim 4^{\circ} \mathrm{C}$ warm Atlantic water of Irminger Current origin, underlying cold Polar water of glacial and Arctic origin (Fig. 1A; Straneo et al. 2010). However, as fjord water properties have only been monitored here since 2008 , it has proven difficult to confirm such a causal relationship between oceanographic and glacier variability. Furthermore, relatively rapid mass changes of the Greenland ice sheet have only been estimated from satellite data since the early 1990 s. Thus, a comprehensive understanding of the inter-annual to decadal variability of the ice sheet on longer timescales is lacking. Without longer records it is difficult to evaluate if the recent mass loss is an outstanding event or is part of a recurring phenomenon acting on interannual, decadal or centennial timescales, or a combination of both.

\section{Reconstruction of Helheim Glacier calving variability}

The link between climatic changes and outlet glacier variability was recently investigated in a study of past changes of Helheim Glacier going back 120 years, analyzing three marine sediment cores retrieved in Sermilik Fjord (Fig. 1B; Andresen et al. 2012). We reconstructed the calving variability based on the assumption that changes in the deposition of sand (ice-rafted debris) directly relate to changes in iceberg rafting from calving activity. The resulting record documents a series of calving events lasting 3 to 10 years (Fig. 2A). The use of the sand deposition as a recorder of the calving history of Helheim Glacier is supported by the agreement between the reconstructed calving changes and the changes in frontal position of the Helheim Glacier since 1933 as observed from satellite data and historical aerial photographs (Fig. 1C, Fig. 2A-B).

\section{Exploring a link with climate}

Increased air and ocean temperatures (both surface Polar water and subsurface Atlantic water) may increase glacier calving through

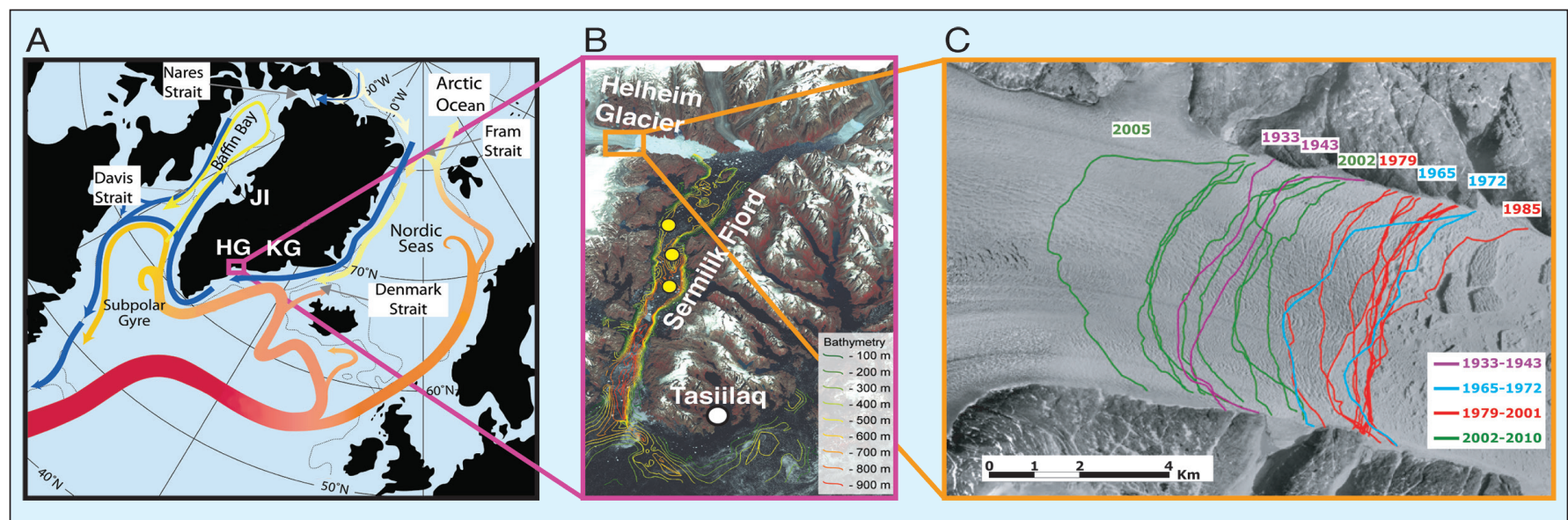

Figure 1: A) Main currents in the North Atlantic Ocean (Straneo et al. 2012) and location of Helheim Glacier (HG), Kangerdlugssuaq Glacier (KG) and Jakobshavn Isbrae (JI), (B) Helheim Glacier and Sermilik Fjord with position of the three cores (yellow dots) taken from water depths 500-600 m (bathymetry from Schjøth et al. 2012 and figure from Andresen et al. 2012) and (C) frontal variation in Helheim Glacier margin position from 1933 to 2010 grouped into time frames characterized by similar frontal behavior (from Andresen et al. 2012). 
a number of processes involving destabilization of the glacier margin (Motyka et al. 2011). Examples of such processes are ocean water undercutting and melting the submerged glacier margin, surface glacial melt water penetrating down the ice sheet, forming crevasses and promoting iceberg formation, or destabilization of the dense ice mélange (mixture) of icebergs and sea ice in front of the glacier margin (Amundson et al. 2010; Vieli and Nick 2011). To investigate potential links between climate variability and Helheim Glacier instability we compared the calving history with records of nearby oceanic and atmospheric variability (Fig. 2). Air temperature variability was taken from the observed summer temperatures at Tasiilaq (Fig. 2C). No long-term ocean measurements are available from Sermilik Fjord or the nearby shelf. Therfore, we used several indirect indicators for subsurface Atlantic water and surface Polar water: (1) Direct measurements of sea surface temperature (SST) from south of Iceland, where Atlantic water extends to the surface while flowing towards southeast Greenland and sliding underneath the East Greenland Current, were used as a measure of Atlantic water variability (Fig. 2D). (2) Changes in the Storis Index related to the amount of sea ice in the East Greenland Current, were used as a measure of Polar water variability (Fig. 2E). (3) Atlantic water and Polar water variability were combined into a so-called Shelf Index (Fig. 2F) assuming that the variability of waters on the shelf mostly reflects changes in the relative volume of these water masses: a positive Shelf Index indicates a thicker and warmer Atlantic water (at the expense of Polar water) and vice versa.

Finally, we compared the calving record with the wintertime NAO Index, which represents the dominant mode of atmospheric climatic variability in the North Atlantic region (Fig. 2G).

\section{Rapid glacier response to climatic changes}

We find that the calving variations are linked with synchronous changes in the source of Atlantic water and with local summer air temperature at multi-decadal timescales. Both these climate parameters reflect the Atlantic Multi-decadal Oscillation (Schlesinger and Ramankutty 1994) in this region. Therefore, we were unable to separate their respective impacts on the Helheim Glacier variability.

At sub-decadal timescales ( 3 to 10 years), calving peaks correlated with shortterm episodes of positive Shelf index and negative NAO index. As previously mentioned a negative NAO phase is often associated with a warm subpolar gyre and

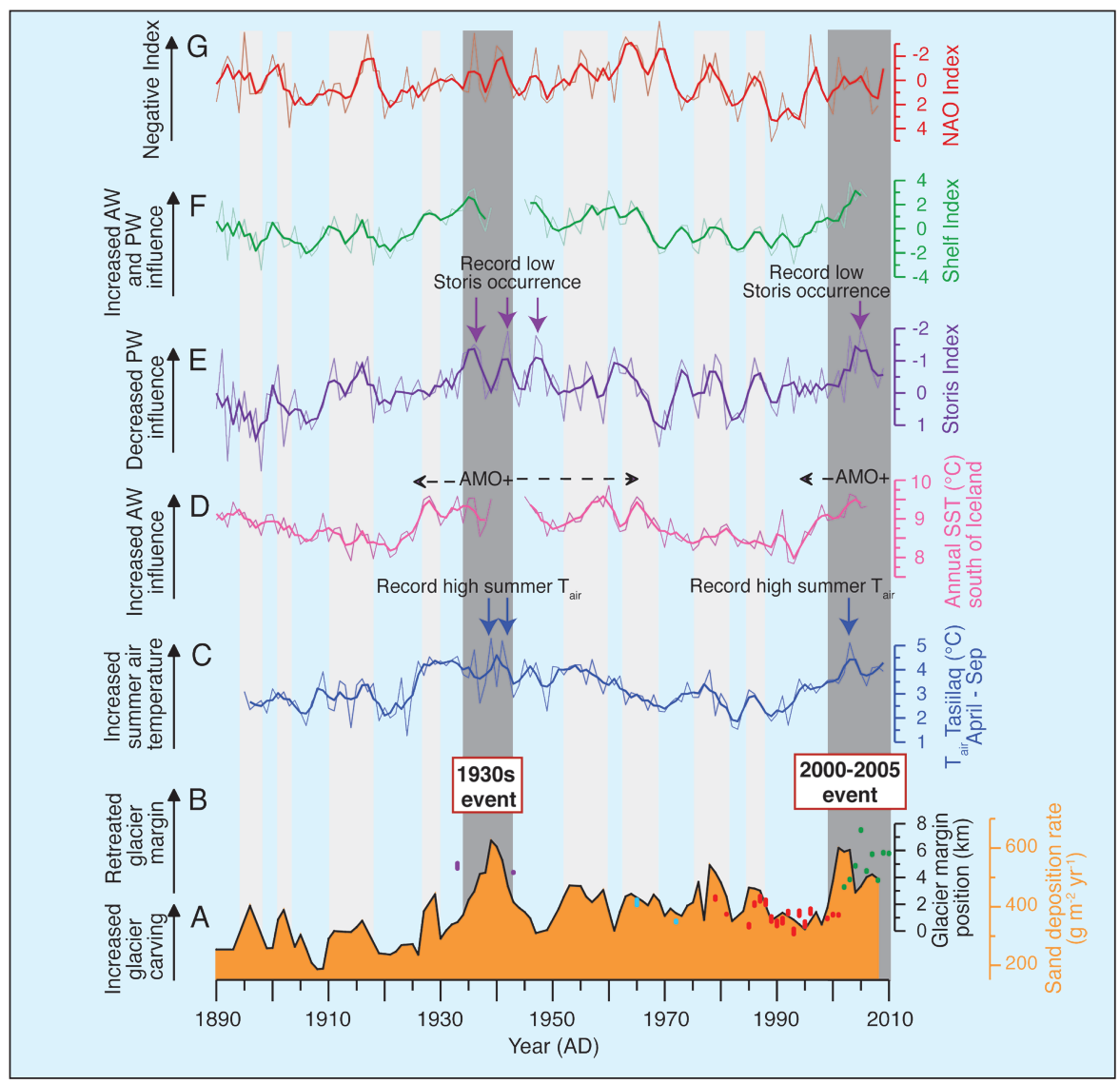

Figure 2: Comparison between the calving record and climate indices for Helheim Glacier (note the lack of some climate data during the $2^{\text {nd }}$ World War). A) Reconstructed calving record of Helheim Glacier from the three sediment cores (Thick lines are 3-year running mean data and thin lines are unfiltered data), (B) Helheim Glacier margin positions indicated relative to the 1993 position according to aerial and satellite images (color coding as in Fig.1C), (C) summer $T_{\text {air }}$ from Cappelen (1995), (D) SST south of Iceland (Andresen et al. 2012), (E) Storis Index (northernmost multi-year sea ice extent observed off southwest Greenland) from Schmith and Hansen (2003) and updated for 2000-2007 in Andresen et al. (2012), (F) Shelf Index (Andresen et al. 2012) and (G) NAO data from www.cru.uea.ac.uk/cru/datal nao. (Note $A W=$ Atlantic Water and PW=Polar Water). Figure modified from Andresen et al. (2012).

increased penetration of Atlantic water on the shelf (Holland et al. 2008), but local wind and air temperatures as well as variability in both the Polar water and Atlantic water source regions also often co-vary with the NAO index on these timescales (Dickson et al. 2000).

The most important finding from this study is that the increase in calving activity observed at Helheim Glacier during the period 2000 to 2005 is only matched in magnitude by a calving event in the late 1930s (Fig. 2). These two episodes are distinct from other calving episodes in our record. This is because they are the only two events that occur during a time interval characterized by the coincidence of a positive (warm) AMO phase, exceptional (for the investigated time period) high summer temperatures, and low Polar water export. The NAO Index was also frequently negative in the late 1930s, though not markedly more negative than during many of the other calving episodes.

\section{Summary}

Our study of three sediment cores from the Sermilik Fjord shows that Helheim Glacier responds to changes in large-scale atmospheric and oceanic conditions on timescales as short as a few years. The magnitude of the increase in calving activity observed at Helheim Glacier from 2000 to 2005 is only comparable to a calving episode that occurred in the late 1930s. A comprehensive understanding of the timescales involved in glacier changes and of the influence of oceans and atmospheric variability is important, if we are to make reliable predictions of future glacier changes and associated sealevel rise in a warming world.

\section{Acknowledgements}

This study has been financially supported by Geocenter Denmark and the SEDIMICE project, the Danish Council for Independent Research Nature and Universe (Grant no. 09-064954/FNU), the Danish Agency for Science, Technology and Innovation as a part of the Greenland Climate Research Centre and NSF ARC 0909373.

The reconstructed Helheim glacier calving record can be downloaded from the Pangaea database.

\section{Selected references}

Full reference list online under:

http://www.pages-igbp.org/products/newsletters/ref2013_1.pdf

Andresen CS et al. (2012) Nature Geoscience 5: 37-41

Buch E, Pedersen SA and Ribergaard MH (2004) Journal of Northwest Atlantic Fishery Science 34: 13-28

Holland D et al. (2008) Nature Geoscience 1: 659-664

Schmith T and Hansen C (2003) Journal of Climate 16: 2782-2791

Straneo Fet al. (2010) Nature Geoscience 3: 182-186 


\title{
Using data assimilation to estimate the consistency between climate proxies and climate model results
}

\author{
Aurélien Mairesse and Hugues Goosse \\ Georges Lemaitre Centre for Earth and Climate Research, Earth and Life Institute, Université catholique de Louvain, Belgium; \\ aurelien.mairesse@uclouvain.be
} The data assimilation technique applied to paleoclimate studies is a promising method to highlight the
compatibility or the incompatibility between (1) different climate proxies and (2) between climatic information
inferred from the proxies and the physics of the climate system represented in models.

\begin{abstract}
T he combination of several climate proxies and/or the results from climate models enables us to reconstruct and understand past climate changes. When data and models are used together, the information inferred from the proxies often serves to validate the climate model results while the models allow exploration of the physical processes responsible for the recorded climatic changes. During the past decade, a new statistical tool called data assimilation has been used in paleoclimatology (Widmann et al. 2010). This tool allows us to build a reconstruction of past climate change which is both consistent with the climate computed by a model and that deduced from proxies.
\end{abstract}

First, we describe how this tool works when it is applied to the paleoclimate research field. Second, we describe a particular application of data assimilation, which can help to elucidate if the hypotheses proposed to explain proxy variations are compatible with the physics of a climate model. This is outlined with a mid-Holocene case study.

\section{How does data assimilation work?}

Data assimilation combines the physical laws included in a climate model with the climate information inferred from proxies to produce paleoclimatic reconstructions consistent with both. In our method, this is achieved using a procedure based on a particle filter with resampling (Dubinkina et al. 2011; see Fig. 1 from van Leeuwen 2009 for a graphical representation) applied to the three-dimensional Earth model of intermediate complexity, LOVECLIM (Goosse et al. 2010).

An ensemble of $\sim 100$ simulations, also referred to as particles or ensemble members, is initiated in parallel. At the beginning of this procedure, all of the particles are identical apart from slightly different initial conditions. Due to the chaotic nature of the climatic system each particle will evolve in a different way. After the first assimilation step (which is one year here but it can be any value greater than or equal to the model time resolution) the likelihood of each member of the ensemble is evaluated in order to determine how close the climate state of each particle is compared with the climate inferred from the proxy data. For each variable (e.g. surface air temperature and sea surface temperature; SST) the likelihood is a function of the difference between the values estimated from the proxy records and the values calculated by the climate model. This function is computed for all the locations and months for which paleodata is available. The particles that have the largest likelihood are retained (i.e. the particles whose climate states are the closest to the past climate reconstructed from the proxies). The other ensemble members are rejected. The remaining particles are resampled in order to keep a constant number of particles (i.e. 100 in this example) and avoid a degenerative issue. We add a small perturbation to the members that have been sampled more than once for the next year of assimilation. The whole procedure is continually repeated until the final year of calculation (i.e. if we perform a 200-year simulation the procedure is repeated 200 times in this example).

The final climate reconstruction obtained by this method is consistent with the LOVECLIM physics, since the LOVECLIM climate model itself is used in the assimilation process. The reconstruction is also as consistent as possible with the climate derived from the proxy data. This is because the method only selects LOVECLIM results that are most compatible with the information inferred from all the climate proxies, for each time step of the simulated time period.

Our method has produced a reconstruction of surface temperature changes over the past millennium (e.g. Goosse et al. 2006, 2012). The data assimilation in those studies performed well since the LOVECLIM results were efficiently constrained to be close to the surface temperature signal recorded by continental data and, therefore, provided a consistent picture of the climate system during these particular time periods. Recently, we have applied this data assimilation method to the mid-Holocene climate.

\section{Data assimilation applied to the mid-Holocene}

A large number of surface air and SST reconstructions are available for the Holocene. A selection from more than 300 published records was performed with the following criteria: (1) each record must come from archives located between $20^{\circ} \mathrm{N}$ and $90^{\circ} \mathrm{N}$ and (2) each record must have a mean temporal resolution of at least 250 years for the period of interest ( 6.5 to $5.5 \mathrm{ka} \mathrm{BP}$ ).

In accordance with these two principles and restricting selection to only publicly available data, we selected 47 records of surface air temperature and SST for the mid-Holocene. The resulting dataset is heterogeneous for the following reasons: (1) this climatic information was inferred from climate proxies preserved in marine, continental, and ice archives (Fig. 1), (2) for a given archive, different proxies have been used to infer the same type of information (e.g. SST reconstructions in marine cores based on alkenones, $\mathrm{Mg} /$ Ca ratio etc., Fig. 1) and (3) the proxies have been measured and interpreted in term of climate variations by different research groups. 


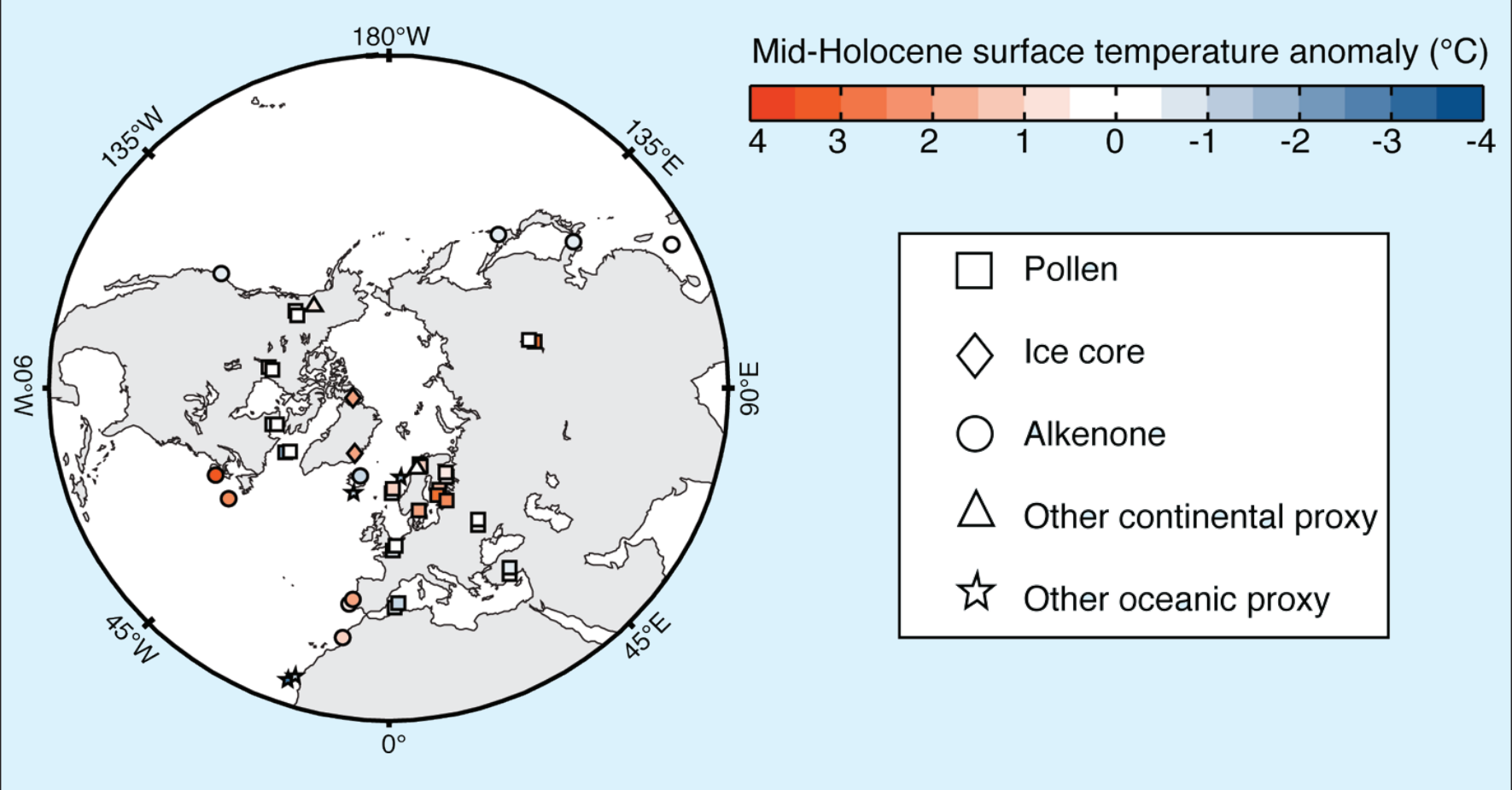

Figure 1: Inferred mid-Holocene surface temperature anomalies $\left({ }^{\circ} \mathrm{C}\right)$ compared to a reference period (1000 to $\left.1500 \mathrm{AD}\right)$. Where there is more than one proxy record at the same location, the markers representing the proxies are slightly shifted for improved readability.

We have performed the first mid-Holocene data assimilation with the selected dataset and the LOVECLIM model. For this 200-year snapshot experiment, the constraint provided by data assimilation is weak and the disagreement between the climate proxies and model results based on this data assimilation method is still large. For all the locations and the months for which proxy information is available, the LOVECLIM results with data assimilation are on average only $10 \%$ closer to the climate signal extracted from the proxies than with the LOVECLIM results produced without data assimilation. In other words, because of the heterogeneous nature of the proxy dataset, the simulations with data assimilation mainly highlight incompatibilities between the proxies and with the model physics rather than producing a shift of the model state that results in a better agreement with the proxybased climatic reconstructions.

\section{Incompatibilities between proxy and model}

First, some variations observed in the climate reconstructions inferred from the proxies cannot be explained by LOVECLIM because they are related to phenomena occurring at a scale smaller than the model grid resolution. For example, this is the case with some SST reconstructions from marine cores retrieved in coastal margins such as the Tagus Estuary (Portugal) where
Holocene SST variations are partly influenced by the Tagus River input (Rodrigues et al. 2009). Such a regional influence in this area is not represented in the LOVECLIM model.

Second, incompatibilities exist between reconstructions based on different types of proxies (see Fig. 1). Future work will aim at identifying these inconsistencies by performing additional experiments with data assimilation. We will run several ensemble simulations, each constrained by climate records from only one type of proxy at a time (e.g. pollens). Each set of simulations will enable the identification of the processes that could explain the recorded signal used according to the climate model physics. Subsequently, it will be also possible to analyze the results of these experiments at locations where other proxies, not selected to drive this set of simulations, are available. For instance, we will compare the results from an assimilation which includes only pollen data, with SSTs inferred from alkenones. This comparison could aid in deciphering whether the SST signal deduced from alkenones should be interpreted as an annual or a summer signal to improve the compatibility between the pollen and the alkenone-based climate records, according to the LOVECLIM physics. This procedure may lead to a tentative revised interpretation of the climate proxy. Even if this proves too challenging, the uncertainty in model-data comparison associated with incompatibilities between proxybased reconstructions could at least be estimated.

\section{Outlook}

We highlight the potential use of the data assimilation method for paleoclimate studies. This method enables us to assess compatibilities and/or incompatibilities between different climate proxy records for the mid-Holocene time interval. In the future, we could use data assimilation to suggest a revised interpretation of the proxies in order to have a better consistency between different climate proxies and enable more accurate model-data comparisons.

\section{Selected references}

Full reference list online under:

http://www.pages-igbp.org/products/newsletters/ref2013_1.pdf

Dubinkina $S$ et al. (2011) International Journal of Bifurcation and Chaos 21: $3611-3618$

Goosse H et al. (2006) Climate Dynamics 27(2): 165-184

Goosse H et al. (2010) Geoscientific Model Development 3(2): 603-633 Goosse H et al. (2012) Global and Planetary Change 84-85: 35-47 van Leeuwen PJ (2009) Monthly Weather Review 137(12): 4089-4114 


\section{Increasing fire activity in a warming climate? Ice core record insights from the present and the last interglacials}

Natalie Kehrwald ${ }^{1}$, P. Zennaro ${ }^{1,2}$ and C. Barbante ${ }^{1,2}$

'Department of Environmental Sciences, Informatics and Statistics, University of Venice, Italy; kehrwald@unive.it

2 Institute for the Dynamics of Environmental Processes, Consiglio Nazionale delle Ricerche, Venice, Italy

Fire impacts climate by changing atmospheric greenhouse gas concentrations, vegetation distributions, and surface albedo. We present a biomarker, levoglucosan, to reconstruct past fire activity from ice cores. This tracer allows us to investigate fire and climate interactions over glacial-interglacial cycles.

\begin{abstract}
The devastating Waldo Canyon fire (North America) forced the evacuation of approximately 30,000 people from their homes in Colorado Springs during June 2012 (Fig. 1). The massive wildfires and associated heat wave that swept across Russia in 2010 were responsible for the deaths of over 55,000 people (Barriopedro et al. 2011), caused 15 billion US dollars in damages and were the result of both natural and anthropogenic climate change (Otto et al. 2012). This destruction demonstrates the importance of understanding the prospect of increased fire activity in a changing climate.
\end{abstract}

\section{Interactions between climate and fire activity}

The relative impact of climate change (including increased deadwood availability due to bark beetle infestations) and human activity on fires (including forest management and housing expansion) can differ between individual fires. Droughts tend to increase fire activity, provided that there is sufficient material to burn. Increased precipitation may also cause more vegetation growth and increase the area susceptible to burning as long as the precipitation remains low enough that it does not suppress fires. Regional fire activity, therefore, depends on a number of variables including temperature, fuel availability, and precipitation, but generally increasing global temperatures enhance global fire activity (Daniau et al. 2010; Power et al. 2008).

Fires in turn, influence climate by emitting greenhouse gases and aerosols into the atmosphere, and by affecting carbon sequestration in vegetation and soils. Deforestation fires alone have caused $\sim 19 \%$ of the anthropogenic warming since preindustrial times (Bowman et al. 2009). Currently, total biomass burning releases up to $50 \%$ as much carbon dioxide into the atmosphere as does fossil fuel combustion (Bowman et al. 2009). The impact of biomass burning emissions on the global radiation balance and the carbon cycle, however, remains one of the least understood aspects of the climate system.

It is essential to determine the interactions between climate and fire activity through time in order to establish if humans are increasing susceptibility to fire in a warming climate. The last interglacial period (LIG, 130-116 ka BP), represents a climate analogous to the present but without the impact of human activity. Ice core records from the LIG and present interglacial contain contemporaneous climate and fire proxies that allow a detailed assessment of fire activity in warming climates with and without anthropogenic influences.

\section{Fire and climate records in ice cores}

Researchers have developed many fire proxies in ice cores during the past decade. Tracers for biomass burning in ice cores with atmospheric residence times ranging from days to weeks include black carbon, particulate organic carbon, monosaccharide anhydrides, organic acids, diacids (oxalate, formate), major ions (ammonium and potassium), isotopes of carbon monoxide and methane, polycyclic aromatic hydrocarbons, and charcoal. In general, the shorter residence time tracers provide more regional records, while the longer residence time tracers can provide hemispheric to global records of biomass burning. Here, we discuss using monosaccharide anhydrides as fire tracers and their applicability to the present and past interglacials.

Biomass burning injects monosaccharide anhydrides such as levoglucosan into the fine particle phase of smoke plumes. Levoglucosan is a specific tracer of fire activity as it is only derived from cellulose burning at temperatures greater than $300^{\circ} \mathrm{C}$
(Schkolnik and Rudich 2006; Simoneit 2002). Levoglucosan is injected into and travels through the atmosphere in smoke plumes before returning to the surface through wet and dry deposition (Fraser and Lakshmanan 2000; Stohl et al. 2007). We trace levoglucosan from a forest fire source to its deposition on glacier surfaces where it is preserved and does not appear to decompose in snow and firn layers (Fig. 2A; Kehrwald et al. 2012). Levoglucosan is unequivocally a cellulose degradation product (Simoneit 2002), while other biomass burning tracers archived in snow and ice cores may have multiple sources.

We investigated samples from a snow pit at the Summit camp in Greenland and combine levoglucosan records with other biomass burning proxy records to provide an analysis of past fire activity from 1987 to 1995 (Fig. 2B-C). We demonstrate that combining levoglucosan concentrations with other biomass burning proxies helps determine the relative contribution of fire versus other sources to total deposition. This is illustrated by an event that occurred between spring 1994 and spring 1995:

- The oxalate and levoglucosan peaks replicate the same known Canadian fire event (Fig. 2C). Although oxalate is a product of forest fire emissions (Legrand and DeAngelis 1996) it may also originate from vehicle emissions (Kawamura and Kaplan 1987).

- Ammonium concentrations in the snow pit also peak during the fire event, but the

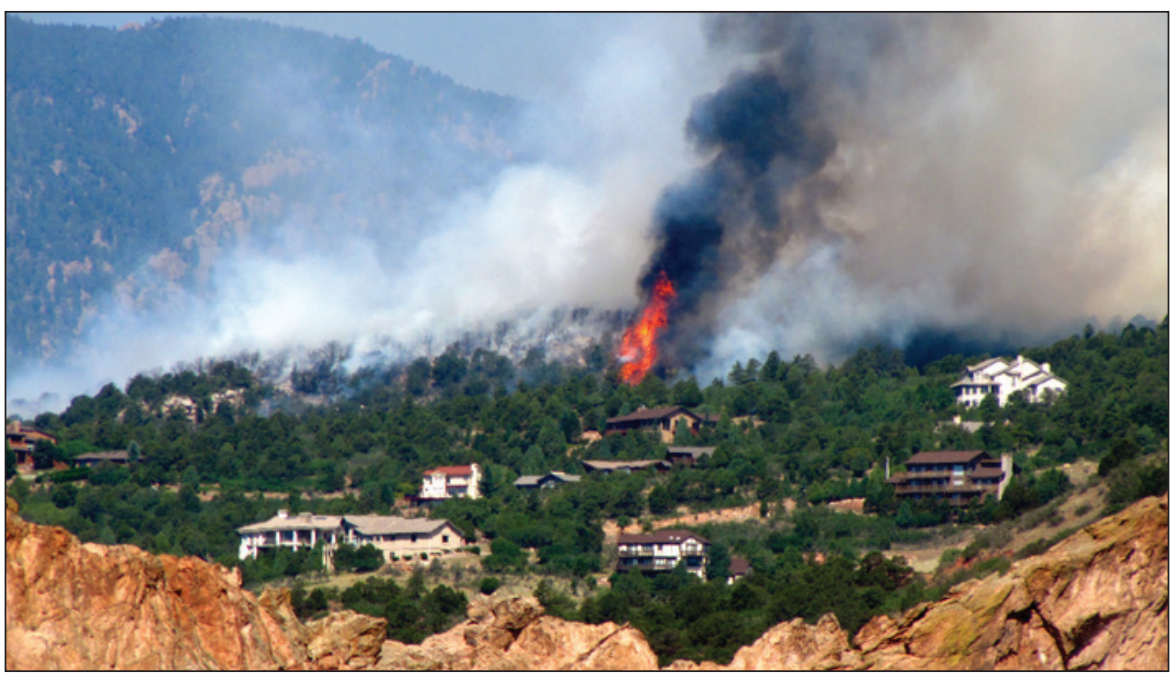

Figure 1: Waldo Canyon fire in Colorado Springs, Colorado, USA ( June 27, 2012). Photo: Erica Rewey. 


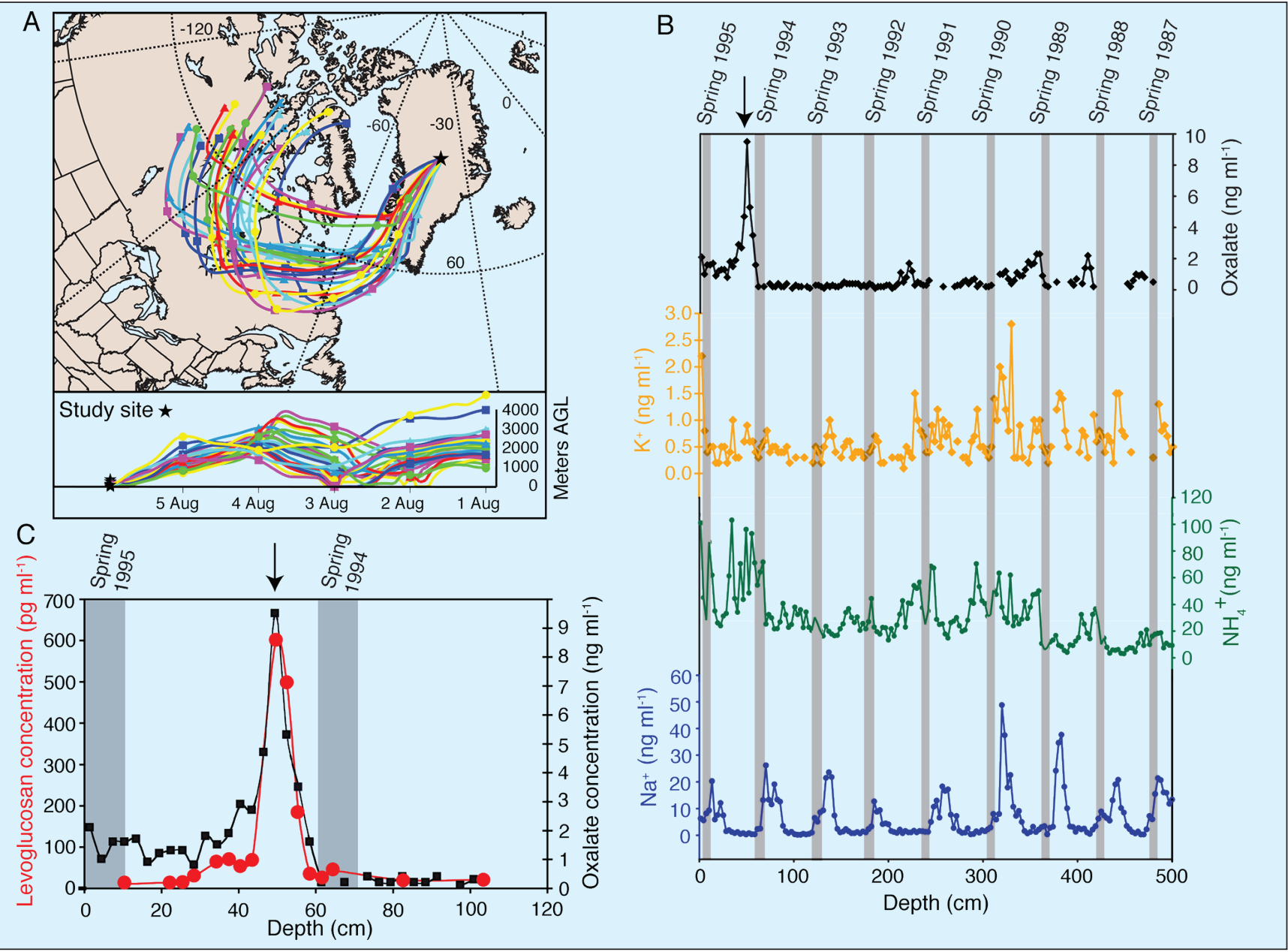

Figure 2: A) Atmospheric transport of smoke plumes from the western Hudson Bay forest fire source to the study site (AGL = above ground level). B) Multiple years of fire markers (ammonium, potassium, and oxalate) determined from a 6-m deep snow pit at Summit, Greenland. Note that the sodium concentration record, also shown, is one of the main tools to date the snow pit (peaks in sodium denote spring accumulation). C) Comparison between oxalate and levoglucosan as biomass burning tracers in the upper section of the snow pit. The black arrows on (B) and (C) point to the same known Canadian fire event. Figure modified from Kehrwald et al. (2012).

increased concentrations are distributed across a relatively wide depth range (Fig. 2B). Elevated concentrations of ammonium (Stohl et al. 2007) may reflect past fires, but atmospheric ammonium may also result from lightning, marine sources, soil processes, or agricultural activity (Hristov et al. 2011; Olivier et al. 2006).

-While potassium concentrations have been identified as a past fire activity proxy (Echalar et al. 1995) they do not reproduce the oxalate and levoglucosan peaks in our record (Fig. 2B). Potassium can be transported to glacier surfaces through sea salts and mineral aerosols (Laj et al. 1997). The differing transport paths and sources of levoglucosan and potassium are reflected in the snow pit concentrations. As a result, if the fire reconstruction from this snow pit were assessed solely from potassium concentrations, they would miss an important fire event.

The research team at the University of Venice has created high-resolution Holocene levoglucosan records from the NEEM and EPICA Dome C (EDC) ice cores and a late Holocene levoglucosan record from Kilimanjaro ice cores. This combination creates a pole-equator-pole transect of Holocene fire records. The Kilimanjaro ice fields are located near the largest savanna system in the world. Savanna and similar grassland fires produce the highest levoglucosan emission factors of various tested vegetation types (Engling et al. 2006) and Kilimanjaro may serve as reference site for high levoglucosan concentrations. NEEM and EDC are located farther away from levoglucosan sources than Kilimanjaro, but both of these polar locations archive a levoglucosan flux above the detection limit. Late Holocene NEEM levoglucosan concentrations correlate with synthesized charcoal records above $55^{\circ} \mathrm{N}$, demonstrating the viability of using levoglucosan concentrations in ice cores as a biomass burning tracer over centennial to millennial timescales. This correlation between sedimentary charcoal and ice core records allows researchers to reconstruct fire histories over larger spatial scales.

The research team is currently determining LIG levoglucosan concentrations from NEEM and EDC ice cores to compare with the Holocene records. Initial tests are encouraging and demonstrate that the LIG ice contains detectable levoglucosan concentrations.

\section{Outlook}

Human activities including slash-and-burn farming, forest fires caused by human ignition, and wildfire suppression alter global fire activity. Anthropogenic activity also increases greenhouse gas concentrations, resulting in warming temperatures and possibly increased wildfires. Paleorecords demonstrate that global fire activity is higher during interglacials than during glacial periods in a purely natural system (Daniau et al. 2010). Imminent measurements of LIG levoglucosan concentrations will provide unique constraints on past fire activity in a warming climate with implications for fire activity in the current climate.

\section{Acknowledgements}

The research leading to these results has received funding under grant agreement no 267696, (ERC-2010-AdG_20100224) "EARLYhumanIMPACT. How long have humans been impacting the climate system?".

\section{Selected references}

Full reference list online under:

http://www.pages-igbp.org/products/newsletters/ref2013_1.pdf

Bowman DMJS et al. (2009) Science 324: 481-484

Engling G et al. (2006) Atmospheric Environment 40: 299-311

Kehrwald N et al. (2012) Tellus B 64, doi: http://dx.doi.org/10.3402/ tellusb.v64i0.18196

Schkolnik G, Rudich Y (2006) Analytical and Bioanalytical Chemistry 385 26-33

Simoneit BRT (2002) Applied Geochemistry 17: 129-162 


\title{
Antarctic interglacial climate variability and implications for changes in ice sheet topography
}

\author{
Valérie Masson-Delmotte ${ }^{1}$, E. Capron ${ }^{2}$, H. Goosse ${ }^{3}$, K. Pol ${ }^{2}$, M. Siddall ${ }^{4}$, L. Sime ${ }^{2}$, S. Bradley and B. Stenni ${ }^{5}$ \\ 'Laboratoire des Sciences du Climat et de l'Environnement, CEA Saclay, Gif-sur-Yvette, France; valerie.masson@lsce.ipsl.fr \\ ${ }^{2}$ British Antarctic Survey, Cambridge, UK; ${ }^{3}$ Georges Lemaître Centre for Earth and Climate Research, Earth and Life Institute, Université catholique \\ de Louvain, Belgium; ${ }^{4}$ Department of Earth Sciences, University of Bristol, UK; ${ }^{5}$ Department of Geological, Environmental and Marine Sciences, \\ University of Trieste, Trieste, Italy
}

\section{New studies focusing on Antarctic climate variability during the current and earlier interglacial periods highlight the interplay between long-term climatic changes and climate variability in Antarctica, and enable the fingerprint of past changes in ice sheet topography to be investigated.}

$\mathrm{N}_{\mathrm{ftan}}$ ew findings have arisen in the ramework of two ongoing European projects that aim at documenting and understanding past Antarctic climate variability. The ESF HOLOCLIP project focuses on Antarctic and marine records of the Holocene ( 15-0 ka BP), while the Past4Future project aims at, among other things, improved spatial and temporal coverage of the last interglacial (LIG; 129$118 \mathrm{ka}$ BP) in water stable isotopes from Antarctic ice cores.

By combining both data and model results obtained during two interglacial periods, characterized by different orbital configuration and over a large range of timescales (from multi-decadal to orbital), we show how these studies contribute to assessing the mechanisms responsible for Antarctic climate variability, and how they inform on the fingerprint of changes in ice sheet topography.

\section{The last millennium}

A good estimate of the magnitude and patterns of Antarctic temperature at a multi-decadal to centennial timescale during the last millennium is essential to understand the response of Antarctic climate to external forcings, and for assessing the ability of climate models to resolve the mechanisms at play (Goosse et al. 2012). Within HOLOCLIP, a composite of Antarctic temperature has been calculated by averaging temperature anomalies derived from seven ice core records (Fig. 1A). This simple method is supported by the coherency displayed between the average of the climate model results at the corresponding grid points, and the simulated average Antarctic temperature. Models and data rule out large $\left(>0.5^{\circ} \mathrm{C}\right)$ preindustrial temperature variations during the last millennium, and show $\sim 0.5^{\circ} \mathrm{C}$ warming since $1850 \mathrm{AD}$. Climate model simulations mainly attribute the multi-centennial cooling trend depicted from 1000 to $1850 \mathrm{AD}$ to volcanic forcing for annual mean temperature, while orbital forcing controls seasonal trends. Ongoing work aims at improving the documentation of Holocene climate and sea ice variability by combining ice core water stable isotope (Fig. 1B) and aerosol records with information from deepsea sediments and coastal records.

\section{Interglacial climate: mean state and variability}

Antarctic ice core records provide insight to a diversity of interglacial periods, characterized by different durations, intensities, and trends (Jouzel et al. 2007; Uemura et al. 2012). Within the Past4Future project, new high-resolution water stable isotope measurements have been performed in order to assess past changes in high-resolution variability. In central Antarctica, deposition and post-deposition processes

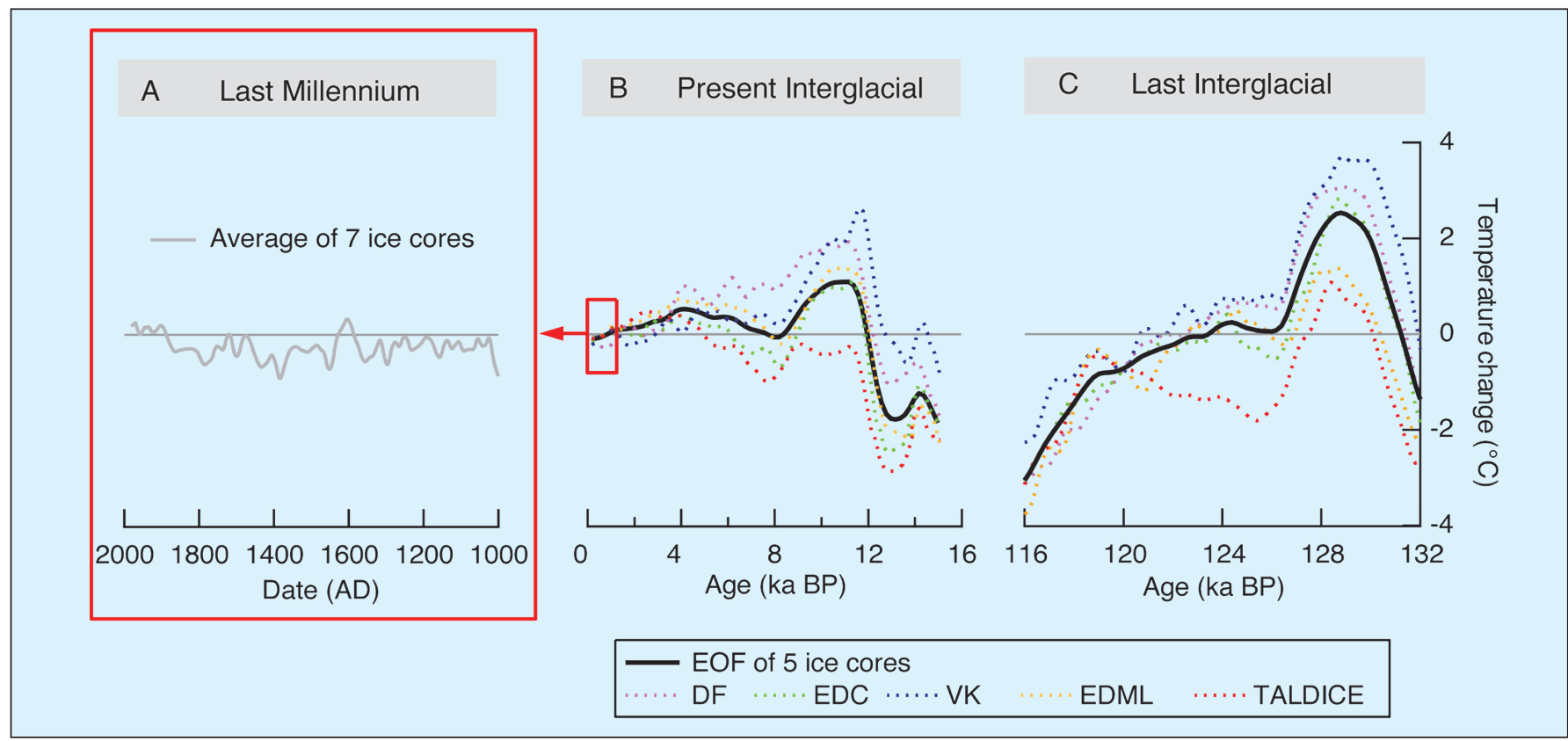

Figure 1: Antarctic records of the present interglacial and the last interglacial periods. This panel shows temperature estimates simply based on the spatial isotope-temperature gradient $\left(0.8 \% 0 \delta^{18} \mathrm{O}\right.$ per $\left.{ }^{\circ} \mathrm{C}\right)$ using $(\boldsymbol{A})$ a stack of seven ice cores for the last millennium and using individual ice cores (Vostok, VK; Dome F, DF; EPICA Dronning Maud Land, EDML; EPICA Dome C, EDC; Talos Dome, TALDICE) and the mean signal extracted using the first principal component (EOF1) for (B) the present interglacial and (C) the LIG. Modeling studies have suggested that past changes in isotope-temperature relationships could lead to larger temperature changes than depicted here (e.g. Sime et al. 2009). 


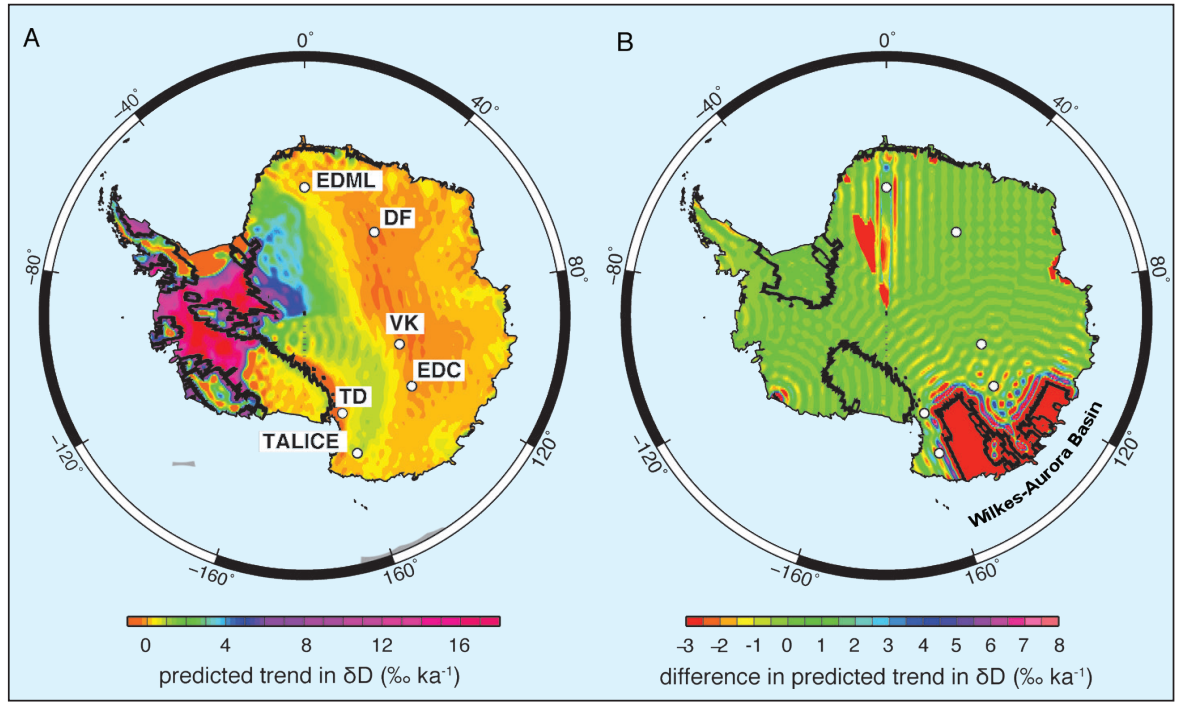

Figure 2: Simulated impacts of changes in Antarctic ice thickness and isostatic adjustment. Circles indicate ice core sites (Vostok, VK: Dome F, DF; EPICA Dronning Maud Land, EDML; EPICA Dome C, EDC; Talos Dome, TALDICE; Taylor Dome, TD) and the solid black lines highlight the location of the edge of each ice sheet model used. A) Predicted stable isotope trends (\%o kyr ${ }^{-1}$ ) driven by surface elevation changes only (not accounting for climatic impacts) resulting from a collapse of the WAIS (from 130 to $118 \mathrm{ka} \mathrm{BP).} \mathrm{Note} \mathrm{that} \mathrm{the} \mathrm{dark} \mathrm{red} \mathrm{and} \mathrm{orange} \mathrm{colors}$ represent \%o kyr ${ }^{-1}$ values greater than the maximum (20) and minimum (-4) on the scale bar, respectively. B) Difference in the predicted stable isotope trends $\left(\%\right.$ kyr ${ }^{i}$ ) between a reference LIG Antarctic ice sheet model (Bradley et al. 2012) and a model (Bradley et al. 2013) where a significant retreat of marine-based ice in the Wilkes and Aurora basins of the East Antarctic Ice Sheet (from 126 to $118 \mathrm{ka} \mathrm{BP}$ ) has been simulated. Modified from Bradley et al. (2012) and Bradley et al. (2013).

such as precipitation intermittency and wind scouring limit the relevant temporal resolution to approximately 20 years. So far, a 45-year resolution has been achieved for Marine Isotopic Stage (MIS) 11 ( 400 ka, Pol et al. 2011) chosen as an exceptionally long interglacial, and a 20-year resolution for the LIG (Pol et al. unpublished data), chosen as an exceptionally warm period.

In Antarctica, MIS 11 is marked by a multi-millennial-long increasing trend, which then decreases. High-resolution deuterium measurements have revealed increased sub-millennial climatic variability in the decreasing temperature phase. During the LIG (Fig. 1C), Antarctic temperature exhibits an early maximum, which corresponds to a bipolar seesaw with respect to Northern Hemisphere climate (Masson-Delmotte et al. 2010). It is followed by a multi-millennial scale plateau, then by a cooling into the glacial inception, punctuated by the onset of glacial millennial climatic variability, established at around 110 ka BP (Capron et al. 2012). Our unpublished high-resolution deuterium data point to minimum variance during the LIG "plateau", above Holocene levels and an increasing sub-millennial climatic variability at the end of the interglacial phase, as observed for MIS 11.

\section{Tracking changes in the Antarctic ice sheet topography}

Further investigation of the Antarctic climate during the LIG was achieved by comparing the records available from six East Antarctic ice cores with their Holocene data. In addition to the common features previously described and well captured in the EPICA Dome C ice core, the same regional differences are depicted during the current and LIG periods. Some earlier studies have shown that these differences can be attributed to precipitation intermittency (e.g. Sime et al. 2009). However, an alternative interpretation lies in different elevation histories due to the interplay between local ice thickness and isostatic adjustment.

The cause for peak Antarctic warmth during the LIG remains disputed. Astronomical forcing alone does not allow climate models to produce warmer than present day Antarctic temperatures. Therefore, other hypotheses such as the bipolar seesaw linked with large-scale ocean circulation perhaps along with the climate impacts of a collapse of the West Antarctic ice sheet (Holden et al. 2008), could explain the early Antarctic optimum. Recent studies have stressed that the Greenland ice sheet may have made only a limited contribution (about $+2 \mathrm{~m}$ of equivalent sea level) to the LIG highstand, pointing to a significant contribution of the West and/or East Antarctic ice sheets to the estimated 6-to-10-m high stand (NEEM community members 2013; Dahl-Jensen et al. this issue).

At the intersection of Past4Future Work Packages focused on interglacial climate variability and ice sheet dynamics (e.g. Siddall et al. this issue), different Past4Future partners have started to explore if a fingerprint of past changes in the Antarctic ice loading could be detected as an elevation-driven temperature trend preserved in East Antarctic ice cores. A "treasure map" was produced, identifying potential drilling sites where a clear fingerprint of a West Antarctic ice sheet collapse could be identified (Bradley et al. 2012). These sites, unfortunately, do not coincide with existing ice core records (Fig. 2A). The same approach proved more successful for the Wilkes-Aurora Basin sector of the East Antarctic ice sheet, and preliminary results (Bradley et al. 2013), assuming a homogeneous climate history, suggest that differences between the coastal TALDICE and central EPICA Dome C water isotopic records may provide information on changes in East Antarctic ice sheet topography (Fig. 2B). This brief overview of recent studies, dedicated to the variability of Antarctic climate during the current and earlier interglacial periods, shows new findings regarding both the interplay between mean climate state and polar climate variability at shorter time scales and new implications for climate - ice sheet evolution.

\section{Outlook}

New information from Antarctic ice cores is needed to further assess the spatial coherency of interglacial climate variability and the relationships between climate and the water cycle, including all water stable isotopes. The use of ice core information alongside ice sheet and climate modeling (including water isotopes) has the potential to test model capabilities and help us reduce uncertainty about the response of the Antarctic ice sheet to warmer than present climate conditions.

\section{Selected references}

Full reference list online under:

http://www.pages-igbp.org/products/newsletters/ref2013_1.pdf

Bradley SL et al. (2012) Global and Planetary Change 88-89: 64-75 Bradley SL et al. (2013) Global and Planetary Change 100: 278-290 Capron E et al. (2012) Geophysical Research Letters 39(15), doi: $10.1029 / 2012 \mathrm{GL} 052656$

Goosse H et al. (2012) Quaternary Science Reviews 55: 75-90 Pol K et al. (2011) Climate of the Past 7(2): 437-450 


\title{
Land biosphere dynamics during the present and the last interglacials
}

TIM BrÜChER AND VICTOR BRovkIN

Max Planck Institute for Meteorology, Hamburg, Germany; tim.bruecher@zmaw.de

\begin{abstract}
Snapshot simulations are obtained for the preindustrial, the mid-Holocene and the last interglacial time periods characterized by different atmospheric $\mathrm{CO}_{2}$ concentrations and orbital forcing. We evaluate the natural variability of vegetation cover, land carbon storage, and fire activity using a coupled climate-carbon cycle model.
\end{abstract}

D uring the last eight glacial-interglacial cycles, atmospheric $\mathrm{CO}_{2}$ concentration has fluctuated between glacial levels of about $180 \mathrm{ppm}$ and interglacial levels of up to about 300 ppm. These $\mathrm{CO}_{2}$ concentration changes appear to be closely linked to Antarctic surface temperature as inferred from ice cores (e.g. Luethi et al. 2008). Several physical and biogeochemical mechanisms responsible for this link have been identified, including changes in sea surface temperatures and deep water formation, marine productivity, $\mathrm{CaCO}_{3}$ accumulation, terrestrial productivity, and weathering. Quantification of their relative roles is under active investigation (e.g. Brovkin et al. 2012). Recently, focus in the paleo-carbon research community has shifted towards the link between surface temperature and $\mathrm{CO}_{2}$ concentration during warm periods, including Quaternary interglacial periods.
Over the penultimate deglaciation, $\mathrm{CO}_{2}$ concentration rapidly increased from $180 \mathrm{ppm}$ to $290 \mathrm{ppm}$ at $128 \mathrm{ka} \mathrm{BP}$, and then stabilized between 270 and 280 ppm for more than $10 \mathrm{ka}$ (Lourantou et al. 2010) over the last interglacial (LIG). At the onset of the Holocene (ca. $12 \mathrm{ka} \mathrm{BP}), \mathrm{CO}_{2}$ concentration was about 265 ppm and reached a minimum of 260 ppm by $7 \mathrm{ka} \mathrm{BP}$. Thereafter, $\mathrm{CO}_{2}$ concentration steadily increased by $20 \mathrm{ppm}$ to the preindustrial level of 280 ppm (Elsig et al. 2009).

To date it is unclear what mechanisms drive atmospheric $\mathrm{CO}_{2}$ concentration trends during interglacial periods. While the majority of climate-carbon cycle model simulations (e.g. Elsig et al. 2009; Joos et al. 2004; Kleinen et al. 2010; Menviel and Joos 2012; Ridgwell et al. 2003) agree that the ocean was the main source of carbon entering the atmosphere, the impact of land carbon changes on atmospheric $\mathrm{CO}_{2}$ concentration is less clear. To understand the role of the land biosphere on atmospheric $\mathrm{CO}_{2}$ concentration changes during the present and the last interglacials, we have used the new climate-carbon cycle model CLIMBER-JSBACH, which is the asynchronously coupled Earth System Model of Intermediate Complexity CLIMBER-2 (Ganopolski et al. 2001) and the land component JSBACH of the Max-Planck Earth System Model described by Raddatz et al. (2007). The models are coupled as follows: After one year of climate-ocean simulation by CLIMBER-2 the atmospheric $\mathrm{CO}_{2}$ concentration, and anomalies of monthly precipitation, temperature, and radiation fields are fed to the land component JSBACH. Given these boundary conditions, JSBACH simulates the new carbon allocation and calculates the carbon flux to the atmosphere, which is fed back to the climate model for the next year of simulation. This model setup

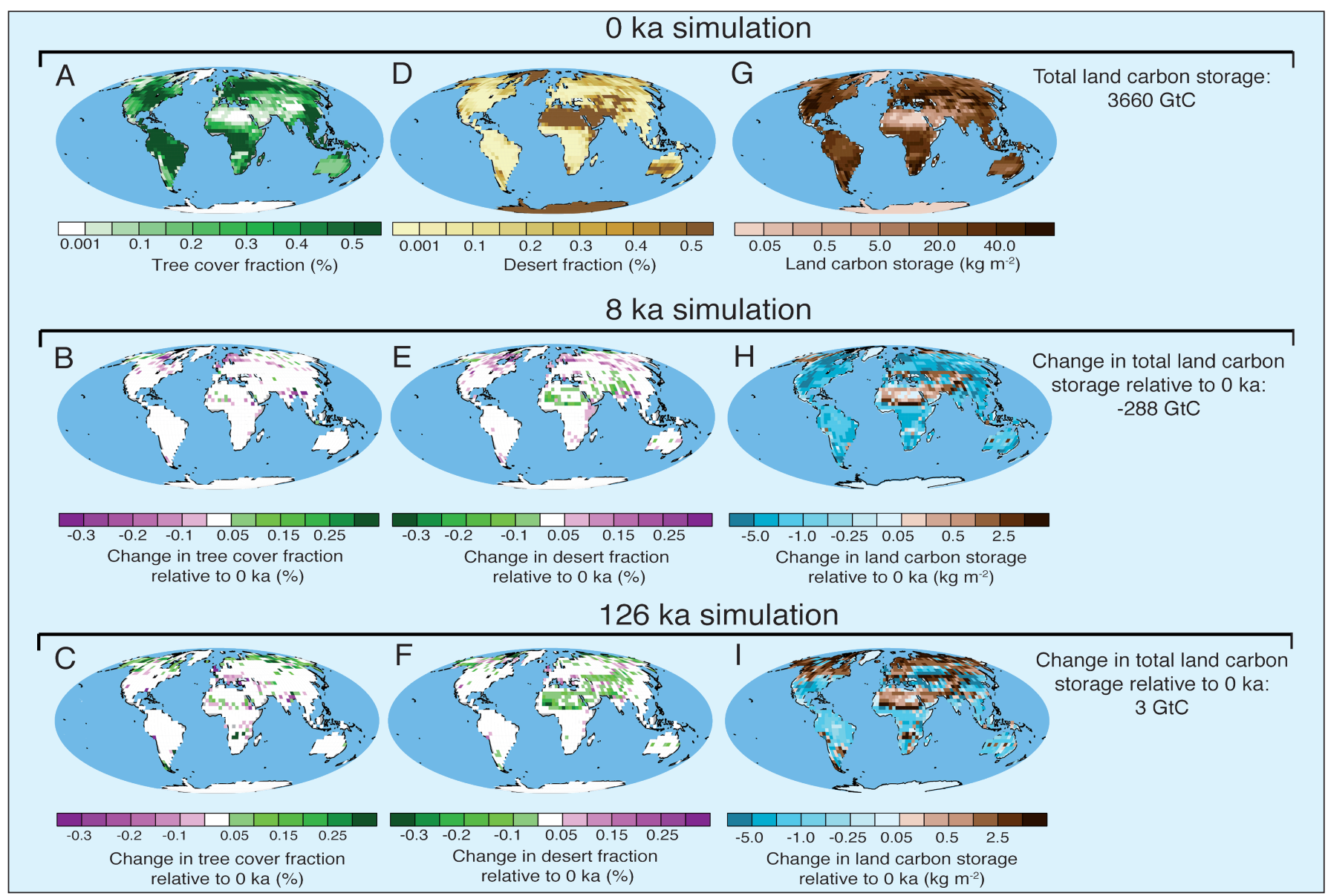

Figure 1: Modeled vegetation and land carbon storage ( $\left.\mathrm{kg} \mathrm{m}^{-2}\right)$ for preindustrial climate: $0 \mathrm{ka} B P(\boldsymbol{A}, \boldsymbol{D}, \boldsymbol{G})$, mid-Holocene: $8 \mathrm{ka} B P(\boldsymbol{B}, \boldsymbol{E}, \boldsymbol{H})$, and the LIG: $126 \mathrm{ka} B P(\mathbf{C}, \boldsymbol{F}, \boldsymbol{I})$ Shown are absolute values for preindustrial climate and interglacial anomalies for tree cover fraction (left), desert fraction (middle), and the total land carbon storage (GtC; right). 


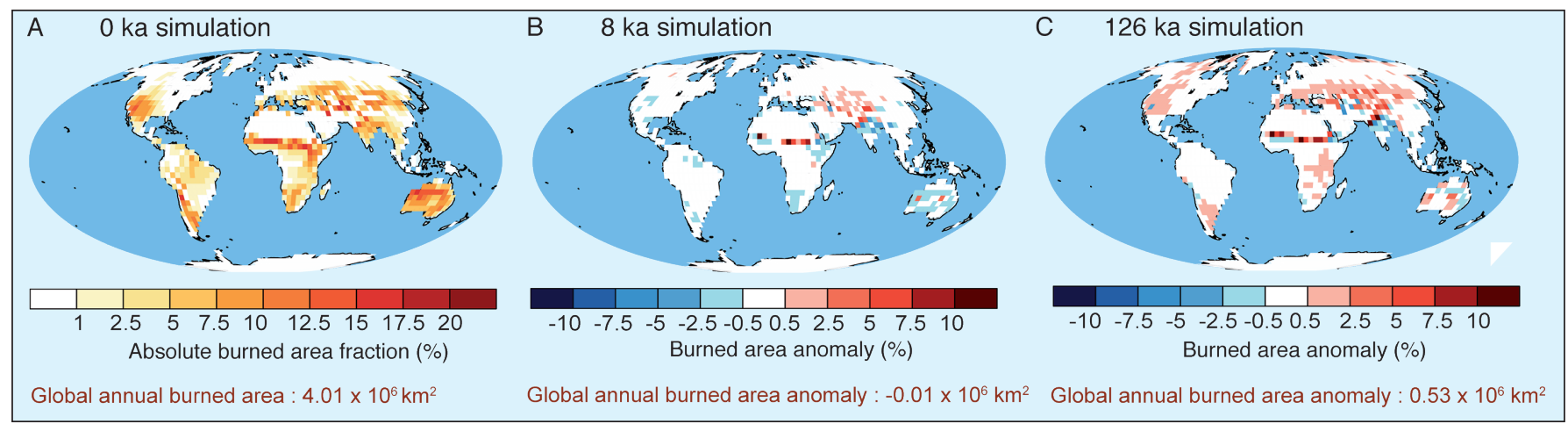

Figure 2: Simulated burned area fraction for $(\boldsymbol{A})$ preindustrial climate. Simulated burned area anomalies for (B) mid-Holocene and $(\boldsymbol{C})$ the LIG. Global annual values are shown below each plot.

ensures that the highly resolved land carbon processes are retained whilst maintaining an adequate computational speed of the climate and ocean carbon cycle model.

We performed three model simulations forced to equilibrium for preindustrial (0 ka $\mathrm{BP})$, mid-Holocene (8 ka BP) and LIG (126 ka BP) time slices. The Earth's orbital parameters and atmospheric $\mathrm{CO}_{2}$ concentrations were prescribed accordingly. Atmospheric $\mathrm{CO}_{2}$ levels were derived from ice core reconstructions with values of $280 \mathrm{ppm}, 260 \mathrm{ppm}$, and $275 \mathrm{ppm}$ for the preindustrial, midHolocene and LIG simulations, respectively. Additionally, we ran another mid-Holocene simulation with an atmospheric $\mathrm{CO}_{2}$ level of 280 ppm.

\section{Changes in vegetation and land carbon storage}

In response to the mid-Holocene and LIG forcings, the boreal forest expands in the northern high latitudes (Fig. 1A-C) while West Africa and parts of Asia become less arid, greener, and cooler due to intensified monsoon systems (Fig. 1D-F). The two regions are associated with precipitation rates up to four times higher under the LIG and mid-Holocene forcings compared with the precipitation rate simulated under preindustrial conditions (variables not shown here). These vegetation and climate changes are in general agreement with pollen-based reconstructions and other model studies (e.g. Jolly et al. 1998).

The integrated land carbon storage change for both interglacial time slices resemble similar anomaly patterns, but differ in their magnitude. The dominant zones where a gain in land carbon storage can be identified are within the African and Asian monsoon regions and the boreal forest (Fig. $1 \mathrm{H}-\mathrm{I})$. Due to a lower atmospheric $\mathrm{CO}_{2}$ level at $8 \mathrm{ka} \mathrm{BP}$ compared with preindustrial $\mathrm{CO}_{2^{\prime}}$ fertilization causes a reduction of total carbon storage. This effect is larger than the effect from climate changes. However, the net result from greenhouse gas and orbital forcing changes in the additional simulation for the mid-Holocene at $280 \mathrm{ppm}$ shows that the biomass carbon is approximately 5 Gt higher than the carbon stored during the LIG.

\section{The role of fire activity in warmer climates}

A simple windthrow (uprooting and breaking of trees due to wind) and fire scheme are implemented to simulate vegetation disturbances within JSBACH, which both affect the carbon cycle. For preindustrial climate conditions, the model simulates about $4 \times 10^{6} \mathrm{~km}^{2}$ burned area each year with hotspots in Africa, Australia, and Southwest America (Fig. 2A). Mid-Holocene and LIG burned area anomalies show higher fire activity over the Sahel and the Tibetan plateau (Fig. 2B-C). Globally, however, the total midHolocene burned area is similar to that of the preindustrial, whereas the total burned area fraction is $0.5 \times 10^{6} \mathrm{~km}^{2} \mathrm{yr}^{-1}$ higher under LIG conditions. Nevertheless, an elevated (280 ppm) atmospheric $\mathrm{CO}_{2}$ mid-Holocene simulation (not shown) results in a burned area similar to the LIG. This increase in total burned area fraction compared with the standard mid-Holocene simulation can be attributed to increased fuel availability (i.e. tree growth) leading to higher fire activity.

The carbon emissions associated with fire activity are $2.5 \mathrm{Gt}_{\mathrm{yr}}{ }^{-1}$ for preindustrial conditions. In comparison, the carbon emissions associated with fire activity in the LIG simulation are $10 \%$ higher and there is a $25 \%$ increase in burned area extent, as the carbon stored in biomass is reduced (not shown). As for the mid-Holocene simulation, there is a decrease of $7 \%$ compared with the preindustrial conditions despite similar burned areas. Since charcoal-based reconstructions (Power et al. 2008) show an opposite trend during the Holocene with increasing fire intensity since the Last Glacial Maximum, it should be noted that the model setup does not account for land use changes and the simulations do not include the large increase in fire activity observed during the last century when calculating the burned area extent. Furthermore, the reconstructions are based on data from individual locations and do not necessarily correspond to the $2 \mathrm{D}$ fields from the model.

\section{Summary}

We performed time slice experiments under preindustrial, mid-Holocene, and LIG conditions to analyze the changes in vegetation distribution, carbon storage on land, and disturbance processes under perturbed climate forcings. The impacts from secondorder processes, such as natural fire activity on carbon emissions, are found to be of the same magnitude (2.5 Gt $\left.\mathrm{yr}^{-1}\right)$ as the simulated anomaly in the total land carbon storage between LIG and preindustrial climate (3 Gt $\mathrm{yr}^{-1}$ ). A recent study, also with JSBACH, showed that during the last 6000 years the boreal wetland $\mathrm{CH}_{4}$ emissions increased by 2 Tg yr $^{-1}$ (Schuldt et al. 2012). This highlights the importance of including these additional processes in models. Using a model setup such as CLIMBER-JSBACH makes it possible to resolve heterogeneous and subscale processes within the biosphere and still be able to perform climate simulations on long time scales.

As part of the Past4Future framework, research groups have also performed transient past interglacial simulations to understand the underlying dynamics behind carbon storage with results compared to available paleodata. Furthermore, we are investigating the impact of different land use scenarios during the Holocene, with the aim of providing an uncertainty range in terms of human impact on Holocene climate and $\mathrm{CO}_{2}$ dynamics.

\section{Selected references}

Full reference list online under:

http://www.pages-igbp.org/products/newsletters/ref2013_1.pdf

Brovkin V et al. (2012) Climate of the Past 8: 251-264

Elsig J et al. (2009) Nature 461: 507-510

Lourantou A et al. (2010) Quaternary Science Reviews 29: 1983-1992

Power MJ et al. (2008) Climate Dynamics 30: 887-907

Schuldt RJ et al. (2012) Biogeosciences Discussions 9: 12667-12710 


\title{
Reconstruction of the last interglacial period from the NEEM ice core
}

\author{
Dorthe Dahl-Jensen ${ }^{1}$, P. GoginenI ${ }^{2}$ and J.W.C. White ${ }^{3}$ \\ ${ }^{1}$ Centre for Ice and Climate, Niels Bohr Institute, University of Copenhagen, Denmark; ddj@gfy.ku.dk \\ ${ }^{2}$ Center for Remote Sensing of Ice Sheets, University of Kansas, USA; ${ }^{3}$ NSTAAR, University of Colorado, USA
}

\begin{abstract}
We report new results from the NEEM ice core, a 2540-m-deep ice core recently drilled in Greenland. In particular, we present reconstructions of past surface temperature and elevation changes during the last interglacial at this new site.
\end{abstract}

T emperatures in the Arctic were high during the last interglacial period (LIG, 130-115 ka BP; Dahl-Jensen 2006; NorthGRIP Project members 2004; Turney et al. 2010) and mean global sea level was 6 to $7.5 \mathrm{~m}$ above the present level (Dutton and Lambeck 2012; Kopp et al. 2009). This strong warming must have caused the Greenland ice sheet and the Arctic ice caps and glaciers to retreat, and thus contributed to the global sea-level rise. Models of the Greenland ice sheet arrive at very different predictions of the volume and shape of the ice sheet during the LIG. The predicted mass loss varies between 0.5 and $5 \mathrm{~m}$ (e.g. Alley et al. 2005; Cuffey et al. 2000; Robinson et al. 2011). Here, we present results from the NEEM ice core that provide new constraints on surface temperature and elevation changes during the LIG in Greenland.

\section{The NEEM ice core}

A 2540-m-long ice core was drilled from 2008-2012 at the North Greenland Eemian Ice Drilling site $\left(77.45^{\circ} \mathrm{N}, 51.06^{\circ} \mathrm{W}\right.$; Steffensen this issue). In 2010, the first measurements of water stable isotopes warned us that below $2200 \mathrm{~m}$ the ice was disturbed and probably folded. It by online laser-spectroscopy in the field

was, however, also clear that the ice below $2200 \mathrm{~m}$ and older than $106 \mathrm{ka}$ BP was from the LIG as the water oxygen stable isotope $\left(\delta^{18} \mathrm{O}_{\text {ice }}\right)$ values were high (about $-31.4 \%$ ). These measurements also indicated that below $2432 \mathrm{~m}$, the ice was probably older than $130 \mathrm{ka} \mathrm{BP}$ and originated from a cold climate period.

Figure 1 shows an image of Radio Echo Sounding along the ice ridge where NEEM is located. The surface and bedrock can be traced and internal layering can be dated at the NEEM site down to the disturbances at $2200 \mathrm{~m}$. Below $2200 \mathrm{~m}$ the images show fuzzy and unclear reflections and the structures seem folded and disturbed. Disturbances of ice older than 100 ka BP are seen in nearly all the Radio Echo Sounding images from central and north Greenland and one should also note that both the GRIP and GISP2 ice core records are disturbed and folded below $100 \mathrm{ka}$ BP (Suwa et al. 2006). The disturbances of the LIG ice in the GRIP, GISP2, and NEEM ice cores are believed to originate from to the rigid ice flow conditions caused by its low impurity concentration compared with the impurity concentration of the surrounding ice from glacial climate periods. The methane $\left(\mathrm{CH}_{4}\right)$ concentration and the isotopic composition of oxygen $\left(\mathrm{O}_{2}\right)$

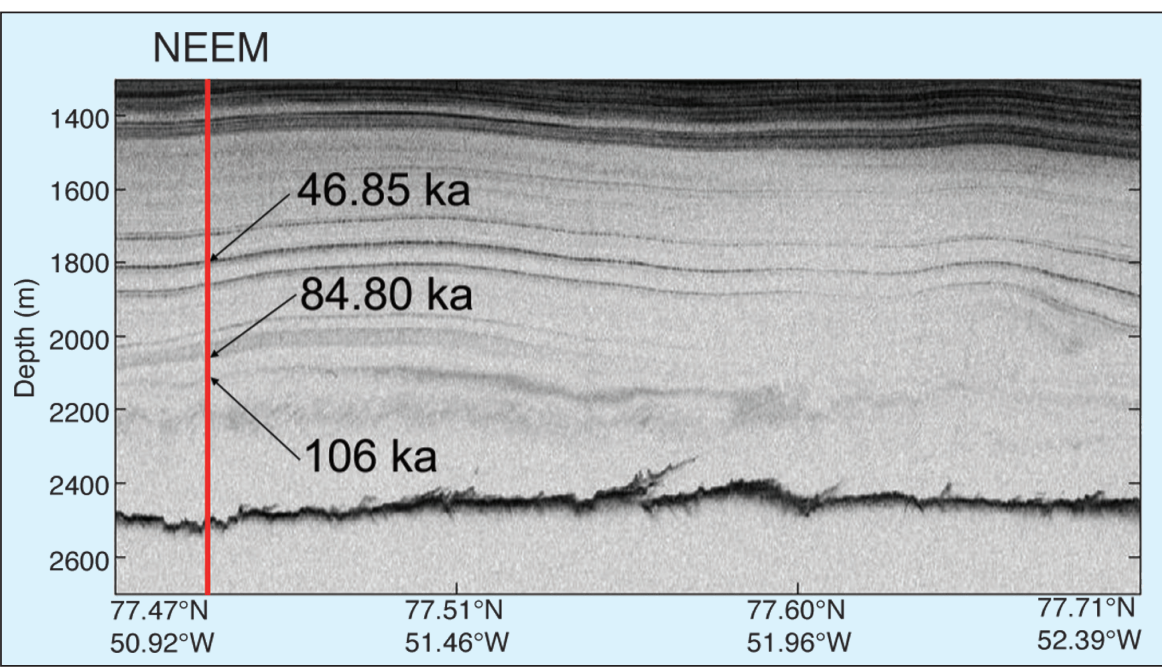

Figure 1: Center for Remote Sensing of ice Sheets (CReSIS) ice penetrating Radio Echo Sounding image from the NASA Operation IceBridge campaign 2011 showing a 48-km-long line crossing the deep drill site. The NEEM site is shown on the image and three dated horizons are marked. measured in the air bubbles enclosed in the NEEM ice are global atmospheric tracers. Thus a chronological climatic sequence back to $128.5 \mathrm{ka} \mathrm{BP}$ can be obtained by comparing $\mathrm{CH}_{4}$ and $\delta^{18} \mathrm{O}$ of $\mathrm{O}_{2}$ measurements from the bottom section of the NEEM core with the records from other ice cores from Greenland (NGRIP) and Antarctica (EPICA Dronning Maude Land EDML) (NEEM community members 2013). Figure $2 A$ presents the reconstructed $\delta^{18} \mathrm{O}_{\text {ice }}$ profile on the EDML time scale from 100 to $128.5 \mathrm{ka}$ BP. Figure 2B shows the measured $\delta^{18} \mathrm{O}_{\text {ice }}$ record on the depth scale and indicates that the zone from 114 to $119 \mathrm{ka} \mathrm{BP}$ (green to yellow) is folded such that the records are mirrored and partly repeated three times, twice inverted. The zone from 2365 to $2432 \mathrm{~m}$ is undisturbed and contains the major part of the ice from the LIG (128.5-116.6 ka BP). We observe a hiatus in the NEEM record as no ice from 108 to $114 \mathrm{ka} \mathrm{BP}$ is found (values from the NGRIP record in white have been included in Figure $2 \mathrm{~A}$ ).

\section{LIG elevation changes at the NEEM site}

The air content in the enclosed air bubbles informs on past surface elevations, as lower air content is found when surface elevations increase. The new NEEM air content record is very noisy between $2370 \mathrm{~m}$ and $2418 \mathrm{~m}$ (gray shaded zone) and then drops to low values (Fig. 2D). It corresponds to the very warm part of the LIG where the $\delta^{18} \mathrm{O}_{\text {ice }}$ values exceed -33 $\%$ (Fig. 2C). Surface melt has certainly removed the air bubbles from the melting ice, resulting in regions with lower air content.

When corrected for the changing summer insolation and for elevation changes related to differences in the present position of the NEEM site and the depositional site of the LIG ice, surface elevation changes at NEEM can be calculated based on the air content record (Fig. 2E, blue curve) (NEEM community members 2013). Between 128 and 122 ka BP, the 


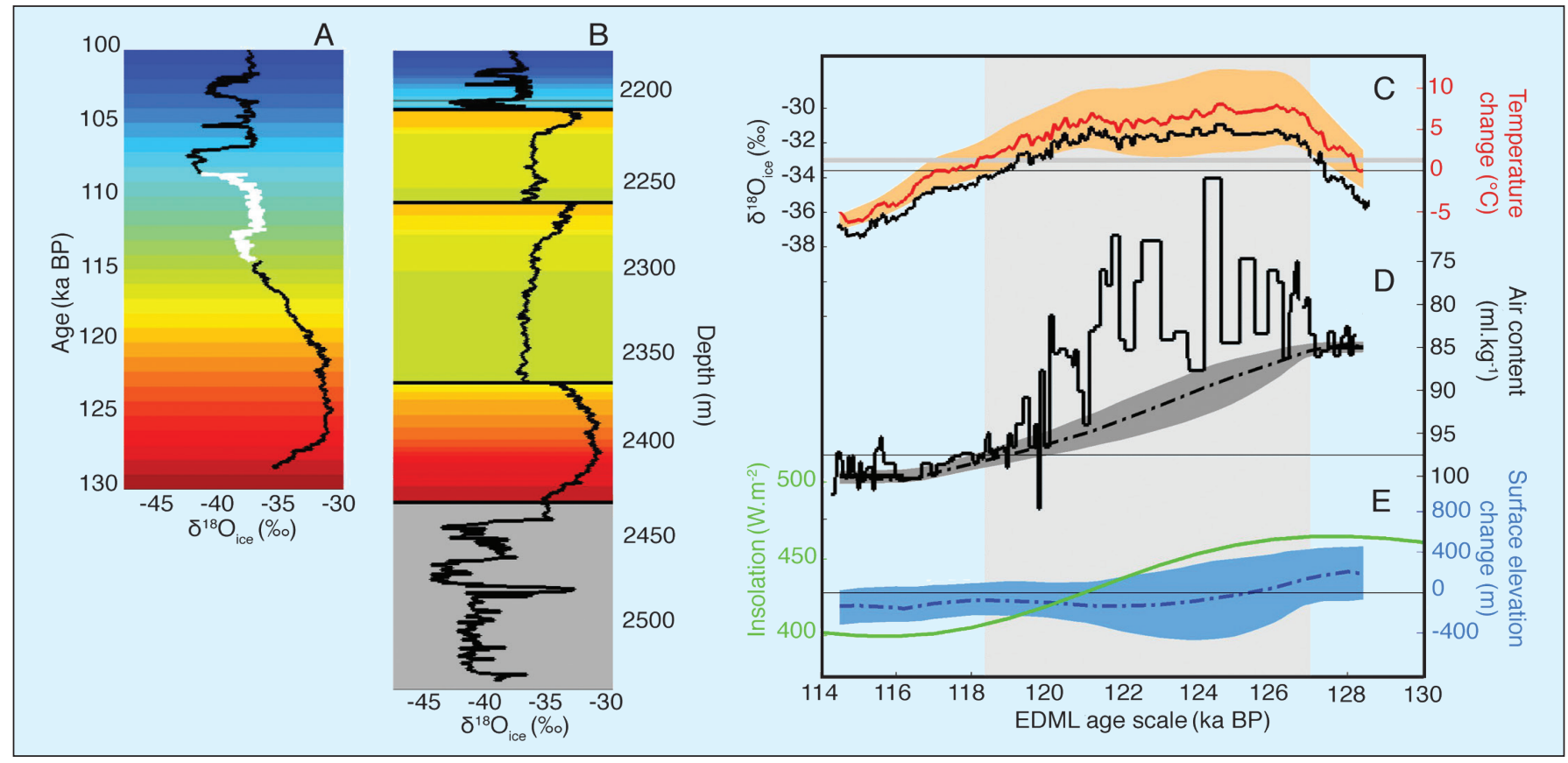

Figure 2: $\boldsymbol{A}$ ) The reconstructed NEEM stable water isotope record $\left(\delta^{18} \mathrm{O}_{\text {ice, }}\right.$ black curve) including NGRIP data between 114-108 ka BP (white) on the EDML1 timescale. The time axis has been color-coded according to age. B) The color-coded dating is plotted with the original data on the NEEM depth scale in order to visualize the discontinuities and the reversed sections. $\mathbf{C}-\mathbf{E})$ Reconstruction of the temperature and elevation history based on the $\delta^{18} \mathrm{O}$ and the air content records during the $L / G$. C) Temperature change reconstruction (red curve) with associated errors (light red shading) and $\delta^{18} \mathrm{O}_{i c e}$ (black curve). The average present $\delta^{18} \mathrm{O}_{\text {ice }}$ value of - $33.6 \%$ is marked with a thin black line and the $\delta^{18} \mathrm{O}_{i c e}$ value of $-33.0 \%$ is marked with a grey line as the limit where surface melt starts. D) Air content on a reversed scale. The soft dashed line was used to reconstruct elevation changes. E) When corrected for upstream flow and local summer insolation changes (green) the air content curve can be "translated" into elevation changes (blue, soft dashed) with the shaded zone indicating the uncertainty range. The zone with surface melt (127-118.3 ka BP) is shaded in light gray.

surface elevation decreases from $210 \mathrm{~m}$ above to $130 \mathrm{~m}$ below the present surface elevation, which translates into a moderate ice thickness change of $400 \mathrm{~m}$ after accounting for isostatic rebound. Based on this estimate, the ice thickness at NEEM decreased by an average of $7 \mathrm{~cm}$ per year between 128 and $122 \mathrm{ka} \mathrm{BP}$ and stayed at this level until $114 \mathrm{ka}$ BP, long after surface melt stopped and when temperatures fell below modern levels.

The reconstructed elevation changes of only about $10 \%$ of the ice thickness at the center of the ice sheet points towards modest volume changes of the Greenland ice sheet during the LIG. While the documentation of ice thickness at one location of the Greenland ice sheet cannot constrain overall ice sheet changes during the LIG, our new results from the NEEM ice core only reconcile with Greenland ice sheet simulations (e.g. Robinson et al. 2011; Stone et al. 2012) that indicate a modest contribution of ca. $2 \mathrm{~m}$ to the observed $\sim 6$ to $8 \mathrm{~m} \mathrm{LIG}$ sea level high stand (Dutton and Lambeck 2012; Kopp et al. 2009). Consequently, these findings strongly imply that Antarctica must have contributed substantially to the LIG sea level rise.

\section{NEEM surface temperature changes over the LIG}

Knowing the surface elevation changes during the LIG allows us to correct the measured $\delta^{18} \mathrm{O}_{\text {ice }}$ values to a fixed elevation and, therefore, "translate" them into past temperature changes. The record is also corrected for the upstream and higher location of the depositional site of the ice from the LIG to produce a record at a fixed site and elevation. The record shows that Greenland temperatures peaked at the onset of the LIG ( 126 ka $\mathrm{BP})$, with surface temperatures $8^{\circ} \mathrm{C}$ warmer than at present at fixed elevation, and then gradually decreased thereafter during the LIG (Fig. 2C).

The reconstructed precipitationweighted annual temperature changes are remarkably high. In general, warmer summer surface temperatures than those of the present are reported from paleorecords (Turney et al. 2010), with some records from high Arctic latitudes indicating surface temperatures at $126 \mathrm{ka} \mathrm{BP}$ as high as those reported from NEEM (Axford, et al. 2011). During the LIG the northern high latitude summer insolation reached a relative maximum at $128 \mathrm{ka} \mathrm{BP}$ (Fig. 2E) with values of $465 \mathrm{~W} \mathrm{~m}^{-2}$ exceeding the maximum values of the present interglacial ( $458 \mathrm{~W} \mathrm{~m}^{-2}$ at $11 \mathrm{ka} \mathrm{BP}$ ). The LIG summer insolation, however, dropped rapidly, reaching values below present, e.g. 428

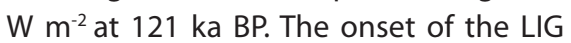
resulted in a short and intense warming associated with an ice thinning of about $400 \mathrm{~m}$ at NEEM. At $121 \mathrm{ka}$ BP the intense and warm period was over and the temperature slowly declined while the ice thickness remained unchanged. These new results indicate that the anatomy of the LIG was different than that of the present interglacial, which is longer but not as intense.

\section{Perspectives}

Constraints on elevation and temperature changes in Greenland during interglacial periods can be found along the north-south ice ridge of the ice sheet where most of the deep ice cores have been drilled. The ability to constrain the Greenland ice sheet surface elevation and temperature history both through the Holocene (Vinther et al. 2009) and the LIG (NEEM community members 2013) provide useful "a priori" knowledge to be used by climate and ice sheet models.

In the framework of the Past4Future project, the ice sheet modeling group will use these recent constraints to improve the estimates of the contribution to sealevel rise from the Greenland ice sheet.

\section{Selected references}

Full reference list online under:

http://www.pages-igbp.org/products/newsletters/ref2013_1.pdf

Kopp RE et al. (2009) Nature 462: 863-868

NEEM community members (2013) Nature 493: 489-494

Turney CSM, Jones RT (2010) Journal of Quaternary Science 25: 839-843 Stone EJ, Lunt DJ, Annan JD Hargreaves JC (2012) Climate of the Past Discussions 8: 2731-2776

Vinther BM et al. (2009) Nature 461: 385-388 


\section{Speleothem records over the last interglacial}

Dominique Genty ${ }^{1}$, S. Verheyden² and K. Wainer ${ }^{3}$

'Laboratoire des Sciences du Climat et de l'Environnement, CEA Saclay, Gif-sur-Yvette, France; dominique.genty@lsce.ipsl.fr ${ }^{2}$ Geological Survey, Royal Belgian Institute of Natural Sciences, Belgium; ${ }^{3}$ Department of Earth Sciences, University of Oxford, UK

We present a review of 13 speleothems from Europe, Asia and South America, covering the penultimate deglaciation and the last interglacial. We highlight the similarities and regional differences in the growth rate and the calcite $\delta^{18} \mathrm{O}$ records in these cave deposits.

$T^{\mathrm{h}} \mathrm{d}$ he discovery of speleothems (cave calcite deposits) as paleoenvironmental archives has significantly enriched the toolbox for reconstructing past changes over the continents. Indeed, research over the last decade has demonstrated the potential of speleothems for providing unique paleoenvironmental and paleoclimatic information based on: (1) precise chronologies relying on Uranium-series dating and (2) high-resolution continental climate records based on carbon and oxygen isotope $\left(\delta^{13} \mathrm{C}\right.$ and $\delta^{18} \mathrm{O}$ respectively) measurements of the calcite.

Among other results, speleothems have revealed that the Asian and South American monsoons show an anti-phase pattern (Cruz et al. 2005; Cruz et al. 2006a) paced by Earth's precession changes (Wang et al. 2001; Wang et al. 2008). In the Northern Hemisphere temperate zone, the millennial scale climatic Dansgaard-Oeschger events occurring frequently over Marine Isotopic Stage 3 (28-60 ka BP) have been detected in stalagmites from Turkey (Fleitmann et al. 2009), from the Austrian Alps (Spötl and Mangini 2002), and from southwestern France (Genty et al. 2003). This non-exhaustive list of results gives a flavor of how speleothem records complement other terrestrial evidence, e.g. from lake sediments (Allen et al. 1999; Brauer et al. 2000) or pollen (Sanchez Goñi et al. 2002; Sanchez Goñi et al. 2008).

In particular, speleothems enable significant advances in providing precise age determination over the penultimate deglaciation (Termination II) and the last interglacial (LIG) period. Could speleothems provide a continuous, well-dated, and wellunderstood reference record for Termination $\|$ ? We review the speleothem $\delta^{18} \mathrm{O}$ records covering Termination II and the LIG that satisfy the following criteria: (1) They should be characterized by a high density of UraniumThorium (U-Th) ages of high precision (i.e. $2 \sigma$ age error $<1-5 \%$ ), (2) the speleothems should have a high enough growth rate so that samples for U-series dating cover a time interval shorter than the uncertainty of the age, and (3) growth rates should be continuous over long periods avoiding long hiatuses. Following these criteria, we selected seven records from Asia (Fig. 1): four from the Sanbao Cave (China; Wang et al. 2008), two from the Dongge Cave (China; Kelly et al. 2006; Yuan et

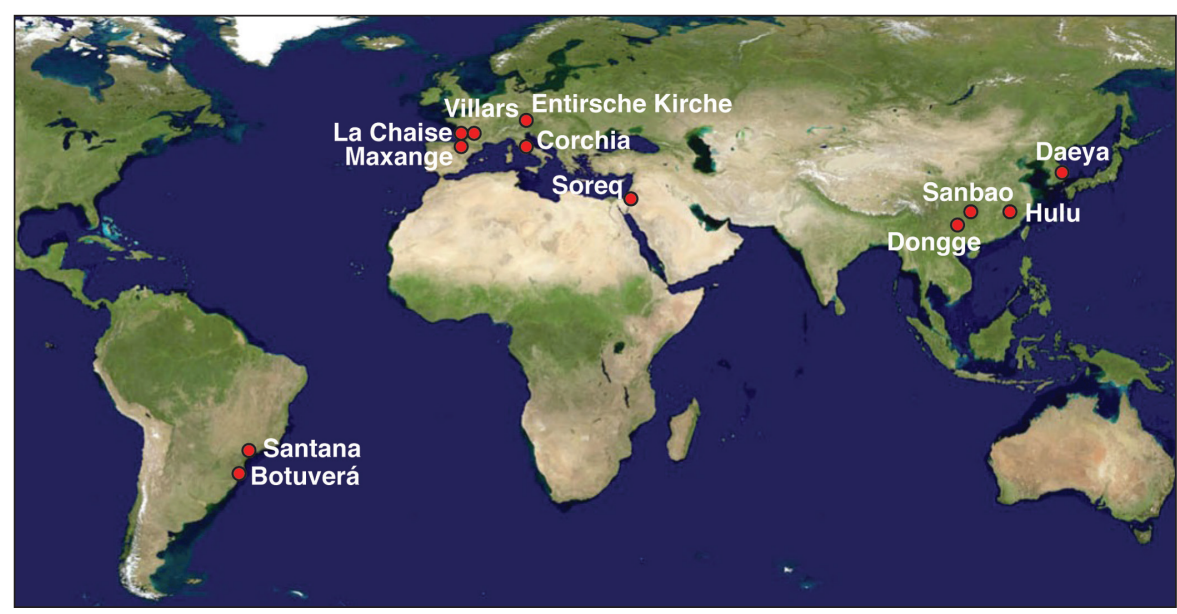

Figure 1: Geographical locations of the selected speleothems.

al. 2004) and one from the Daeya Cave (Korea; Jo et al. 2011). From South America, we selected two records from Brazil. They were retrieved in the Botuvera Cave (Cruz et al. 2005; Cruz et al. 2006b) and in the Santana Cave (Cruz et al. 2006a). We further considered six records from European/Mediterranean caves (Fig. 1) located in Corchia (Italy; Drysdale et al. 2005; Drysdale et al. 2009), La Chaise (France; Couchoud et al. 2009), Entrische Kirche (Austria; Meyer et al. 2008; Meyer et al. 2012), Villars (France; Wainer et al. 2011), Maxange (France; Genty and Wainer unpublished) and Soreq (Israel; Bar-Matthews and Ayalon 2002). While various parameters have been measured on speleothems such as calcite $\delta^{13} \mathrm{C}$ and trace elements, we focus here only on the $\delta^{18} \mathrm{O}$ signal of the calcite and its growth-rate.

\section{Calcite $\delta^{18} \mathrm{O}$}

Several environmental factors influence the sensitivity of the calcite $\delta^{18} \mathrm{O}$ to rainfall $\delta^{18} \mathrm{O}$ and/or temperature (McDermott 2004). Firstly, changes in the location of the water vapor source, in the source's isotopic composition, and also changes in rainfall amount influence the calcite $\delta^{18} \mathrm{O}$. This results in lower $\delta^{18} \mathrm{O}$ when the climate is more humid and warmer, e.g. as shown by monsoon speleothem records and the Corchia record in Italy (Cruz et al. 2006a; Drysdale et al. 2005; Jo et al. 2011; Wang et al. 2008; Fig. 2). Secondly, the temperature in the cave (close to the mean annual external temperature) may also have a significant influence on the calcite precipitation fractionation, and consequently on the calcite $\delta^{18} \mathrm{O}$ (i.e. $\delta^{18} \mathrm{O}$ decreases when temperature increases), as suggested in the Villars stalagmite (e.g. Genty and Wainer unpublished; Wainer et al. 2011). Thirdly, changes in the seasonality of precipitation (e.g. the proportion of winter versus summer precipitation) can influence the calcite $\delta^{18} \mathrm{O}$ in specific cases such as in the Entrische Kirche Cave record (Meyer et al. 2008, 2012) where the seasonality effect drives the increase of calcite $\delta^{18} \mathrm{O}$ over Termination II while the climate continues to warm (Fig. 2A).

\section{Speleothem growth rate}

The speleothem growth rate is also a key parameter for climatic reconstruction. The calcium content of the dripping water and the drip rate mainly control the growth rate. Those two factors are influenced by climatic conditions (e.g. external temperature, precipitation) and soil and vegetation activity (Baker et al. 1998; Dreybrodt 1988). As a consequence, the records from densely U-Th dated speleothems generally reveal a close link between growth rate and calcite $\delta^{18} \mathrm{O}$ (Fig. 2). Within a single stalagmite, the growth rate can vary from a few $\mu \mathrm{m} \mathrm{yr}^{-1}$ during cold and dry periods to more than $1 \mathrm{~mm} \mathrm{r}^{1}$ during warmer and more humid climate phases. The chronology can, therefore, only be constrained if a high number of precise dates can be generated on an as small as possible time interval.

We observe that all the low-latitude stalagmites from Asia and South America grew continuously over Termination II (Fig. 2B), while in Europe only the Corchia stalagmite seems to present such a progressive growth (i.e. with no hiatus) (Fig. 2A). Unfortunately, the low growth-rate in the Corchia speleothem, less than $30 \mathrm{~mm}$ of calcite deposition from its base at $\sim 170$ until $\sim 129$ ka BP, limits the acquisition of multiple precise ages over Termination II. Chronological limitations also 
exist for Entrische Kirche, Maxange, and La Chaise stalagmites, which started to grow during or just after Termination II and a hiatus is visible in the Villars record before $130 \mathrm{ka} \mathrm{BP}$ (Fig. 2A).

\section{Termination II and LIG records}

Figure 2 shows the calcite $\delta^{18} \mathrm{O}$ and growthrate records from the selected speleothems. We observe that (1) most of the European speleothems started growing between 132 and $122 \mathrm{ka}$ BP and all display an abrupt increase in growth rate during a short period: between $\sim 129.7$ and $~ 125.8$ ka BP (Fig. 2A). On the contrary, the onset of Asian and South-American speleothem deposition and/or growth rate increase is more scattered and ranges from $\sim 138$ to 123.4 ka BP (Fig. 2B). (2) Interestingly, while $\delta^{18} \mathrm{O}$ records show roughly similar changes concentrated around $130 \mathrm{ka}$ in Europe and in Asia, the growth rate changes are much more important in European samples than in low latitude ones (Asia, South America). This suggests that the climatic contrasts between cold and warm phases of the deglaciation are different between mid-latitude and low-latitude regions. (3) The Corchia record, through its comparison with the MD95-0242 marine sediment core (Drysdale et al. 2009), suggests the start of termination II at $141 \mathrm{ka} \pm 2.5 \mathrm{ka}$. This is

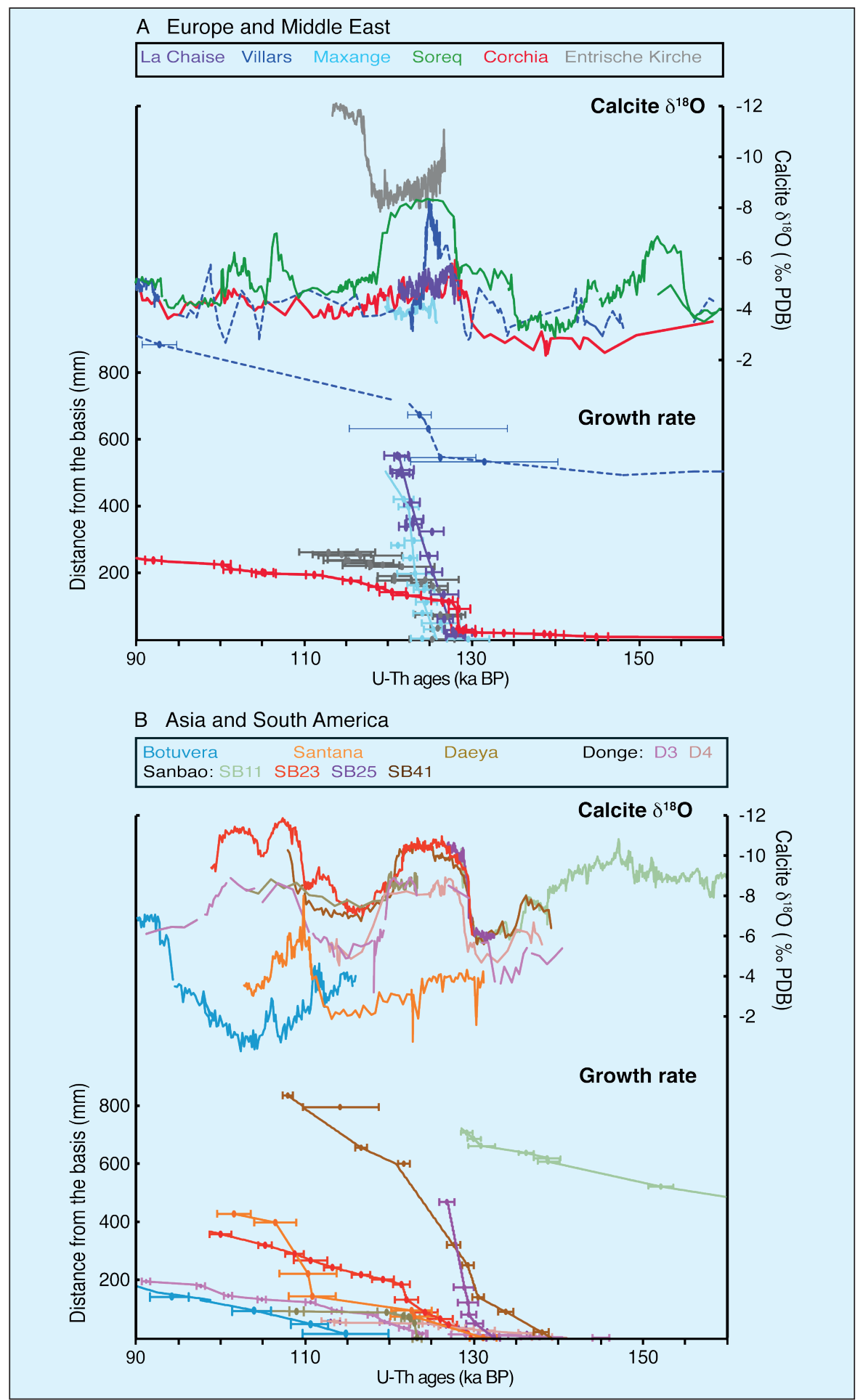

Figure 2: A) Calcite $\delta^{18} \mathrm{O}$ and growth rate records for European speleothems and calcite $\delta^{18} \mathrm{O}$ record for a Middle East speleothem. B) Calcite $\delta^{18} \mathrm{O}$ and growth rate records for Asian and South-American speleothems.

only slightly marked by the calcite $\delta^{18} \mathrm{O}$ and the growth rate curves. No comparable transition signal at this age is found in Asian speleothems, which on the contrary, display a $\delta^{18} \mathrm{O}$ increase interpreted as a weakening of the Asian monsoon. However, a major transition is clearly visible in the Corchia record in both the calcite $\delta^{18} \mathrm{O}$ and growth rate, between $\sim 131.5$ ka and $\sim 128.5 \mathrm{ka}$. Additional well-dated speleothems are urgently needed to shed light on the timing of the onset of Termination II in Europe compared with Asia. (4) A good agreement between the Corchia and La Chaise records is observed for the timing of the LIG climatic optimum and the calcite $\delta^{18} \mathrm{O}(\sim 128$ ka $B P \pm 1)$. However, the calcite $\delta^{18} \mathrm{O}$ from Villars Cave, which is geographically closer to La Chaise Cave than the Corchia Cave, reveals a different shape over the LIG and lower calcite $\delta^{18} \mathrm{O}$ values. Interestingly, the Villars calcite $\delta^{18} \mathrm{O}$ amplitude change over Termination ॥ has a similar magnitude to the record from the Soreq cave located in the Middle East.

This comparison clearly reflects (1) different regional responses to climate forcing and (2) region- and site- specific controlling factors of the calcite $\delta^{18} \mathrm{O}$ values.

\section{Concluding remarks}

Speleothem time-series have become an invaluable terrestrial archive to reconstruct climate changes. The $\delta^{18} \mathrm{O}$ records and the growth rate curves discussed here show an abrupt and general warming onset between $\sim 129.7$ and 125.8 ka BP in Europe. Under a monsoon climate regime, we observe also an abrupt variation in the $\delta^{18} \mathrm{O}$ records. However the growth rate curves are much more scattered (i.e. between $\sim 138$ and 123.4 ka BP) suggesting a less marked climatic transition. New data gathered in the framework of the Past4Future project (see Verheyden et al. this issue) should enable us to clarify the observed regional differences over the LIG. In addition, the increasing speleothem demand will certainly need a coordinated and internationally referenced sample management system in order to minimize the impact on cave preservation.

\section{Acknowledgements}

We warmly thank the authors who made their data available to construct the figures.

\section{Selected references}

Full reference listonline under:

http://www.pages-igbp.org/products/newsletters/ref2013_1.pdf

Cruz FW etal. (2006a) Earth and Planetary Science Letters 248: 495-507 Drysdale RN etal. (2009) Science 325: 1527-1531 Wainer Ketal. (2011) Quaternary Science Reviews 30: 130-146 Wang YJ etal. (2001) Science 294: 2345-2348 Yuan D etal. (2004) Science 304:575-578 


\title{
Dating and synchronizing paleoclimatic records over the last interglacial
}

\author{
Emilie Capron ${ }^{1}$, A. Landais ${ }^{2}$, P.C. Tzedakis ${ }^{3}$, E. Bard ${ }^{4}$, T. Blunier ${ }^{5}$, D. Dahl-Jensen 5 , T. Dokken ${ }^{6}$, R. Gersonde ${ }^{7}$, F. Parrenin ${ }^{8}$, M. Schulz ${ }^{9}$, B. Vinther ${ }^{2}$ \\ AND C. WAELBROECK ${ }^{2}$ \\ 'British Antarctic Survey, Cambridge, UK; ecap@bas.ac.uk \\ 'Laboratoire des Sciences du Climat et de l'Environnement, CEA Saclay, Gif-sur-Yvette, France; ${ }^{3}$ UCL Department of Geography, University \\ College London, London, UK; ${ }^{4}$ Centre de Recherche et d'Enseignement de Géosciences de l'Environnement, Aix en Provence, France; ${ }^{5}$ Depart- \\ ment of Geophysics, University of Copenhagen, Denmark; ${ }^{6}$ Bjerknes Center Centre for Climate Research, Bergen, Norway; ${ }^{7}$ Alfred Wegener \\ Institute, Bremerhaven, Germany; ${ }^{8}$ Laboratoire de Glaciologie et Géophysique de I'Environnement, Grenoble, France; ${ }^{9}$ MARUM, Center for \\ Marine Environmental Sciences, and Faculty of Geosciences, University of Bremen, Germany
}

\section{We review some of the available strategies for a coherent dating of ice, marine, and terrestrial records from various latitudes over the last interglacial.}

W ithin the Past4Future project, specific efforts are dedicated to the improvement of absolute age scales and to the synchronization of climate records from different archives and different latitudes. A specific committee has been set up to develop guidelines for dating and synchronization to help with synthesizing and integrating results from the Work Packages that produce and compare the datasets.

While the Holocene is relatively well dated, the last interglacial (LIG) lasting approximately from 129 to $118 \mathrm{ka} \mathrm{BP}$, has been attributed different durations depending on the considered records (e.g. Kukla et al. 1997; Shackleton et al. 2002). These differences result from regional disparities and dating inconsistencies (Dutton and Lambeck 2012). Building a reference timeframe for the LIG is thus essential to disentangle climatic external forcing and internal feedbacks as well as to depict the regional sequences of events.

Here, we review some of the existing absolute constraints and synchronization strategies over the LIG for providing a coherent stratigraphic framework to present paleoclimatic records. We also provide an example of developing a common timescale for marine and ice core records over the LIG using approaches discussed below. The list of age markers discussed hereafter is not exhaustive but the complete document established by the Past4Future dating committee is available at http://www.past4future.eu/ index.php/resources/project-resources (M5.1.2 Workshop: Integration of results, 2012)

\section{Absolute age markers}

Speleothems provide absolute ages of climate events thanks to dating methods based on Uranium-series. For example, the largest increase of the Asian Monsoon activity (as reflected in the Sanbao speleothem abrupt calcite $\delta^{18} \mathrm{O}$ decrease) over the penultimate deglaciation (Termination II) occurred at 129 ka BP with an associated error of less than 100 years (Cheng et al. 2009; Fig. 1E). For European speleothems, less abundant in Uranium, dating constraints are usually less precise (e.g. Genty et al. 2003).
The upper parts of ice cores in high-accumulation areas can be dated by identifying and counting annual layers (e.g. Svensson et al. 2008). However, ice cores lack deep and old absolute dating horizons except for tephra layers. To date, only the absolute dating of the tephra from

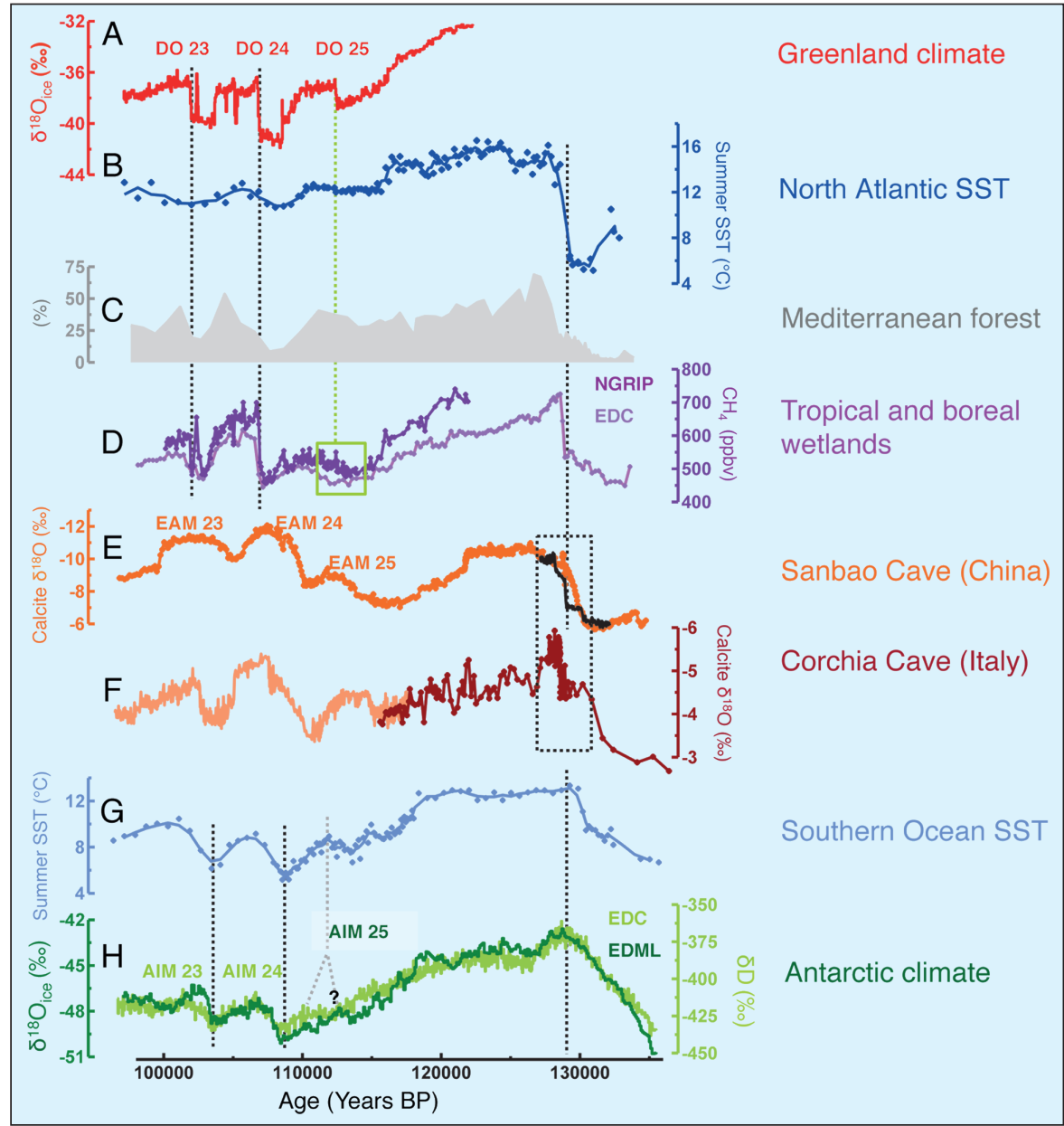

Figure 1: A) NorthGRIP $\delta^{18} \mathrm{O}$ (NorthGRIP Project members, 2004), B) Summer Sea Surface Temperature (SST) from ODP 980 marine core (Oppo et al. 2006), C) Temperate tree pollen percentages from MD95-2042 marine core (Shackleton et al. 2002), D) Atmospheric methane concentrations from NorthGRIP (Dark purple, Capron et al. 2010) and EDC (Light purple, Loulergue et al. 2008) ice cores, E) Speleothem $\delta^{18} \mathrm{O}$ from Sanbao Cave (orange Wang et al. 2008; black, Cheng et al. 2009), F) Speleothem $\delta^{18} \mathrm{O}$ from Corchia Cave (brown, Drysdale et al. 2007; light orange, Drysdale et al. 2009), G) Summer SST from MD02-2488 marine core (Govin et al. 2012), H) EDC SD (Jouzel et al. 2007) and EDML $\delta^{18} \mathrm{O}$. (EPICA community members, 2006). All records are synchronized onto the EDC3 timescale except the speleothem records. Dashed lines highlight the unambiguous tie points used to synchronize marine records onto ice core records (Govin et al. 2012). The green rectangle and dashed line highlight the ambiguous signature of GIS 25 onset in the North GRIP methane concentration record (Capron et al. 2012). The black dashed rectangle highlights that the abrupt $\delta^{18} \mathrm{O}$, shift over Termination II is not synchronous in the various speleothem records. The yellow areas indicate the divergence between ice core and speleothem records in the age of Dansgaard-Oeschger (DO) events 23,24, and 25. The grey dashed lines point to the AIM 25 event as identified in the EDC (Jouzel et al. 2007) and in the EDML (Stenni et al. 2010) water isotopic profiles and illustrates the difficulty to define unambiguous pointers over the glacial inception. 
Mount Moulton volcanic event provides an absolute age constraint at $92.1 \pm 4.4$ ka BP (Dunbar et al. 2008) included in the EPICA Dome C timescale (hereafter, EDC3 timescale; Parrenin et al. 2007). In order to place additional constraints, orbital tracers $\left(\delta \mathrm{O}_{2} / \mathrm{N}_{2}\right.$, air content, $\left.\delta^{18} \mathrm{O}_{\mathrm{atm}}\right)$ have been implemented for ice core timescales (e.g. Dreyfus et al. 2007; Kawamura et al. 2007; Parrenin et al. 2007; Raynaud et al. 2007). But because the mechanisms behind these orbital tracers are yet to be fully understood (e.g. Landais et al. 2012; Dreyfus et al. 2007), the associated uncertainties are large (e.g. $6 \mathrm{ka}$ for $\delta^{18} \mathrm{O}_{\mathrm{atm}}$ ).

A close inspection of the last glacial inception and the succession of Greenland Stadials (GS) and Interstadials (GIS) reveals significant differences in the timescales of the onset of GIS 23, 24 and 25 as recorded in NorthGRIP $\delta^{18} \mathrm{O}_{\text {ice }}$ (Fig. $1 \mathrm{~A})$ and their counterparts in speleothem records from Corchia Cave (Drysdale et al. 2007, Fig. 1F) and Sanbao Cave (Cheng et al. 2009; Wang et al. 2008; Fig. 1E).

\section{Record synchronization}

Ice core synchronization is done on (1) the ice phase through identification of the same volcanic events (e.g. Parrenin et al. 2012) or ${ }^{10} \mathrm{Be}$ variability from different ice cores (Raisbeck et al. 2007), and (2) the gas phase through global atmospheric tracers (methane concentration, $\delta^{18} \mathrm{O}_{\mathrm{atm}}$ e.g. Blunier et al. 1998, Fig. 1D).

For example, a chronology for the EPICA Dronning Maud Land (EDML) ice records, coherent with the EDC3 timescale (as illustrated with the EDML and EDC water isotopic profiles on Figure $1 \mathrm{H}$ ) has been developed by synchronizing volcanic horizons and dust peaks from the EDML ice with EDC ones (Ruth et al. 2007; Severi et al. 2007). Subsequently, the NorthGRIP record has been put on the EDC3 age scale synchronizing the abrupt changes in $\mathrm{CH}_{4}$ concentration (Fig. 1D) and $\delta^{18} \mathrm{O}_{\text {atm }}$ variations linked to the DO events between 70 and $123 \mathrm{ka}$ BP (Capron et al. 2010). However, this synchronization exercise has some limitations when clear methane concentration or $\delta^{18} \mathrm{O}_{\text {atm }}$ signatures are lacking (e.g. Capron et al. 2012; Fig. 1D, green square).

Direct correlation of the plateau of benthic foraminifera $\delta^{18} \mathrm{O}$ minimum values is commonly applied for synchronizing marine sediment records during the LIG (e.g. Cortijo et al. 1999). However, this method has limitations when considering records from different water depths and oceanic basins (Skinner and Shackleton 2005; Waelbroeck et al. 2011). An alternative synchronization approach would be based on the identification of tephra layers in marine sediment with a similar chemical composition (e.g. Rasmussen et al. 2003).

Changes in the Earth's magnetic field intensity are recorded in marine, terrestrial, and ice records (e.g. Raisbeck et al. 1987). While absolute dating of tephra layers and speleothems allow attribution of an absolute timescale to the Earth's magnetic field variations, the latter can then be used to link the various archives (e.g. Zhou and Shackleton 1999).

\section{Climatostratigraphic alignment}

While it is desirable to use global markers or joint analyses of different proxies within the same physical sequence (e.g. dust measured both in ice and marine cores), relative dating can sometimes only be derived indirectly from climatic records. Climatostratigraphic alignment is inevitably based on assumptions about the mechanisms linking climate and measurements. These underlying hypotheses have to be explicitly formulated.

Possible alignments between marine and ice core records are based on the hypothesis that Sea Surface Temperature (SST) changes in the sub-Antarctic zone of the Southern Ocean (respectively in the North Atlantic) occurred simultaneously with air temperature changes over inland Antarctica (respectively Greenland) (e.g. Govin et al. 2012; Shackleton et al. 2002). Figure $1(A-B, D, G-H)$ illustrates how this approach can produce a coherent relative timescale between marine and ice core records from both hemispheres (Govin et al. 2012). Age pointers were defined at the start of Termination II and over the millennial-scale events identified towards the end of the LIG (Fig. 1A-B, G-H). However, regional disparities in climatic event expression lead to a relative uncertainty of up to $1 \mathrm{ka}$ (Buiron et al. 2012). Also, it remains problematic to define precise tie points within the LIG (Govin et al. 2012) and one should limit the use of tie points to unambiguous climatic features.

At a regional scale, marine SST and speleothem records may be aligned on the principle that variations in regional SSTs, air temperatures, evaporation and moisture transport are synchronous, and ultimately affect speleothem $\delta^{18} \mathrm{O}$ signatures (e.g. Drysdale et al. 2009). These changes in moisture availability and air temperature should also affect synchronously terrestrial ecosystems. Such an approach could potentially be used to align speleothem and pollen records at the start and end of the LIG and within the LIG.
Cheng et al. (2006) suggested that abrupt calcite $\delta^{18} \mathrm{O}$ shifts from Chinese speleothems correlate to sharp methane concentration changes measured in ice cores that are associated with abrupt climate changes from the last glacial period and the last two climatic terminations. This hypothesis has been used to constrain the EDC3 timescale over Termination II (Parrenin et al. 2007; Fig. $1 D, E, H)$. However, the interpretation of speleothem $\delta^{18} \mathrm{O}$ and $\delta^{13} \mathrm{C}$ in terms of climatic or environmental parameters is not straightforward (e.g. Baker et al. 1997). In particular, the climatic interpretation of Chinese stalagmite $\delta^{18} \mathrm{O}$ has been recently challenged (Pausata et al. 2011; Wang and Chen 2012). Also, the question as to whether rapid calcite $\delta^{18} \mathrm{O}$ variations measured in Chinese speleothems are systematically synchronous with abrupt methane concentration increases requires further investigation (Fleitman et al. unpublished data).

\section{Perspectives}

The guidelines for dating and synchronization established so far aim for moving toward a coherent LIG dating. Within that context, a coherent timescale between several ice and marine records from both hemispheres has already been established (e.g. Capron et al. 2010; Govin et al. 2012).

Matching various paleo-records also requires assessing rigorously the coherence of the different dating methods and developing integrated techniques. For example, the EDC3 timescale will be replaced soon by AICC2012, a new Antarctic Ice Core Chronology derived from an inverse model that integrates and optimizes absolute and new relative constraints from several ice cores (Bazin et al. 2012).

The guidelines will be updated as new higher-resolution records emerge that may allow for increasing the number of chronological tie points over past interglacials through the identification of additional rapid events and the use of improved radiometric techniques (e.g. Aciego et al. 2010).

\section{Selected references}

Full reference list online under:

http://www.pages-igbp.org/products/newsletters/ref2013_1.pdf

Capron E et al. (2010) Quaternary Science Reviews 29: 222-234

Cheng H et al. (2009) Science 236: 248-252

Govin A et al. (2012) Climate of the Past 8: 483-507

Parrenin Fet al. (2007) Climate of the Past 3: 485-497

Shackleton NJ, Hall MA, Vincent E (2000) Paleoceanography 15: 565-569 


\title{
Sea surface temperature controls on warm climate water isotopes in Greenland ice cores
}

\author{
Louise C. Sime ${ }^{1}$, V. Masson-Delmotte ${ }^{2}$, C. Risi ${ }^{3}$ and J. SJolte ${ }^{4}$ \\ 'British Antarctic Survey, Cambridge, UK; Isim@bas.ac.uk \\ 2Laboratoire des Sciences du Climat et de l'Environnement, Gif-sur-Yvette, France; ${ }^{2}$ Laboratoire de Météorologie Dynamique, Paris, France; ${ }^{4}$ Lund \\ University, Sweden
}

\section{We present new atmospheric isotope simulations in order to investigate the effect of sea surface temperature changes on the relationship between Greenland surface temperature and water isotopes.}

$R_{t}$ cently, ice core scientists have obtained for the first time a Greenland ice core record covering the entire last interglacial (LIG; Dahl-Jensen this issue; NEEM community members 2013). Previously, ice cores drilled in Greenland have shown that the stable water isotopic value $\left(\delta^{18} \mathrm{O}\right)$ of LIG ice at fixed elevation was enriched relative to present day, with a maximum enrichment across central Greenland regions of at least $+3 \%$ at 126 ka BP (e.g. NorthGRIP Project members 2004). This $+3 \%$ o enrichment has been interpreted as indicating LIG Greenland warmth, but also lower LIG ice sheet topography or warmth outside of Greenland. Thus, achieving a better understanding of the regional drivers of Greenland precipitation $\delta^{18} \mathrm{O}$ is of broad interest to the ice core and wider paleoclimate communities.

\section{LIG forcing versus greenhouse gas driven warming}

In the framework of the Past4Future project, two recent papers have used atmospheric isotope enabled General Circulation Models (GCM) to investigate climatic controls on $\delta^{18} \mathrm{O}$ measured in Greenland ice cores. Each paper has focused on a specific modeling approach.

The first approach uses simulations from the IPSL-CM4 model to simulate the LIG climate using realistic boundary conditions, i.e. 126 ka BP orbital configuration and greenhouse gas (GHG) levels
(Masson-Delmotte et al. 2011). The second approach (also preliminarily investigated in Masson-Delmotte et al. 2011) is as follows: First, two different warm sea surface temperature (SST) scenarios are simulated using the IPSL-CM4 and HadCM3 GCMs forced with high GHG values (see Box 1). Second, the impact of the two SST scenarios on isotopic changes over Greenland is simulated with the respective isotopeenabled atmosphere-only versions of IPSL-CM4 and HadCM3 (Sime et al. 2013). Hereafter, we refer to these three simulations as : (1) IPSL_LIG: IPSL-CM4 LIG simulation driven by $126 \mathrm{ka}$ BP orbital and 126 ka BP GHG forcing; (2) IPSL_A: IPSL-CM4 simulation using present day orbital forcing alongside higher levels of GHG forcing and (3) HadCM3_B: HadCM3 simulation using present day orbital forcing alongside higher levels of GHG forcing (Box 1).

To facilitate simulation inter-comparison, we firstly average the simulated $\delta^{18} \mathrm{O}$ increases over central Greenland (regions above $1300 \mathrm{~m}$ ). We then linearly scale the results so that the three simulations each have a $3 \%$ increase in $\delta^{18} \mathrm{O}$ compared with present day (Fig. 1). This enables a direct comparison between simulated temperature increases over Greenland, and SST changes that could force the observed LIG 3\%o $\delta^{18} \mathrm{O}$ increase. Although observationally based (NorthGRIP Project members 2004), the target of an average of $+3 \%$ in LIG $\delta^{18} \mathrm{O}$ is somewhat arbitrary.
It may not be necessary for the $\delta^{18} \mathrm{O}$ increase to average $3 \%$ across all central regions of Greenland in order to match all interglacial ice core observations. The SST changes simulated within IPSL_A and HadCM3_B also have a degree of arbitrariness, i.e. alternative patterns of SST changes could also drive up Greenland $\delta^{18} \mathrm{O}$ values.

A broad comparison between simulations shows that IPSL_LIG and IPSL_A SST patterns differ where orbitally-dependent seasonal behavior occurs (Fig. 2A-B). However, these differences appear to be smaller than those observed between the purely GHG (orbits as present day) forced IPSL_A and HadCM3_B experiments (Fig. $2 B-C)$.

\section{What surface temperature chang-} es drive a $+3 \%$ increase in $\delta^{18} \mathrm{O}$ ?

For Greenland, above $1300 \mathrm{~m}$, the scaled IPSL_LIG simulation suggests an averaged interglacial surface temperature increase greater than $14^{\circ} \mathrm{C}$. However it also features "cliff-edges" in $\delta^{18} \mathrm{O}$ and surface temperature (Fig. 1A). IPSL_A simulates an interglacial Greenland surface temperature increase of $\sim 10$ to $14^{\circ} \mathrm{C}$ (Fig. 1B) while HadCM3_B simulates an interglacial Greenland surface temperature increase of $\sim 2$ to $8^{\circ} \mathrm{C}$ (Fig. 1C). For the IPSL_A and HadCM3_B simulations, the surface temperature and $\delta^{18} \mathrm{O}$ changes tend to be larger in the northern and central regions

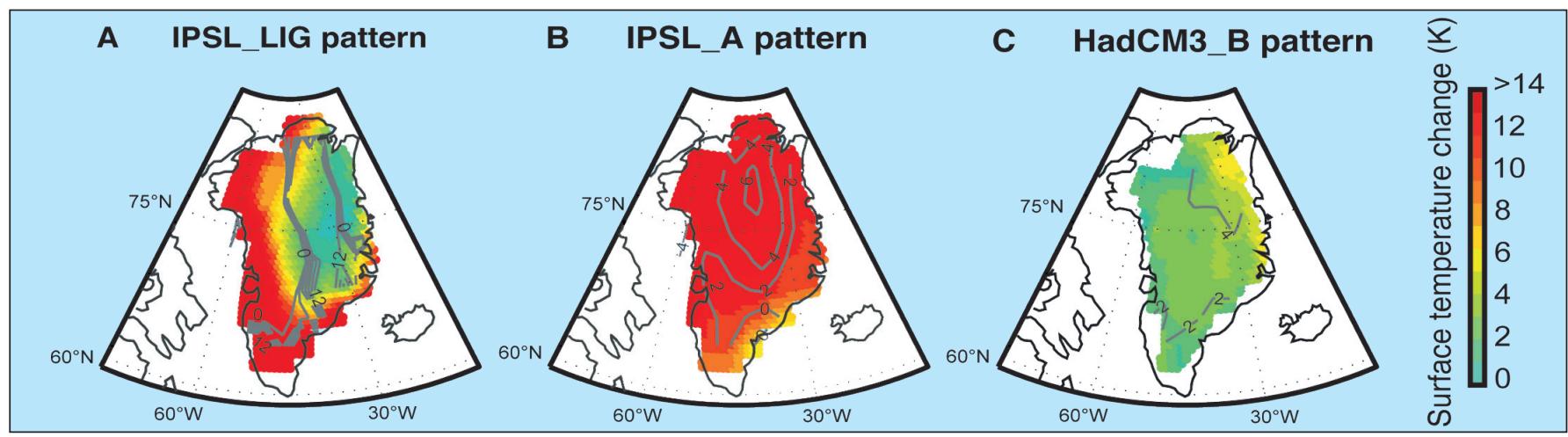

Figure 1: Scaled differences between the control (present day) and the warmer simulations. Climate and isotopic results are scaled such that central Greenland $\delta^{18} \mathrm{O}$ increases by $+3 \%$. A) IPSL_LIG simulation, (B) IPSL_A simulation and (C) HadCM3_B simulation. Shading over Greenland shows the difference between the control and individual simulation values of surface temperature. Contouring shows the difference between the control and individual simulation values of $\delta^{18} \mathrm{O}$. Intervals are $2 \% 0$ and the range is from 0 to $12 \%$. Figure from Sime et al. (submitted) 
Box 1: Orbital forcing configuration and greenhouse gas (GHG) values for the three simulations: IPSL_LIG (Masson-Delmotte et al. 2011) IPSL_A, HadCM3_B (Sime et al. 2013)

\begin{tabular}{l|l|l} 
Simulation & Orbital forcing & \multicolumn{1}{|c}{ GHGs } \\
\hline IPSL_LIG & $126 \mathrm{ka}$ & $126 \mathrm{ka}$ \\
\hline IPSL_A & present-day & $\begin{array}{l}4 \times \text { preindustrial } \\
\mathrm{CO}_{2}\end{array}$ \\
\hline HadCM3_B & present-day & $\begin{array}{l}\text { SRES A1B } \\
2100 \text { scenario }\end{array}$
\end{tabular}

of Greenland compared to present day (Fig. 1B and 1C).

The "cliff-edge" pattern across Greenland from the IPSL_LIG simulation indicates "simulation noise", and scaling to the $+3 \%$ o target requires SST increases that are not within observational bounds (Fig. 2A; McKay et al. 2011; Turney et al. 2010). Thus, despite the appeal of the 126 ka BP simulation (IPSL_LIG) approach, we suggest that climate model dynamics currently prevent an accurate simulation of LIG climate when using realistic orbital and GHG forcing. These model deficiencies could be due to missing physical processes in the ocean, atmosphere, and sea ice sub-models as well as missing climate feedbacks due to a neglect of dynamic vegetation and ice sheet evolution in the model. This motivates the use of isotopic simulations driven by higher levels of GHGs (such as the IPSL_A and HadCM3_B simulations) when attempting to learn about past warm climates.

We show that understanding SST changes is key to understanding warm climate Greenland isotopic changes (Masson-Delmotte et al. 2011; Sime et al. 2013). Indeed, precipitation sourced from local high-latitude regions is enriched in $\delta^{18} \mathrm{O}$. Increasing (decreasing) the proportion of locally sourced precipitation therefore raises (lowers) $\delta^{18} \mathrm{O}$ in Greenland snow. Thus SST changes which drive differences in evaporative sources, strongly affect Greenland $\delta^{18} \mathrm{O}$ values. From the results of the IPSL_A simulation, we observe strong SST increases south of $50^{\circ} \mathrm{N}$ but only small changes around northern Greenland (Fig. 2B). This leads to a higher proportion of distally sourced $\left(\delta^{18} \mathrm{O}\right.$ depleted) Greenland precipitation. The HadCM3_B simulation shows that the northern regions of Greenland experience SST increases of up to $\sim 10^{\circ} \mathrm{C}$ (Fig. $2 \mathrm{C}$ ), associated with reduced sea ice cover (not shown). This leads to substantially more local precipitation and as a result, enriched ice $\delta^{18} \mathrm{O}$.

\section{What can we learn from these re- sults?}

Our simulations provide an insight into how ice core observations could be related to wider climatic changes across the North Atlantic and Arctic Oceans. On one hand, we observe from the HadCM3_B simulation that if the seas to the north of Greenland get warmer and sea ice is reduced, then central Greenland $\delta^{18} \mathrm{O}$ increases of $3 \%$ (Fig. 1C) can be simulated with associated SSTs of around $+4^{\circ} \mathrm{C}$ (Fig. 2C). This pattern of sea surface warming lies within current interglacial observational constraints (McKay et al. 2011; Turney et al. 2010). On the other hand, the IPSL_A simulation shows that if the Arctic SSTs north of Greenland are almost unchanged and SST warming is instead concentrated in the south of Greenland (Fig. $2 \mathrm{~B})$ the $3 \% \circ \delta^{18} \mathrm{O}$ rise requires Greenland surface temperatures to increase by between $\sim 8$ and $14^{\circ} \mathrm{C}$ (Fig. 1B). It also requires an SST change to the southeast of Greenland of more than $\sim 20^{\circ} \mathrm{C}$ (Fig. 2B). Such a large change is very unlikely and this suggests that the warming resulting from the HadCM3_B may be more representative of LIG changes.
To summarize, while during colder than present day climates, Greenland $\delta^{18} \mathrm{O}$ originates from distal precipitation sources (Masson-Delmotte et al. 2005), our new simulations suggest that during warmer climates, Greenland $\delta^{18} \mathrm{O}$ precipitation can originate from local high latitude regions. As a result, we propose that sea surface warming and sea ice loss in regions north of Greenland may have caused much of the observed Greenland $\delta^{18} \mathrm{O}$ rise and also contributed to a central Greenland temperature increase of about $+4^{\circ} \mathrm{C}$ during the LIG. SST reconstructions from marine sediment cores drilled in regions to the north of Greenland would be necessary to test our hypothesis.

\section{Outlook}

Our experiments have shown that improved model parameterizations and/ or coupling with dynamic ice sheet and vegetation models are necessary for investigating Greenland LIG changes forced by more realistic orbital and GHG forcings. Isotope-enabled model simulations, which include dynamic ice sheets, would also be useful for helping us infer LIG ice sheet changes from isotopic observations. Finally, performing atmospheric isotopic model simulations is also beneficial in understanding other ice core tracers used to interpret Greenland moisture source changes (such as the deuterium excess and the recently developed $\delta^{17} \mathrm{O}$ tracer).

\section{Selected references}

Full reference list online under:

http://www.pages-igbp.org/products/newsletters/ref2013_1.pdf

Masson-Delmotte V et al. (2011) Climate of the Past 7, 1041-1059 Masson-Delmotte V et al. (2005) Science 309: 118-121

McKay NP, Overpeck JT, Otto-Bliesner BL (2011) Geophysical Research Letters 38, doi: 10.1029/2011GL048280

NorthGRIP Project members (2004) Nature 431: 47-151

Sime LC et al. (2013) Quaternary Science Reviews 67: 59-80

\section{A IPSL_LIG pattern}

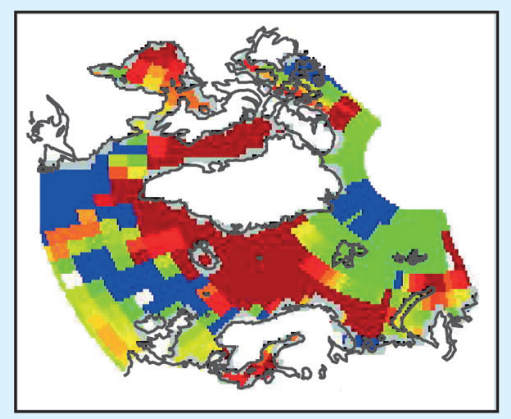

\section{B IPSL_A pattern}

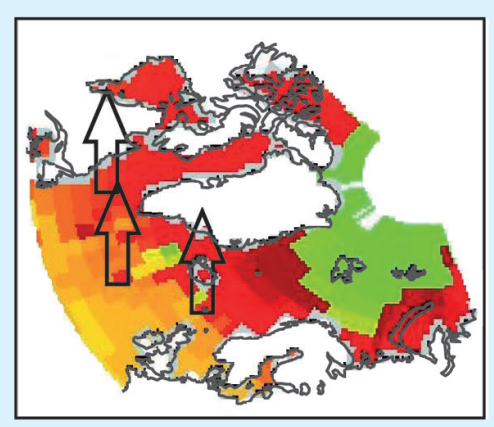

\section{HadCM3 B pattern}

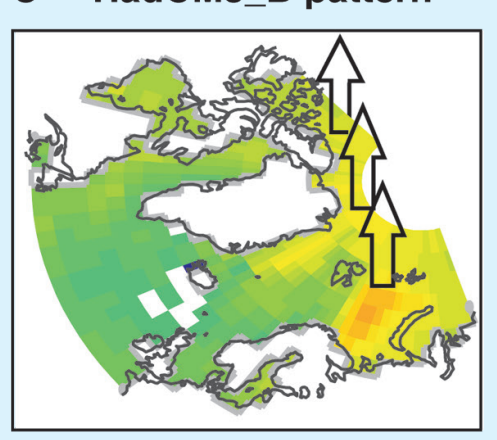

Figure 2: Differences between the control (present day) and warmer simulation SSTs. Scaled (as in Fig. 1). A) IPSL_LIG simulation, (B) IPSL_A simulation and (C) HadCM3_B simulation. The viewpoint in each case is from above Europe, looking across the North Atlantic Ocean, Greenland, and part of the Arctic Ocean. Schematic arrows show the main changes in precipitation (evaporation) sources for Greenland snow. 


\section{Reconstruction of past sea ice extent}

Rainer Gersonde ${ }^{1}$ and Anne de Vernal ${ }^{2}$

'Alfred-Wegener-Institute for Polar and Marine Research, Bremerhaven, Germany; Rainer.Gersonde@awi.de GEOTOP, Université du Québec à Montréal, Montréal, Canada

Past sea ice extension is a critical component of the Earth's climate system. Reconstructions relying on geochemical, sedimentological and microfossil-based proxy records in ice and sediment climate archives are presented here.

$\mathrm{O}_{\mathrm{s}}^{\circ}$ August 27, 2012 the US National Snow \& Ice Data Center (NSIDC, http://nsidc. org/arcticseaicenews/) and the National Aeronautics and Space Administration (NASA, http://www.nasa.gov/topics/earth/features/ arctic-seaice-2012.html) alerted the public about the lowest Arctic summertime sea ice extent measured since the satellite-based sea ice survey was started in the late 1970s. The observed August 2012 minimum sea ice extent of $4.1 \times 10^{6} \mathrm{~km}^{2}$ confirms the ongoing decline of perennial Arctic sea ice, which potentially began in the middle of the last century (Kinnard et al. 2008). The decline reached 2 to 3\% per decade between 1979 and 1996 and accelerated to 12 to $13 \%$ per decade since then (Comiso 2012). This rapid loss of sea ice, higher than anticipated by the forecasts of the IPCC 2007 report (Stroeve et al. 2007), may lead to the disappearance of summer Arctic sea ice by 2050 if not earlier, according to several model simulations (Wang and Overland 2009). Arctic sea ice decline, which is related to Arctic surface water temperature increase (Comiso 2012), represents a striking example of current climate change related to anthropogenic global warming (Spielhagen et al. 2011; Kinnard et al. 2011).

Although sea ice is generally restricted to high latitudes, its formation, extent and seasonal variability play a critical role in the Earth's climate and ocean dynamics at global and regional scales, affecting surface albedo, the exchange of energy fluxes between ocean and atmosphere, thermohaline ocean circulation and formation of deep water masses, primary and export productivity, and weather system formation (e.g. Budikova 2009) (Fig. 1A). Sea ice is a fast changing environmental component of the Earth system (Fig. 1B) and effectively amplifies climate and environmental change due to positive feedback mechanisms. The recent changes in Arctic sea ice extent are of concern to scientists and policy-makers, and this topic is regularly reported in the media. Thus we need to further extend sea ice records into the past to document the natural variability of sea ice beyond short term satellite measurements to better understand the recently observed changes and enhance our ability to perform projections of future sea ice extent.

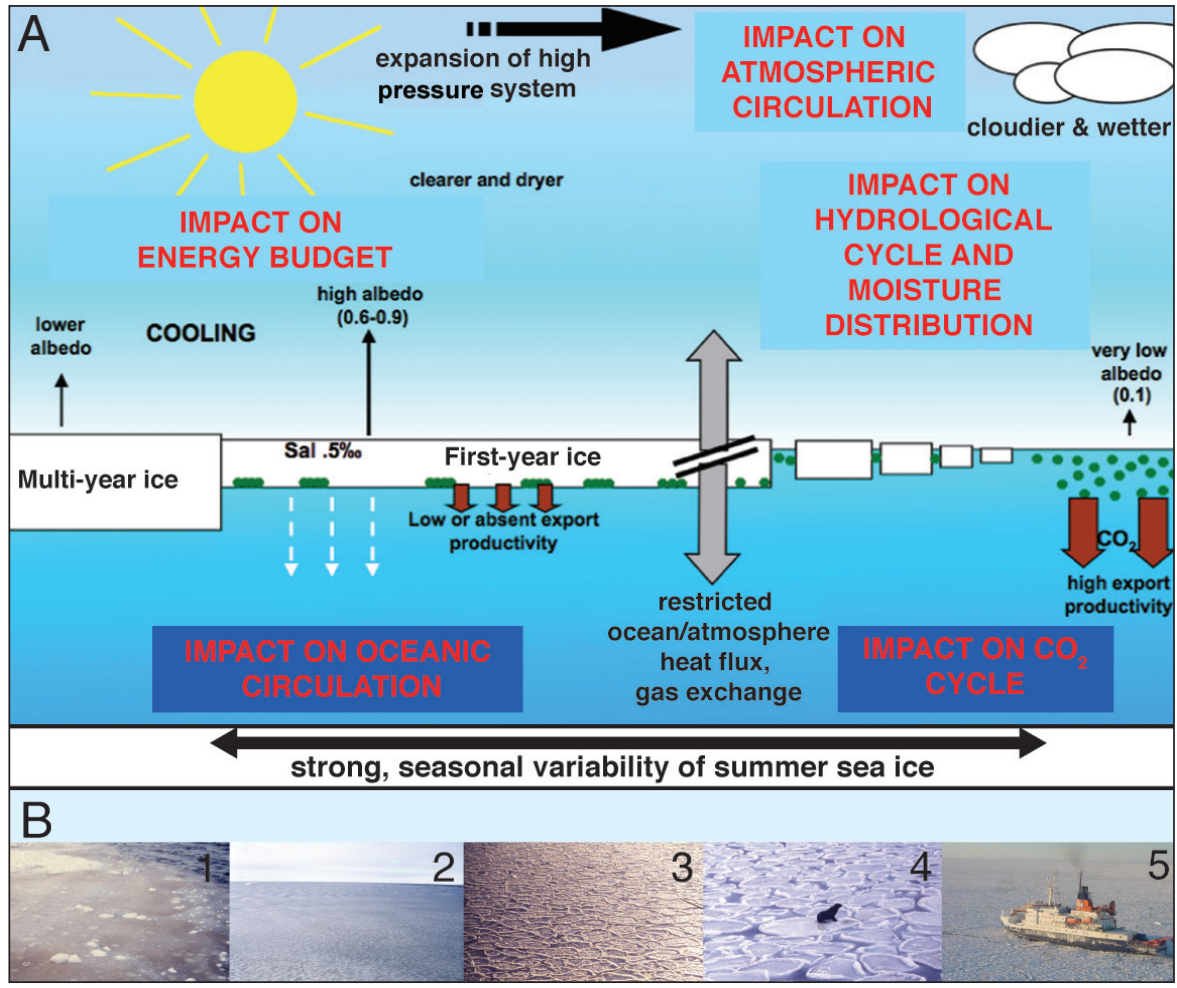

Figure 1: A) Schematic representation of major sea ice related environmental and climatic parameters (adapted from Gersonde and Zielinski 2000). B) Photo gallery showing the development of Antarctic sea ice (a fast changing environmental factor) from frazil ice (1) to aggregation of ice crystals (2) to form pancake ice (3), freezing and rafting of pancake ice (4, see fur seal for comparison) to form a close ice cover (5, crossed by the German research vessel ice breaker Polarstern). The different steps of this process take only a few days to weeks. Photos: R. Gersonde.

\section{Historical sea ice records}

At the hemispheric scale, sea ice reconstructions for historical periods predating the start of satellite surveys are hampered by the lack of observational datasets. Nevertheless, Kinnard et al. (2008) extended the observation-based record of Arctic sea ice back to $1870 \mathrm{AD}$. This was mainly based on statistical analysis of ice edge position data. The record was then extended to $560 \mathrm{AD}$ based on a high-resolution multi-proxy approach using ice, terrestrial, and marine records. This historical record demonstrates that the observed modern decline of sea ice has been unprecedented for the past 1,450 years (Kinnard et al. 2011). Rayner et al. (2003) simulated Arctic and Antarctic sea ice and their seasonal variability back to 1856 AD, taking into account historical observations and modern climatologies. Their analysis indicates reductions in Antarctic sea ice extent by the middle of the last century; a result supported by a comprehensive study of whaling positions (de la Mare 2009) and ice core proxy records (Abram et al. 2010). Such a finding is puzzling, since satellite-derived information indicates a slight increase in Antarctic sea ice (about 1\% per decade) during the past 40 years (Turner et al. 2009).

\section{Sea ice on geological time scales}

Sea ice reconstructions on geological timescales rely on indirect observations obtained from marine and ice core records. Various proxies have been developed to estimate sea ice extent, concentration, annual occurrence, and seasonal pattern. However, each proxy has its own limitations. While winter sea ice extent can be reconstructed somewhat accurately with a number of proxies, estimating the extent of the perennial sea ice field remains challenging. Moreover, while the analyses of cores may yield time series at given locations, the reconstruction of sea ice extent in space with the position of maximum and minimum limits requires densely distributed data. Consequently, comprehensive glacial/interglacial reconstructions require combining different proxy records and consideration of sedimentation patterns to map sea ice extent and its variability. 
Sea ice proxies include chemical tracers in ice cores and biogenic remains of microorganisms as well as non-biogenic particles in marine records. Flux rates of methanesulfonic acid (MSA) and sea salt sodium in ice cores are used to reconstruct past sea ice extent (e.g. Becagli et al. 2009; Wolff et al. 2006) but their interpretation is equivocal and more studies are needed to understand and calibrate these proxies (Abram et al. 2010). Marine reconstruction methods include the use of microfossil marker species, transfer functions based on microfossil assemblages, stable isotope signals, biomarker and terrigenic particles. Specific diatom species are able to dwell in sea ice, attached to it or within sea ice governed cold-water environments (less than $-1.5^{\circ} \mathrm{C}$ ). Some of these species produce biomarkers or secrete siliceous valves that can be preserved in the sediment record. For example, a proxy to reconstruct past Arctic sea ice is the IP25 biomarker (a C25 monounsaturated highly branched isoprenoid lipid) (Belt et al. 2007). IP25 is produced by a sea icerelated diatom, which secretes thinly walled siliceous valves generally not preserved in the sedimentary record. To better quantify sea ice occurrence, Müller et al. (2011) have proposed using a combination of IP25 and a phytoplankton productivity proxy. The occurrence of IP25 is restricted to the polar North (e.g. Müller et al. 2009). A similar biomarker has recently been proposed for reconstruction of Antarctic sea ice (Massé et al. 2011).

The abundance pattern of sea ice related diatom species preserved in the sediment record represents a powerful tool for Southern Ocean sea ice reconstruction. While early work (Hays et al. 1976) simply used the boundary of diatom-rich and diatom-poor sediments for the mapping of the sea ice extent at the Last Glacial Maximum (LGM), later studies considered the composition of diatom assemblages and reconstructed sea ice quantitatively as expressed by the annual duration (month per year) of sea ice occurrence using a diatom transfer function (Crosta et al. 1998). A combination of different diatom-based methods allowed the first comprehensive circumAntarctic reconstruction of the LGM winter and summer sea ice distribution as part of the
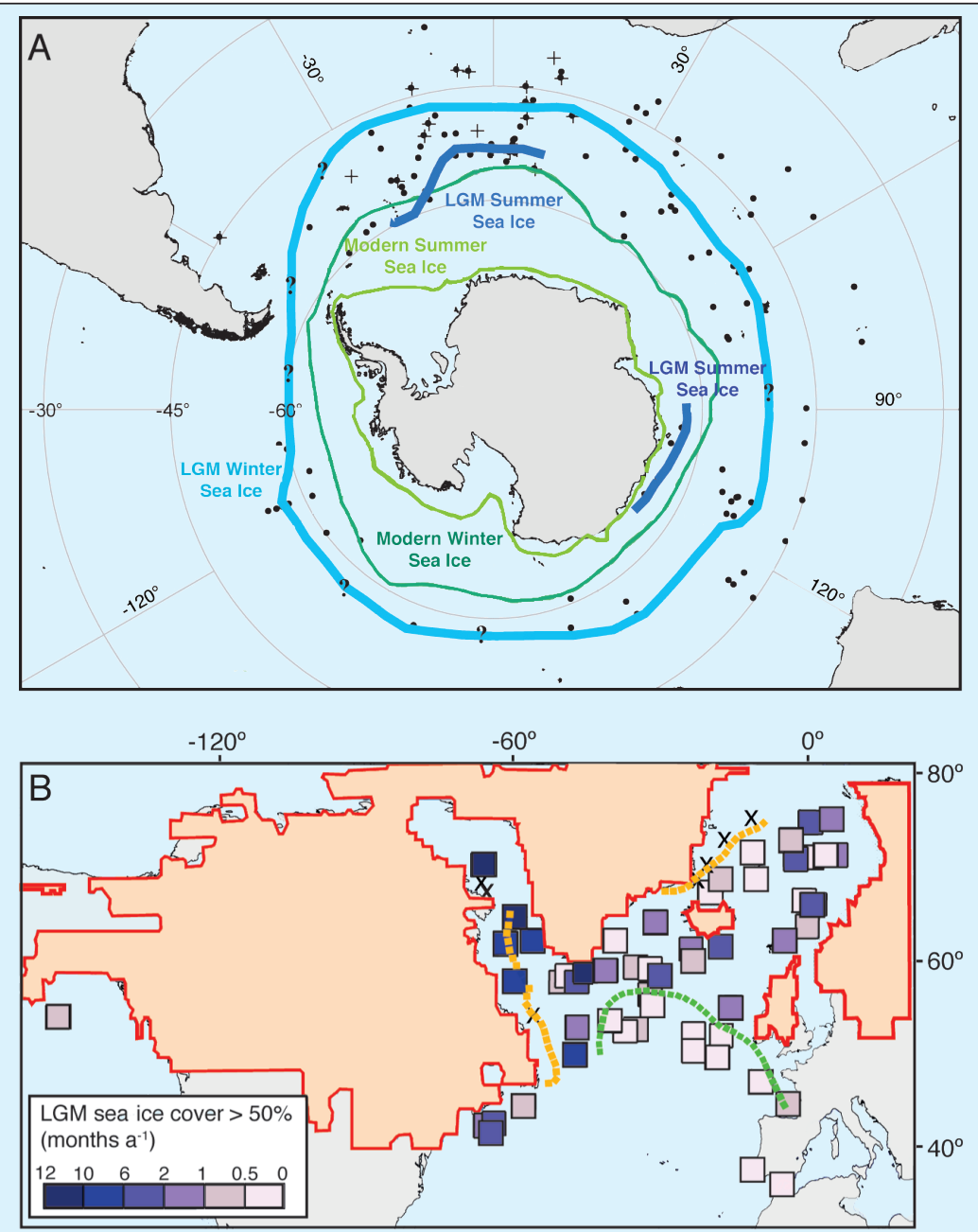

Figure 2: A) Reconstruction of Antarctic winter and summer sea ice extents during the Last Glacial Maximum based on diatom proxies (blue lines). For comparison modern winter and summer sea ice extents are indicated (green lines). The LGM reconstruction in the Pacific sector and the Drake Passage are weak because of the small number of available cores at the time of data compilation. Dots indicate locations with diatom-based reconstruction, crosses indicate locations with radiolarian-based reconstruction (modified from Gersonde et al. 2005). B) Reconstruction of sea ice cover in the North Atlantic during the Last Glacial Maximum based on organic walled dinoflagellates. The orange and green dashed lines correspond to the probable limits of summer (perennial) and winter sea ice limits, respectively (modified from de Vernal et al. 2005).

MARGO project to be realized (Gersonde et al. 2005; Fig. 2A).

In Northern Hemisphere high latitudes, the use of diatoms, however, is often restricted by silica dissolution. Some reconstructions from Quaternary sediments are nevertheless available for the North Atlantic (e.g. Justwan and Koç 2008), the Labrador Sea and the polar North Pacific. In contrast, organic-walled dinoflagellate cysts display a broad distribution pattern and are usually well-preserved in sediment. They have successfully been used for past sea ice reconstructions (e.g. de Vernal et al. 2005, 2008) documenting the LGM sea ice distribution in the North Atlantic (Fig. 2B). Other potentially useful proxies include ostracode species that live parasitically on sea ice-related amphipods (Cronin et al. 2010), the isotopic signature of a sea ice-related planktic foraminifer species (Hillaire-Marcel and de Vernal 2008), and the relationship between sea surface temperatures derived from the planktic foraminiferal assemblage record and sea ice occurrence (Sarnthein et al. 2003). Finally, the application of different sedimentological proxies for reconstruction of Arctic sea ice and its transport pathways has been attempted (Stein 2008). An interesting combination of terrigenic components (ice-rafted debris) and the occurrence of an extinct diatom species, which may be related to an extant sea ice-related diatom genus, has been used for the establishment of a two-million-year sea ice record which occurred in the middle Eocene Arctic Ocean (Stickley et al. 2009).

\section{Outlook}

In the framework of the Past4Future project, bipolar reconstructions, derived from several of the proxies described above, are generated to enhance our knowledge of sea ice variability during the present and last interglacial stages and the preceding glacial/interglacial transitions. The challenge to produce time series of sea ice extent into past warmer than present climates and to study natural sea ice variability under such conditions is central to the Sea Ice Proxy (SIP) working group supported by PAGES (de Vernal et al. 2012).

\section{Selected references}

Full reference list online under:

http://www.pages-igbp.org/products/newsletters/ref2012_3pdf

BeltST etal. (2007) Organic Geochemistry 38: 16-27

Comiso JC (2012) Journal of Climate 25, doi: 10.1175/JCLI-D-11-00113.1

deVernal A et al. (2005) Quaternary Science Reviews 24: 897-924

Gersonde R, Crosta X, Abelmann A, Armand L (2005) Quaternary Science Reviews 24: 869-896

Kinnard Cetal. (2011) Nature 479: 509-512 


\title{
A climate model inter-comparison of last interglacial
} peak warmth

\author{
Emma J. Stone ${ }^{1}$, P. Bakker ${ }^{2}$, S. Charbit ${ }^{3}$, S.P. Ritz and V. Varma ${ }^{5}$ \\ School of Geographical Sciences, University of Bristol, UK; emma.j.stone@bristol.ac.uk \\ Earth \& Climate Cluster, Department of Earth Sciences, Vrije Universiteit Amsterdam, The Netherlands; ${ }^{2}$ Laboratoire des Sciences du Climat et \\ de I'Environnement, CEA Saclay, Gif-sur-Yvette, France; ${ }^{4} \mathrm{Climate}$ and Environmental Physics, Physics Institute and Oeschger Centre for Climate \\ Change Research, University of Bern, Switzerland; ${ }^{5}$ Center for Marine Environmental Sciences and Faculty of Geosciences, University of Bremen, \\ Germany
}

A last interglacial transient climate model inter-comparison indicates regional and inter-model differences in
timing and magnitude of peak warmth. This study reveals the importance of different climate feedbacks and
the need for accurate paleodata in terms of age, magnitude and seasonality to constrain model temperatures.

Daleorecords and climate modeling studies indicate that Arctic summers were warmer during the last interglacial (LIG, ca. 130 to 115 ka BP) and global sea level was at least $6 \mathrm{~m}$ higher than today (Dutton and Lambeck 2012; Kopp et al. 2009), implying a reduction in the size of the Greenland and Antarctic ice sheets (Siddall et al. this issue). Previous snapshot climate model simulations for the LIG have shown summer Arctic warming of up to $5^{\circ} \mathrm{C}$ compared with the present day (Kaspar et al. 2005; Montoya et al. 2000), with the largest warming in Eurasia and the Greenland region. The LIG period provides an opportunity to test the current suite of climate models of varying degrees of complexity, under forcings that result in a warmer than present climate. To date, however, there has been no standardized inter-comparison of LIG climate model simulations.

Five European modeling groups (forming part of the Past4Future project) have performed experiments in order to characterize the response of the climate system to LIG changes in various climate forcings and biophysical feedback processes. These forcings and feedbacks include greenhouse gas concentrations (GHG), orbital configuration (ORB), vegetation feedbacks (VEG), and changes in ice sheet geometry (ICE). A key aim of this inter-comparison is to perform a number of sensitivity studies (e.g. ORB only, ORB+GHG, $\mathrm{ORB}+\mathrm{GHG}+\mathrm{VEG}, \mathrm{ORB}+\mathrm{GHG}+\mathrm{ICE}$ ) to ascertain the relative importance of the forcings and feedbacks in determining the trends and variability of LIG climate.

The Past4Future project has enabled the first long (> $10 \mathrm{ka}$ ) transient standardized inter-comparison for the LIG to be realized. These simulations consist of a range of model complexity with various forcings and feedbacks included: one full general circulation model CCSM3 (ORB; Collins et al. 2006; Yeager et al. 2006), one low-resolution general circulation model, FAMOUS (ORB+GHG; Smith 2012; Smith et al. 2008), and three Earth System Models of Intermediate Complexity: 1) CLIMBER-2 (ORB+GHG; Petoukhov et al. 2000), 2) Bern3D (ORB+GHG+ICE; Müller et al. 2006;

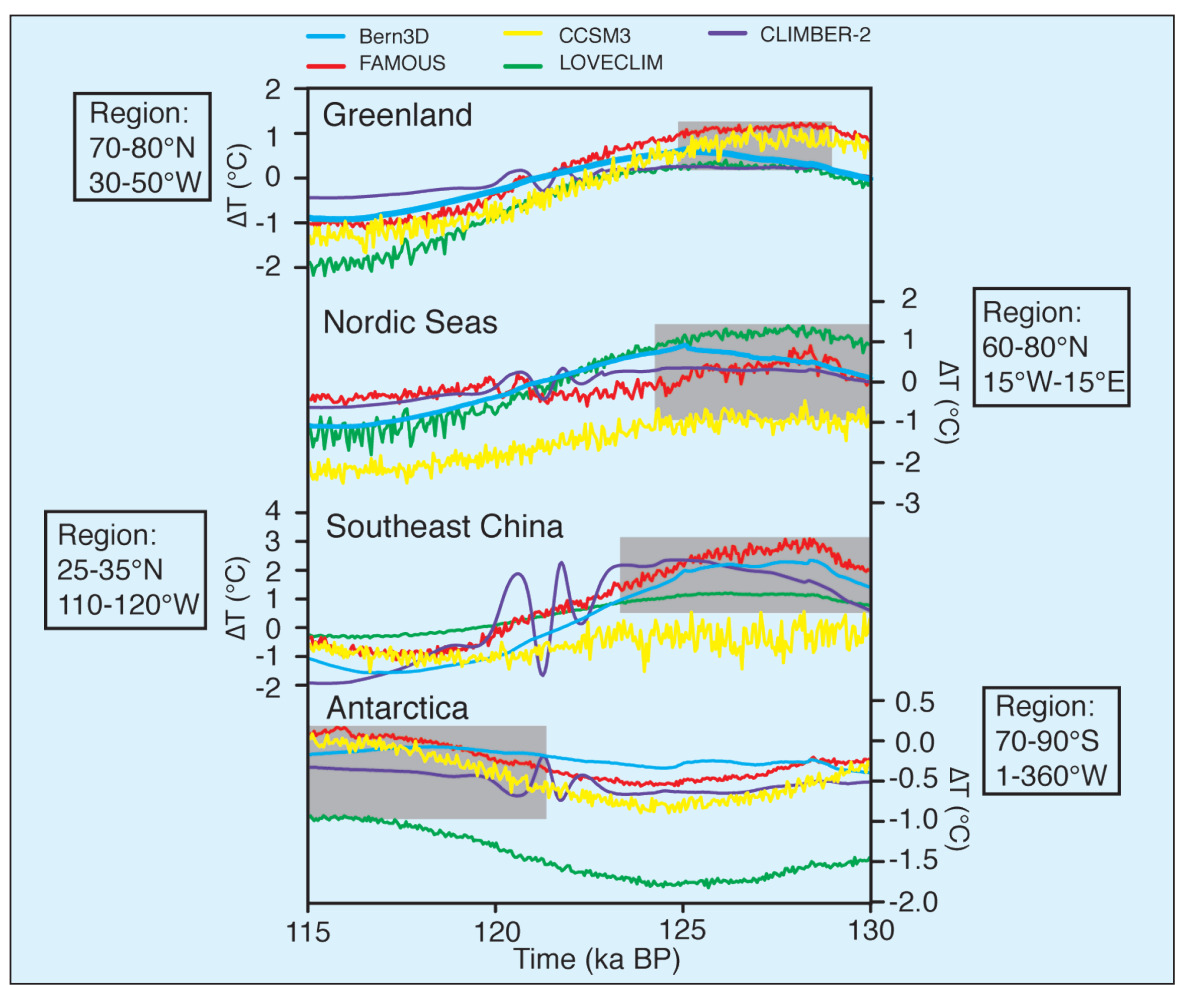

Figure 1: Summer 50-year global mean temperature anomalies spanning the LIG (ca. 130 to $115 \mathrm{ka} B P$ ) for five climate models of varying complexity. Note that these anomalies are calculated with respect to a preindustrial equilibrium climate representative of 1850 AD. For more details with respect to model setups and forcings see Bakker et al. (2012). The range in timing of the peak interglacial warmth is indicated by the gray bars.

Ritz et al. 2011), and 3) LOVECLIM (ORB+GHG; Goosse et al. 2010). CLIMBER-2, Bern3D, FAMOUS, and LOVECLIM use GHG and orbital forcings that conform closely to a set of standards described by the Paleo-modeling Intercomparison Project (PMIP3) while CCSM3 uses the same orbital configuration but with greenhouse gas values fixed according to mean LIG values. Bern3D is the only model that prescribes ice-sheet changes (and an associated freshwater forcing) by including the effect of remnant Northern Hemisphere ice sheets from the penultimate glaciation (all other models use present day ice sheet geometry).

One of the difficulties in understanding the response of the climate to LIG forcings is the lack of consensus in the paleodata on the timing of peak interglacial warmth in different regions of the Earth (e.g. The Nordic Seas and North Atlantic; Govin et al. 2012; Van Nieuwenhove et al. 2011). The interpretation of temperature signals of different resolution and seasonality obtained from paleoclimatic archives is also contentious (Jones and Mann 2004). Our climate modeling approach aims to inform on the spatial and temporal differences in peak warmth observed in the data, as well as on assessing the robustness of our climate model results (Bakker et al. 2013). Through this task it is also possible to gain an understanding of the climate feedbacks (e.g. changes in ocean overturning circulation and sea-ice) that are at play resulting from changed GHG concentrations and astronomical forcing.

\section{How does LIG summer temperature response compare in four different regions of the Earth?}

Figure 1 shows the 50-year summer average surface air temperature anomalies over four defined regions of the globe where paleodata exist for the time period 130 to $115 \mathrm{ka}$ BP. These model results demonstrate not only the differences in the timing of peak summer warmth 
between regions but also discrepancies between the models themselves. Greenland shows peak summer warmth during the early LIG for all five models with positive temperature anomalies compared with pre-industrial values ranging from $\sim 0.1$ to $1^{\circ} \mathrm{C}$, albeit substantially smaller than the $+5^{\circ} \mathrm{C}$ anomaly obtained from ice core records (e.g. NorthGRIP Project members 2004). Future simulations, which include a reduced Greenland ice sheet, may reconcile this difference between models and data.

Simulated maximum summer temperature anomalies for the Nordic Seas (-1.0 to $1.0^{\circ} \mathrm{C}$ ) and southeast China $\left(\sim 0\right.$ to $\left.3^{\circ} \mathrm{C}\right)$, however, indicate a less robust result between the models in terms of timing and temperature change. We compare our model results with a recent data synthesis by Turney and Jones (2010) and show that no model produces a maximum summer temperature anomaly as large as that inferred from paleodata (up to $+9^{\circ} \mathrm{C}$ ) for the Nordic Seas. This discrepancy could be due to missing feedback processes in the model simulations (such as vegetation changes), misrepresentation of ocean circulation and a simplistic representation of sea ice dynamics. Furthermore, the discrepancy could be larger still because the Turney and Jones (2010) data synthesis has been interpreted as an annual rather than a summer temperature signal. We also note that the Bern3D model simulation, which includes remnant ice sheets from the previous glacial, shows a delay in peak LIG warmth for Greenland and the Nordic Seas compared with the other models indicating the importance of this feedback.

In contrast to Greenland, timing of summer peak warmth in the Southern Hemisphere shows a substantial delay, with peak summer values (from -1 to $0.1^{\circ} \mathrm{C}$ ) only being obtained after $120 \mathrm{ka}$ BP. This contradicts a recent paleodata study (Govin et al. 2012) suggesting Southern Hemisphere peak warmth actually preceded Northern Hemisphere warming during the early part of the LIG.

\section{Seasonal timing of LIG maximum warmth}

Figure 2 shows the spatial distribution of timing of maximum LIG warmth during January and July. Superimposed are the four regions described above and given in Figure 1. During Northern Hemisphere winter (January), there is large variability between models in the timing of maximum warmth ranging from ca. 119 to $128 \mathrm{ka}$ BP over Greenland and the Nordic Seas. We relate these discrepancies at high northern latitudes during winter to differences in sea-ice feedback mechanisms (Bakker et al. 2013). In contrast, Southern Hemisphere winter (July) temperatures over Antarctica show less variability in timing of peak winter warmth. The temperature anomalies reach a maximum

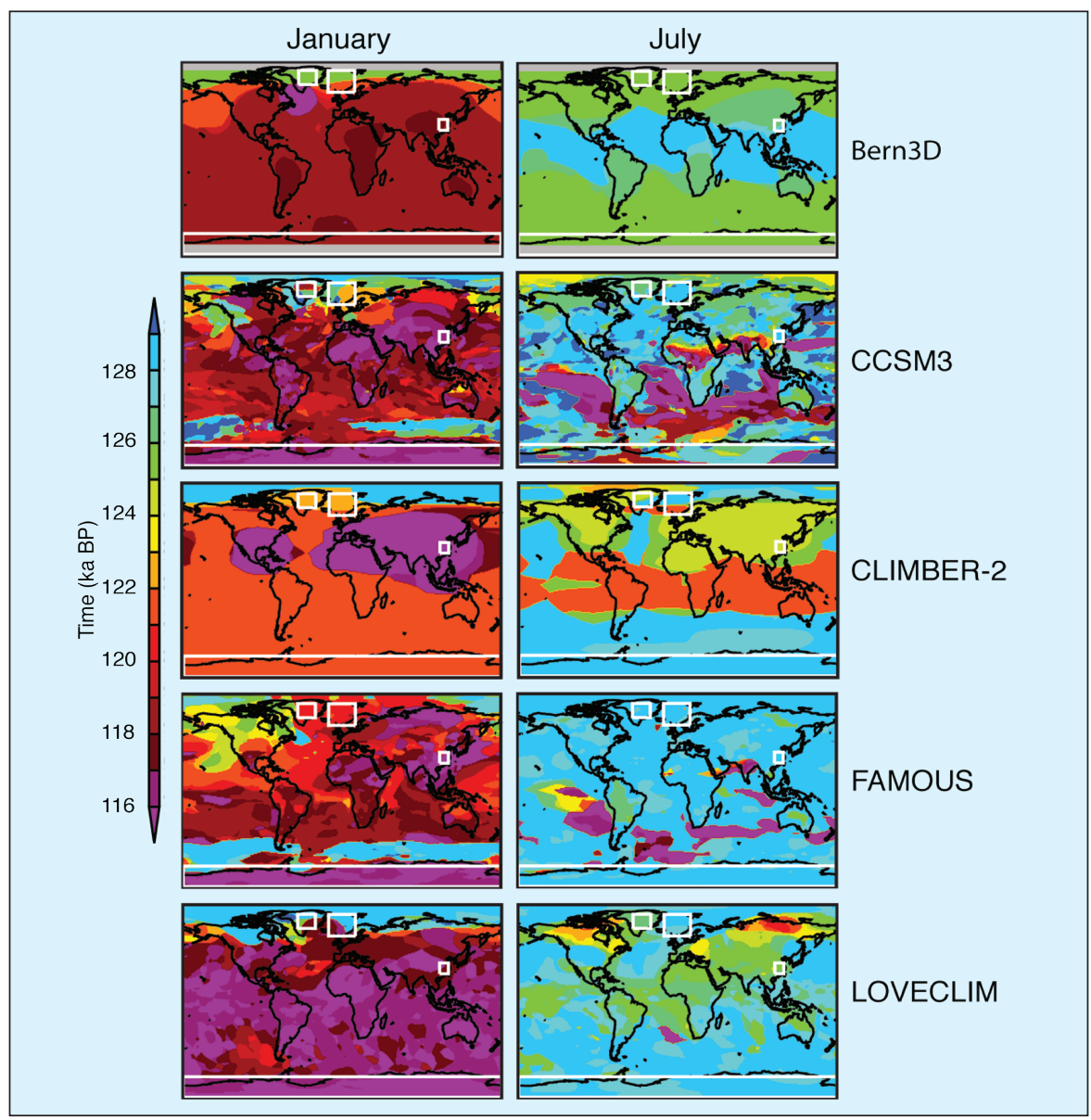

Figure 2: Timing of maximum LIG warmth for the months January and July for the five climate models of varying complexity. The regions defined in Figure 1 for Greenland, Nordic Seas, southeast China, and Antarctica are depicted by the white boxes. Figure modified from Bakker et al. (2013).

ca. 128 ka BP for CLIMBER-2, LOVECLIM and FAMOUS relating to those simulations which include the same forcings. There is a delay in peak warmth for Bern3D and CCSM3 (CCSM3 does not include transient GHGs and Bern3D includes remnant ice sheets and changes in freshwater forcing).

During the northern summer months, the inter-model comparison shows consistent timing of maximum warmth at high latitudes, ranging between ca. 124 and 128 ka BP (Fig. 2). This consistency is also the case for the Southern Hemisphere in July, but austral summer maximum warmth occurs much later (after 118 ka BP). In northern mid-to-low latitude regions, such as southeast China, all model simulations show reasonably similar results in timing of maximum warmth during the northern summer (July) and winter (January) months.

\section{Perspectives}

The Past4Future LIG modeling group provides important information for the data community regarding locations for relevant potential new paleoclimatic data. We also provide insights into understanding the mechanisms that result in differences in peak warmth timing and magnitude from proxy data temperatures around the world. Our results inform on the impact of remnant ice sheets and the importance of understanding the sensitivity of climate feedbacks during periods of enhanced warming. Part of the Past4Future data and modeling community remit is to reconstruct a coherent picture of LIG climate with the use of climate models to explain the temperature patterns observed in proxy observations. The next stage will be to take part in a detailed multi-millennial scale temperature comparison between model and data for the LIG. This will aim at understanding and explaining the differences between climate model results and how they might constrain future predictions of global warming.

\section{Selected references}

Full reference list online under:

http://www.pages-igbp.org/products/newsletters/ref2013_1.pdf

Bakker P et al. (2013) Climate of the Past 9: 605-619

Govin A et al. (2012) Climate of the Past 8: 483-507

NorthGRIP Project members (2004) Nature 431: 147-151

Turney CSM, Jones RT (2010) Journal of Quaternary Science 25: 839-843 Van Nieuwenhove N et al. (2011) Quaternary Science Reviews 30: $934-$ 946 


\title{
Continuous in-field measurements of gas concentration
} from ice cores

\author{
Thomas Blunier ${ }^{1}$, J. Chappellaz ${ }^{2}$ and E. Brook ${ }^{3}$ \\ ${ }^{1}$ Centre for Ice and Climate, Niels Bohr Institute, University of Copenhagen, Denmark; blunier@gfy.ku.dk \\ ${ }^{2}$ Laboratoire de Glaciologie et Géophysique de l'Environnement, CNRS, Université Joseph Fourier-Grenoble, France; ${ }^{3}$ Department of Geosci- \\ ences, Oregon State University, Corvallis, USA
}

\section{New techniques have revolutionized the way trace gases are measured from ice cores. What took decades to complete in the past now only takes a few months. We report about the recent development in measuring the methane concentration from ice cores.}

ce cores provide a unique opportunity

to access the past composition of the

Earth's atmosphere. Up to now methane concentration measurements have been made on individual ice samples. Such work is laborious and it took two decades to obtain the methane data for the composite record shown in Figure 1A.

Initially chemical measurements were also obtained from individual ice samples. During the 1990s a methodology known as Continuous Flow Analyses was invented and has been further developed since (Bigler et al. 2011; Kaufmann et al. 2008). This method is based on the continuous melting of a section of the ice core. The meltwater is then split and diverted into detectors specific to the chemical ion species to be analyzed. In this way a large range of chemical components can be analyzed directly at the ice core drill site. Note that for these chemical measurements, a debubbler unit is required to remove the air from the ice (on the order of $10 \%$ by volume) since the air would hamper the chemical analysis. It has been a long-term ambition to measure the gas composition of ice cores using a similar methodology.
The University of Bern, Switzerland, has developed such a system.

\section{First in-the-field methane concen- tration measurements}

The system, developed in Bern, is based on a small portable Gas Chromatograph for methane concentrations (Schüpbach et al. 2009). The debubbler unit has been modified so that the expelled air is routed through a membrane unit to separate the air from the remaining water. The membrane unit consists of a hydrophobic membrane tube where the outside of the tube is flushed with ultrapure Helium. The air passes through the membrane and is taken up by the Helium stream. The Helium/air sample mixture is then dried and transferred through a column trap held at the temperature of liquid nitrogen to concentrate the air sample. Finally, this air sample is injected into the Gas Chromatograph. This new way of measuring ice core air composition has proven successful and produces a measurement at $\sim 15 \mathrm{~cm}$ intervals along the core with a measurement uncertainty of $3 \%$, i.e. sufficient to reveal the main features of atmospheric methane concentration changes (Schüpbach et al. 2009). Still, the resolution potentially achievable is limited by the requirement to (1) pre-concentrate the sample and (2) separate the trace gases chromatographically.

\section{Introduction of laser spectrom- eters to ice core works}

The research teams at LGGE (Laboratoire de Glaciologie et Géophysique de I'Environnement, Grenoble, France) and $\mathrm{CIC}$ (Centre for Ice and Climate, Copenhagen, Denmark) have independently developed the use of cavity enhanced laser spectrometry for obtaining methane concentration measurements. Whilst the LGGE group has made improvements to a prototype instrument (SARA) in collaboration with a laser physics research laboratory at Grenoble (LIPhy, http:// www-Isp.ujf-grenoble.fr/SARA-Analyzerlaser-of-traces-of), the CIC group has adapted a commercially available Picarro instrument for the specific requirement of ice core analysis.

During the 2009 NEEM deep drilling campaign, the CIC scientists made the

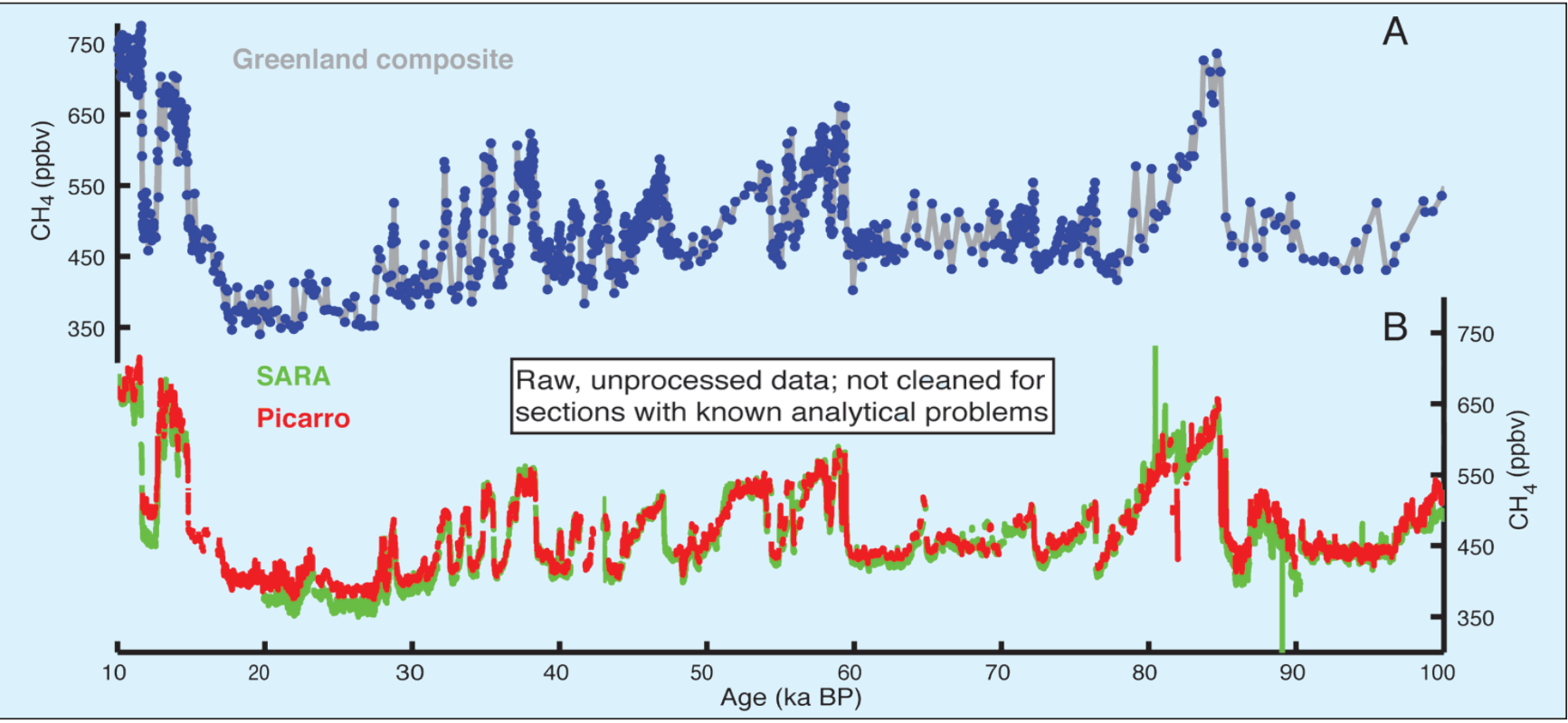

Figure 1: Methane concentration variations over the last $100 \mathrm{ka}$. A) Composite record from several Greenland ice cores (Blunier et al. 2007), (B) Raw data obtained with the SARA (green curve) and Picarro laser spectrometers (red curve). This data is preliminary, uncalibrated, and for illustrative purposes only. It is known to contain sections with analytical issues. 
first attempt to couple a Picarro instrument to the existing Bern Continuous Flow Analyses setup. The instrument was connected to the outlet of the Gas Chromatograph gas trapping system in order to measure the sample diluted in Helium. This setup was initially unsuccessful due to the variable dilution of the sample but it demonstrated that laser instruments could be successfully used in the field. Furthermore, initial tests indicated that it would be possible to obtain reliable results if gas concentration measurements were made on the undiluted flow.

\section{Success during the NEEM 2010 field season}

During the 2010 field season, the project was expanded and included two laser instruments backed up by the Gas Chromatograph system (Fig. 2). LGGE and $\mathrm{CIC}$ researchers developed a way of extracting the gas in the melt stream without diluting the sample using a Membrana MicroModule unit and the setup was modified such that the gas/water stream from the debubbler unit was routed directly through the membrane unit. On the gas side of the membrane the air extracted from the ice was pumped through a drier to remove water vapor and then successively through the SARA and Picarro analyzers (Fig. 2). Figure 1 shows the composite of several Greenland ice core methane concentration records obtained over the last 20 years (Fig. 1A) and the raw methane concentration data obtained from the respective laser spectrometers (Fig. 1B). In just two months of using the laser spectrometers the teams were able to obtain measurements that previously took two decades to perform.

Although the system was regularly calibrated with a standard gas, there are obvious differences and inconsistencies between the records. These arise from leaks in the setup and from incomplete gas extraction. For the 2010 records the only way to calibrate the data was to measure some individual samples. While, in principle, the measurements should be continuous, they were in fact broken up into sections of $1.1 \mathrm{~m}$. At the beginning of each section the cavities of the spectrometers are filled with standard gas, which is then slowly replaced with sample gas. Over the course of time in places where sample and standard gas coexist in the cavity the methane concentration of the sample cannot be measured, and in the 2010 setup up to one third of the sample was lost, resulting in only some sections being continuously measured for their methane concentration.

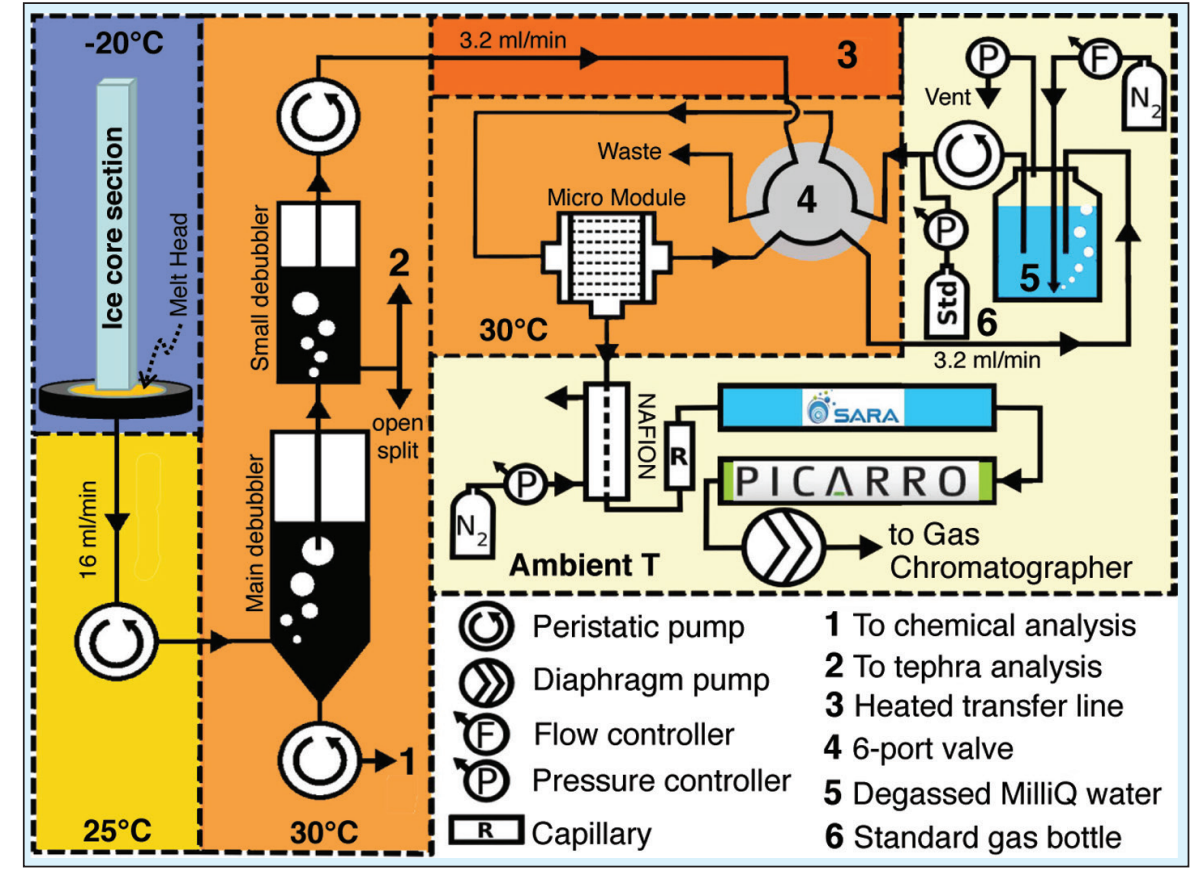

Figure 2: Schematic of the NEEM 2010 field setup for measuring methane concentrations.

Since 2010, there has been continuous development and improvement in the sample calibration procedure. We now receive good data getting the system into a dynamical steady state situation. In this way solubility correction and eventual leaks are constant and identical for calibration measurements and samples. The precision of the laser systems is significantly better than that of a Gas Chromatograph system with an uncertainty as small as $0.4 \%$.

Stowasser et al. (2012) investigate to what degree the time resolution of methane records can be improved by continuous measurements. Atmospheric variations are smoothed by traveling through the open porous space (firn) in the top part of the ice sheet (the first $\sim 60-100 \mathrm{~m}$ ) before the gas becomes trapped permanently in the ice. To obtain the full resolution of the smoothed concentration record trapped in the ice, the dispersion by the measurement system has to be less than the smoothing that occurs in the firn layer. The CIC system obtains a spatial resolution of $5 \mathrm{~cm}$, which is adequate to detect any climatically relevant fluctuations in methane back to at least $66 \mathrm{ka}$ BP in the NEEM ice core.

The significant advantage of the online gas concentration measuring technique is the higher resolution that can be obtained in a very short amount of time. This is especially true for the last millennium and part of the Holocene where the system enables a sub-annual temporal resolution on the NEEM ice core to be obtained. At first glance this ability is meaningless, as the atmospheric variations (e.g. annual fluctuations) are completely smoothed out, but we also found indications of sub-annual methane signals in the NEEM ice core. These signals could point to either in-situ production of methane in the NEEM ice or, alternatively, an artifact of the trapping process of air in the firn layer (e.g. stratigraphic inversions due to firn layers trapping gases at different depths) (Rhodes et al. unpublished data). Future investigations are necessary to clarify these issues.

\section{Outlook}

Laser spectrometer development has rapidly improved over the past few years. In the future it will be possible to analyze not only one atmospheric component such as the methane concentration described here, but a suite of atmospheric components simultaneously. This has already been achieved by the SARA instrument, which has measured both methane and carbon monoxide on a section of the NEEM ice core. Within the framework of the Past4Future project, online measurements of trace gases will be able to supply climate models with the most complete dataset to date.

\section{Selected references}

Full reference list online under:

http://www.pages-igbp.org/products/newsletters/ref2013_1.pdf

Bigler M et al. (2011) Environmental Science and Technology 45: 44834489

Blunier T et al. (2007) Climate of the Past 3: 325-330

Kaufmann PR et al. (2008) Environmental Science and Technology 42 8044-8050

Schüpbach S et al. (2009) Environmental Science and Technology 43: 5371-5376

Stowasser C et al. (2012) Atmospheric Measurement Techniques 5: 9991013 


\title{
Sea level variations during the last interglacial
}

\author{
Mark Siddall ${ }^{1}$, R.C.A. Hindmarsh ${ }^{2}$, W.G. Thompson ${ }^{3}$, A. Dutton ${ }^{4}$, R.E. Kopp ${ }^{5}$ and E.J. Stone ${ }^{6}$ \\ 'Department of Earth Sciences, University of Bristol, UK; mark.siddall@bristol.ac.uk \\ ${ }^{2}$ Science Programmes, British Antarctic Survey, Cambridge, UK; ${ }^{3}$ Department of Geology and Geophysics, Woods Hole Oceanographic Institu- \\ tion, Woods Hole, USA; ${ }^{4}$ Department of Geological Sciences, University of Florida, Gainesville, USA; ${ }^{5}$ Department of Earth \& Planetary Sciences \\ and Rutgers Energy Institute, Rutgers University, New Brunswick, USA; ${ }^{6}$ School of Geographical Sciences, University of Bristol, UK
}

\section{The Last Interglacial Global Mean Sea Level is believed to be 6 to $9 \mathrm{~m}$ above the present and might have two distinct maxima. Here, we discuss the possible fluctuations and their implications for ice sheet evolution.}

$T$ he duration and timing of the Last Interglacial (LIG) Global Mean Sea Level (GMSL) fluctuations are active areas of research, with distinct features of this sea level change increasingly being reproduced in diverse datasets and syntheses (Dutton \& Lambeck 2012; Kopp et al. 2009; Thompson et al. 2011). We review and discuss these possible changes in LIG GMSL and, in particular, what we may infer from them in terms of changes to continental ice.

\section{Implications of the magnitude of the LIG GMSL maximum relative to today}

Kopp et al. (2009) first synthesized a database of local sea level reconstructions for the LIG using statistically rigorous techniques within the framework of a glacioisostatic adjustment model. They estimated that GMSL during the LIG peaked above $6.6 \mathrm{~m}$ (95\% probability), but was unlikely to have peaked above $9.4 \mathrm{~m}$ (33\% probability).
Through an alternative deterministic approach, Dutton and Lambeck (2012) found very similar results with a range of 5.5 to 9 $m$. This puts LIG sea level within the window of other Quaternary GMSL maxima $( \pm$ $10 \mathrm{~m}$ around modern sea level; Siddall et al. 2006) but places the LIG GMSL higher than most past interglacial GMSL.

The Antarctic ice sheet may have, therefore, retreated considerably during the LIG (by 0.7 to $7.6 \mathrm{~m}$ sea level equivalent), given the modeled estimates of the other contributing factors to sea level variations such as ocean thermal expansion and past temperature change (McKay et al. 2011), small glacier and ice cap contribution (Radić and Hock 2010) and Greenland retreat reconstructed from ice cores and ice sheet modeling (e.g. Cuffey and Marshall 2000; Lhomme et al. 2005; Otto-Bliesner et al. 2006; Robinson et al. 2011; Stone et al. 2013; Tarasov and Peltier 2003).

Although the loss of the West Antarctic Ice Sheet (WAIS) has been thought of as the most likely candidate, we cannot afford to simply assume that this is the case on the basis of potentially simplistic first-order assumptions. For example, mechanisms have been suggested which stabilize the WAIS during ice sheet retreat (Gomez et al. 2010). Even under a collapse scenario, the WAIS would be unlikely to totally disappear, instead leaving ice on land and reducing the plausible WAIS LIG sea level contribution to $3.3 \mathrm{~m}$, allowing for the effects of glacial isostatic adjustment and changes in the position of the marine margin (Bamber et al. 2009). This leaves open the possibility of a reduced East Antarctic Ice Sheet (EAIS) during the LIG of up to $4.3 \mathrm{~m}$. Improved understanding of sub-ice sheet topography points to this possibility (Le Brocq et al. 2010; Pingree et al. 2011) and evidence of ice rafted debris originating from zones within the EAIS has been identified for earlier periods in the Antarctic ice sheet history (Pierce et al. 2011).

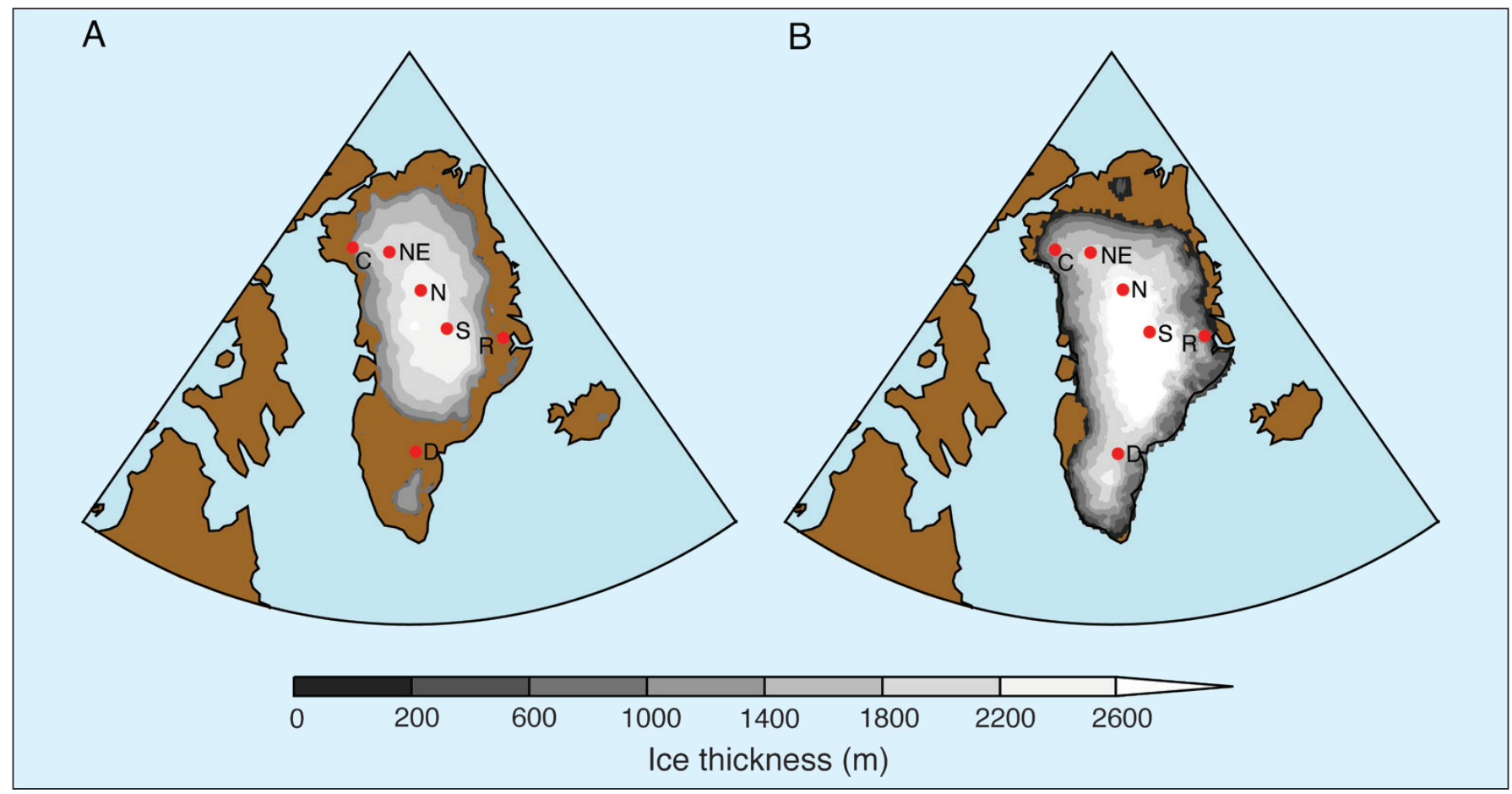

Figure 1: Simulated LIG minimum Greenland ice sheet thickness showing (A) saddle collapse from Otto-Bliesner et al. (2006) and (B) northern ice sheet retreat from Stone et al. (2013). Ice core locations are also shown: Camp Century [C], Dye-3 [D], NEEM [NE], NGRIP [N], Renland [R] and Summit [S]. Note that the presence of ice at Dye-3 may suggest that the saddle collapse mechanism was less extreme than what is shown in (A). Figure modified from Otto-Bliesner et al. (2006) and Stone et al. (2013). 


\section{Implications of the existence of two distinct GMSL maxima during the LIG}

There is a suggestive similarity between the results of Kopp et al. (2009) and Thompson et al. (2011) in a period during which sea level falls and rises again by several meters over several thousand years. The fluctuation has an amplitude of $6.5 \pm 10.5 \mathrm{~m}$ in the GMSL reconstructions of Kopp et al. (2009) and of the order of $5 \mathrm{~m}$ in those of Thompson et al. (2011), in the Bahamas fossil coral terraces (which provide a selfconsistent stratigraphic framework for the fluctuation). Evidence of rapid sea level changes during the LIG exists in distinct stratigraphic units, suggesting multiple reef-growth episodes (e.g. Hearty et al. 2007). However, until recently it has proved difficult to resolve the age differences between distinct reef units. Results from conventional Uranium/Thorium geochronology suggest a long, stable GMSL maximum with only a vague suggestion of any fluctuation (e.g. Stirling et al. 1998). It is certainly worth considering which mechanisms may have driven such fluctuations, if they did indeed occur (Dutton and Lambeck 2012).

We can first consider the implications of the fluctuation amplitude of the order of $5 \mathrm{~m}$. Given this amplitude, we can rule out the effects of ocean thermal expansion and the global glacier budget as their respective contributions are too small to drive such a change (McKay et al. 2011; Radić and Hock, 2010). This leaves the ice sheets. We therefore examine what processes could plausibly explain a signal of this amplitude from the ice sheets and divide these into three classes:

\section{- Contribution from the Greenland ice sheet}

Ice sheet modeling focused on the LIG indicates substantial inland reduction of the Greenland ice sheet compared to the present (e.g. Cuffey and Marshall 2000; Otto-Bliesner et al. 2006; Robinson et al. 2011). Some of these simulations indicate a change from an ice sheet with two domes joined by a saddle to one ice sheet with two separate domes (e.g. Fig. 1A; OttoBliesner et al. 2006; Robinson et al. 2011) while other simulations indicate a retreat of the ice sheet in northern Greenland (e.g. Fig. 1B; Fyke et al. 2011; Stone et al. 2013). Both of these can be argued to be dynamically unstable, driven by a positive feedback. Melting of the ice represented by the saddle could, therefore, result in a fluctuation due to a rapid transition between two stable states. However, the amplitude of any saddle collapse would not be large enough to explain a sea level fluctuation as large as $5 \mathrm{~m}$. Furthermore, ice sheet models have not shown yet such a rapid transition in ice volume for the LIG perhaps due to missing complex physical processes in the models.

Box 1: One possible scenario for evolution of the Greenland and Antarctic ice sheets during the LIG.

The following terms are defined as: GrIS: Greenland Ice Sheet

AIS: Antarctic Ice Sheet

EAIS: East Antarctic Ice Sheet

GMSL: Global Mean Sea Level

WAIS: West Antarctic Ice Sheet

STAGE 1 - The GrlS reaches its minimum first and the AIS has partially retreated (for example, the EAIS is reduced compared to today). GMSL reaches its first peak.

STAGE 2 - The GrIS begins to regrow and the AIS remains partially retreated. GMSL falls.

STAGE 3 - The GrIS continues to regrow but the AIS retreats more quickly (for example the WAIS reduces). GMSL rises.

STAGE 4 - The AIS begins to regrow (now in phase with the GrIS) and the glacial inception commences. GMSL falls.

\section{- Contribution for the West Antarctic ice sheet}

Changes to the Antarctic ice sheet would presumably occur largely at the margins in regions of sub-marine based ice, such as the WAIS or Wilkes-Aurora regions. Complete collapse of the WAIS to small ice caps in Marie-Byrd Land and Ellsworth Land is in some senses dynamically analogous to a Greenland saddle-collapse. Although this ice provides a good explanation for the high GMSL during the LIG, it is an open question as to whether grounding-line readvance could occur sufficiently fast to initiate the sea level fall. A re-advance of the WAIS may not be an adequate explanation for GMSL fall and rise based on our present understanding.

\section{- Contribution of both Antarctic and Greenland ice sheets}

The final set of explanations refers to the phasing of the ice sheet minima in Greenland and Antarctica. Given the difference in the phasing of insolation and the plausible hemispheric asymmetry in meridional heat transfer between the poles (e.g. Stocker and Johnsen 2003), there is no special reason to assume that the ice sheet minima are coincident. There are many possible combinations of this phasing. Box 1 provides one of the more plausible scenarios.

Distinguishing these different options is a matter for future research. One key avenue will be dating the timing and duration of the GMSL maxima, because this will help elucidate mechanisms related to Northern and Southern Hemisphere insolation. Another key avenue will be exploiting geographic patterns in sea level change, combined with sedimentary observations near ice sheets, to constrain changes in different ice sheet volumes over the LIG. More observations to better constrain the magnitude of the sea level oscillation will be critical to help discern the potential ice sheets involved. Finally, additional suggestions that GMSL during the LIG peaked more than twice (Rohling et al. 2008; Thompson et al. 2005; Thompson et al. 2011) would require more creative thinking in terms of understanding the mechanisms driving these persistent oscillations.

Oppenheimer et al. (2008) define the concept of "negative learning" in the following terms: "New technical information may lead to scientific beliefs that diverge over time from the a posteriori right answer". Whatever the story really is, evidence for high, fluctuating GMSL during the LIG must leave us with very open minds regarding ice sheet behavior to avoid the past traps of "negative learning" when it comes to past and future changes in ice sheets.

\section{Acknowledgements}

This discussion largely came out of the PALSEA PAGES workshop held at University of Wisconsin, Madison in June 2012 (this issue, p. 40). We are grateful to Bette Otto-Bliesner for providing the results shown in Fig. $1 \mathrm{~A}$.

\section{Selected references}

Full reference list online under:

http://www.pages-igbp.org/products/newsletters/ref2013_1.pdf

Dutton A, Lambeck K (2012) Science 337: 216-219

Kopp RE et al. (2009) Nature 462: 863-867

Le Broca AM, Payne AJ, Vieli A (2010) Earth System Science Data 2: 247-260

Oppenheimer M, O'Neill BC, Webster M (2008) Climatic Change 89: $155-172$

Thompson WG, Curran HA, Wilson MA, White B (2011) Nature Geoscience 4: 684-687 


\title{
Paleofire workshop
}

\author{
Venice, Italy, 21-23 June 2012
}

\section{Natalie Kehrwald ${ }^{1}$, C. Barbante ${ }^{1,2}$, C. Whitlock and V. Brovkin ${ }^{4}$}

'Department of Environmental Science, Informatics and Statistics, University of Venice, Italy; kehrwald@unive.it ${ }^{2}$ Institute for the Dynamics of Environmental Processes, Consiglio Nazionale delle Ricerche, Venice, Italy; ${ }^{3}$ Department of Earth Sciences, Montana State University, Montana, USA; ${ }^{M}$ Max Planck Institute for Meteorology, Hamburg, Germany

F ires are an integral aspect of the Earth System, affecting climate through the release of aerosols and greenhouse gases, altering natural vegetation patterns and land carbon storage, and transforming land use. Charcoal, ice core, and modeling communities have been addressing climate and fire interactions from different perspectives. Each community has historically used separate approaches. This difference can partly be attributed to proxy availability or the necessity to produce data for various audiences including fire control and time-slice climate reconstructions. This workshop aimed at facilitating interactions between the three communities. The key workshop goals were to:

(1) Determine the status of existing data from each group and analyze the strengths and weaknesses of each data type,

(2) Identify how we can present our data so that each community (charcoal, ice core and modeling) can best use the results to further improve understanding of fire-related processes,

(3) Highlight ways to integrate the data of each group.

The charcoal community has compiled the Global Charcoal Database (GCD; www.ncdc.noaa.gov/paleo/impd/gcd. $\mathrm{html}$ ) to create regional reconstructions and analyses of fire activity during specific time slices. Charcoal records can offer detailed local information that is often used to produce fire danger indices or to aid in land management. There are extensive charcoal records covering North America, the Mediterranean, and Australia, while other areas such as central Russia and Africa have sparse records, due in part to the lack of lakes with suitable sediments. The growing collaboration among researchers who study the impacts of fire and climate over regional scales will allow for the inclusion of charcoal records from larger lakes, permitting a more detailed understanding of fire history, particularly in data-sparse regions.

Ice core reconstructions of past fire activity complement charcoal studies because multiple parameters can be used to distinguish between fires from biomass

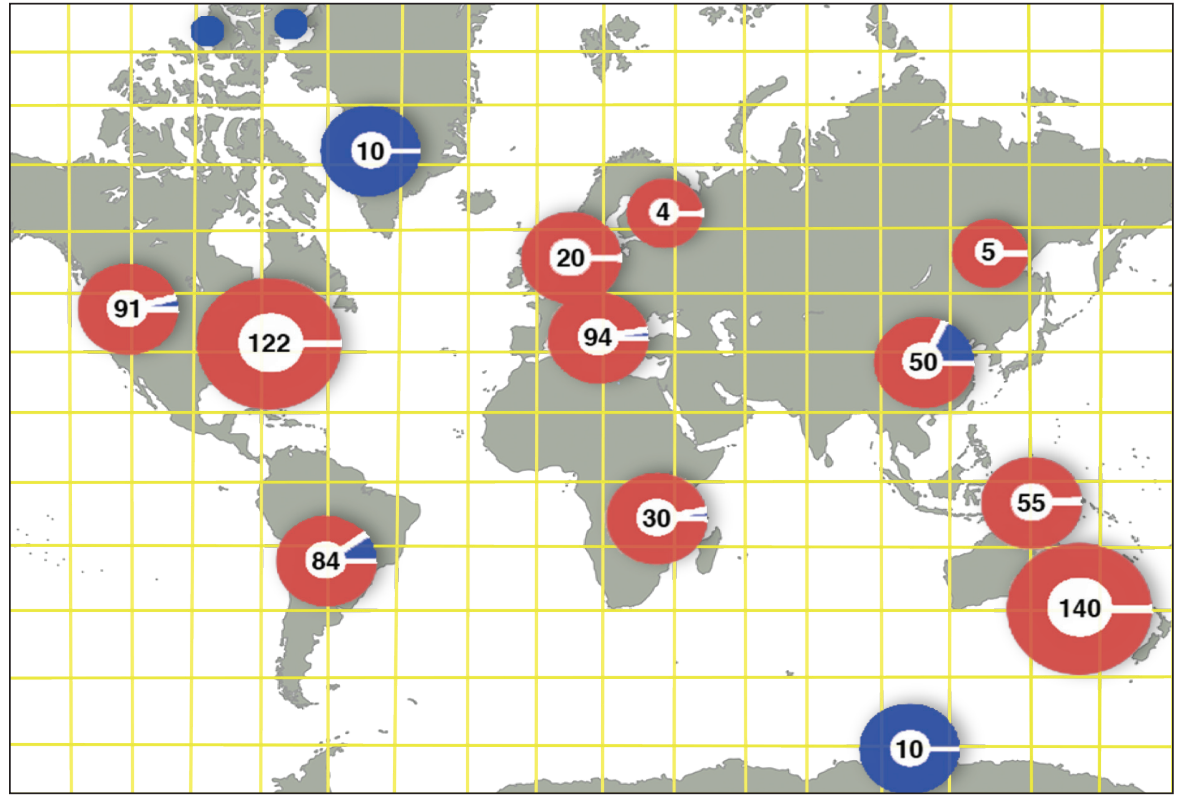

Figure 1: The Global Charcoal Database core locations (red, Daniau et al. 2012) and ice core sites to bedrock (blue) by geographic region. The numbers are the totals of both proxy records per location. The grid is a schematic representation of the ability of climate models to integrate multiple parameters over wide spatial scales and across areas where proxy data do not exist.

fuel sources and those from fossil fuel emissions. Biomass burning tracers in ice cores with atmospheric residence times ranging from days to weeks include black carbon, elemental carbon, particulate organic carbon, monosaccharide anhydrides such as levoglucosan, organic acids, ammonium, nitrate and potassium, polycyclic aromatic hydrocarbons, and charcoal. Markers with an atmospheric residence time ranging from months to years tend to be hemispheric to global in scope. These ice core markers include carbon monoxide, $\delta^{18} \mathrm{O}$ of carbon monoxide, $\delta^{13} \mathrm{C}$ of methane, and non-methane hydrocarbons. The variety of tracers in ice cores allows the researcher to select markers based on a particular research goal, such as the production of high-resolution measurements or the unambiguous determination of past vegetation fires. Such reconstructions are steadily increasing, as new techniques demand smaller sample sizes. However, the multitude of ice core proxies and the novelty of many of these techniques currently create challenges for standardizing records into a compilation similar to the GCD.

Fire models are able to simulate firerelated processes at multiple spatial and temporal scales. Applied to past climates, the current generation of Earth System models is capable of providing regional reconstructions of changes in fuel load and moisture, biomass and burned area, and charcoal deposition. Atmospheric transport models are routinely used to estimate backward trajectories of aerosol particles and trace gases and to identify source and sink regions. Future work includes simulating the transport of tropospheric ozone or tracers such as organic biomarkers and black carbon, as well as a detailed comparison of simulated changes in burned area with charcoal and ice core proxies.

Workshop participants agreed that future research directions should focus on calibration studies for individual proxies, as well as between proxies. The workshop provided an opportunity to begin compiling and using an array of proxy data and model output to address major research questions in interdisciplinary fire science.

\section{Reference}

Daniau A-L et al. (2012) Global Biogeochemical Cycles 26, doi:10.1029/2011GB004249 


\title{
Sea level changes into MIS 5: From observations to predictions
}

\section{NSF Workshop - Palma de Mallorca, Spain, 10-14 April 2012}

\author{
Bogdan P. Onac', J.A. Dorale ${ }^{2}$ and J.J. Fornós ${ }^{3}$ \\ 'Department of Geology, University of South Florida, Tampa, USA; bonac@usf.edu \\ ${ }^{2}$ Department of Geoscience, University of lowa, USA; ${ }^{3}$ Departament de Ciències de la Terra, Universitat de les IIles Balears, Palma, Spain
}

$S^{e a}$ ea level history throughout the Quaternary shows a complex spatial and temporal pattern, and provides a globally averaged record of continental ice volume variations (Alley et al. 2005; Lambeck and Chappell 2001). Observations of this variability provide key constraints on the timing and amplitude of the forcing mechanisms that trigger the growth and decay of ice masses. With over a third of the world's population living near coastlines, understanding the history and future impacts of global sea level change ranks as a top priority in the Earth sciences.

As uncertainties are inherent to the methodologies and settings of all sea level reconstructions, there is a continued need for additional, independent sources of sea level data that may provide unique insights and crosschecks to the existing framework of former eustatic changes in sea level. The coastal caves of Mallorca with their unique speleothem encrustations (Fig. 1) provide one such source of additional sea level data (Tuccimei et al. 2012), which can be used to precisely document the elevation and timing of various sea level stands in the western

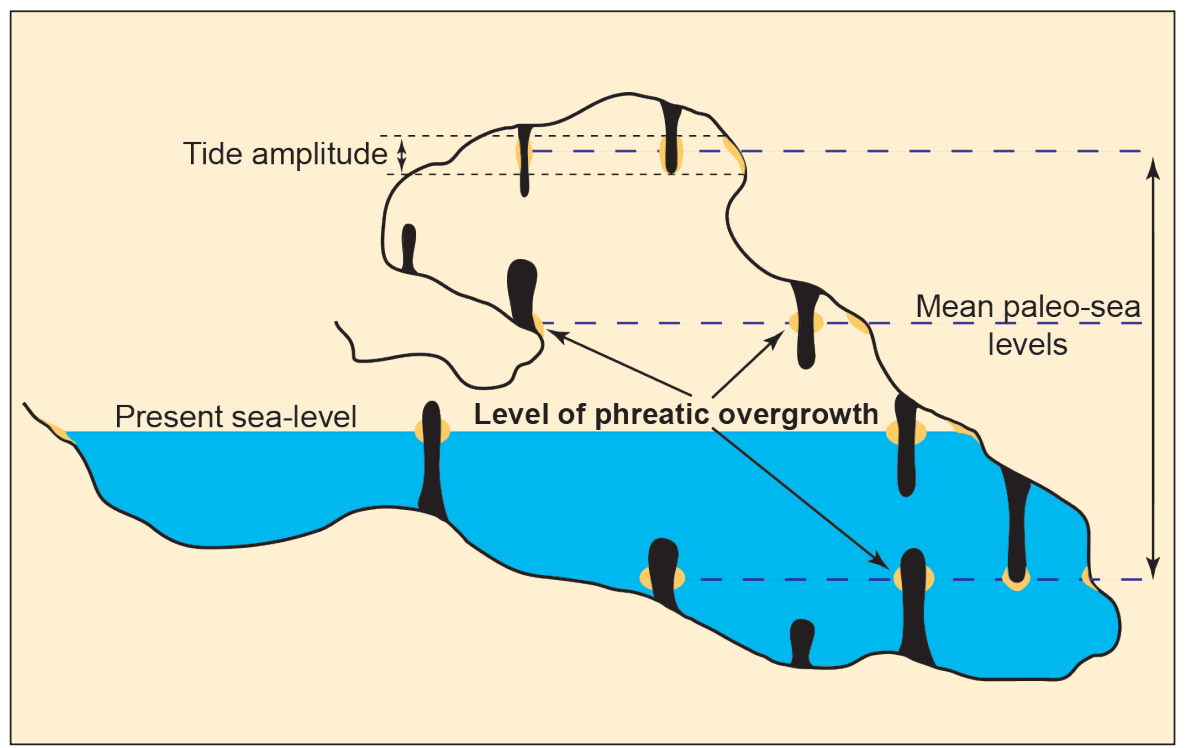

Figure 1: Schematic cross-section through a coastal cave in Mallorca showing multiple levels of phreatic overgrowth on speleothems. Past sea water levels (long dashed lines) left clear encrustation marks on existing speleothems or along the cave walls (shown in yellow). Figure modified after Tuccimei et al. (2012). resolution (Dorale et al. 2010). The western Mediterranean was chosen as the workshop site so that participants (especially those working with corals, ice, or models) could visit the coastal caves of Mallorca and acquaint themselves with the setting of this promising approaches (Fig. 1).

The purpose of the workshop was to bring together an international group of researchers to discuss and promote opportunities for collaboration on the topics of sea level data acquisition, calibration, and modeling. The meeting attracted 43 participants from nine countries, including 15 students and early career scientists. The workshop focused on the interpretation of sea level changes during marine isotope stage 5 (MIS 5) and the onset of MIS 4.

The event was organized into three distinct sections: two days of presentations (both oral and poster), two days of field trips, and a half-day round table discussion that concluded the meeting and explored directions for future research. The first section included 20 oral presentations, of which six were
Mediterranean region with sub-meter invited keynotes, and nine were posters. The speakers covered a wide spectrum of problems pertinent to sea level changes, including detailed studies of reef and marine terraces, submerged speleothems, marine notches, marine sediment sequences, phreatic overgrowth on speleothems, flank margin caves, cave minerals, timing of MIS 5, Quaternary fauna, and advanced sea level modeling studies. Sea level modeling was a major focus of discussion during the round table, which tackled the following topics: (1) ways of reconciling controversial MIS 5 a data sets from sea level fields around the world, (2) the use of glacio-hydro-isostasy modeling to address the issue above, (3) challenges in addressing past sea level positions and how the community should bridge the gap between field observation and models, and (4) observational and modeling constraints on sea level rise/fall and ice extent/volume.

Finally, the workshop highlighted the interactions among researchers at various stages of their careers, from well-established scientists to junior faculty members, with particular emphasis on the participation of post-doctoral, undergraduate, and graduate students.

\section{Acknowledgements}

The Organizing Committee would like to thank the U.S. NSF (OISE project \#1022243), the Spanish Government's Ministerio de Economía y Competitividad/FEDER (project CGL2010-18616), PAGES, and USF Libraries for the generous financial and logistic support that made the workshop possible. Support by members of the Karst Research Group at the University of South Florida and students at the University of Balearic Islands were greatly appreciated.

\section{References}

Alley RB, Clark PU, Huybrechts P, Joughin I (2005) Science 310: 456460

Dorale JA et al. (2010) Science 327: 860-863

Lambeck K, Chappell J (2001) Science 29: 679-686

Tuccimei P et al. (2012) Quaternary International 262: 56-64 


\title{
$5^{\text {th }}$ PALSEA Workshop - Madison, Wisconsin, USA, 6-8 June 2012
}

\author{
Andrea Dutton ${ }^{1}$, E.J. Stone ${ }^{2}$ and A. Carlson ${ }^{3}$ \\ 'Department of Geological Sciences, University of Florida, Gainesville, USA; adutton@ufl.edu \\ ${ }^{2}$ School of Geographical Sciences, University of Bristol, UK; ${ }^{3}$ Department of Geoscience, University of Wisconsin, Madison, USA
}

$T^{\text {nestan }}$ he $5^{\text {th }}$ annual PAGES PALSEA Working Group workshop held in June 2012 was dedicated to understanding paleo constraints on future sea level rise. The main focus of this workshop was on ice sheet climate interactions and their implications for coastal engineering, although discussions also addressed a broader range of issues such as database efforts (A. Rovere, Columbia University, USA), ongoing challenges for modelers and observational scientists, and how and where these issues intersect. The workshop drew 39 participants, with strong international representation, bearing the hallmark of previous PALSEA workshops. A broad range of expertise was represented including climate and ice sheet modeling, glacial-isostatic modeling, and field-based techniques addressing prior ice sheet extent and relative sea level position - all the techniques needed to estimate future local sea level rise.

The sessions revolved around several themes, largely addressing ice sheet response and ice-climate interactions on a variety of timescales - from the early and late Holocene to previous interglacials as well as the Pliocene and the future.

In particular, among the variety of topics discussed, there was focus on the quantitative sources of additional water to the last interglacial sea level highstand. New analyses of Greenland Ice Sheet behavior during this time period were presented (Helsen et al. 2011; Stone et al. 2013; A. Quiquet, CNRS, France and D. Dahl-Jensen, University of Copenhagen, Denmark), in addition to a synthesis of Greenland Ice Sheet contributions from the past 20 years that generated in-depth discussion on the likely budget from Greenland and Antarctica. The geometry of the Greenland Ice Sheet during this time period was also discussed with different methodologies showing similar patterns of substantial loss of ice from the southwest (Fig. 1).

Another prominent topic was the deterministic versus stochastic nature of ice sheet response and the concept of ice sheet "weather" (M. Siddall, University of Bristol, UK). This led to a debate on the ability to use hazard analysis tools to assess the possible ice sheet contribution to sea level over the coming century based on the idea that outlet glaciers of ice sheets may not behave smoothly. Other discussions included assessments of the present (see Figure 1) and future behavior of the Greenland and Antarctic Ice Sheets from both a paleo and present modeling perspective (P. Applegate, Stockholm University, Sweden; P. Whitehouse, Durham University, UK; R. DeConto, University of Massachusetts, USA).

The mechanism of saddle collapse between ice domes in North America via a simple height-mass-balance feedback was proposed to explain rapid meltwater events during the last deglaciation (Gregoire et al. 2012). The applicability of this mechanism to other ice sheets of various sizes during different time periods was also discussed.

Data-oriented presentations focused on a wide range of questions and techniques on the Greenland and Antarctic Ice Sheets during the Holocene (J. Anderson, Rice University, USA; R. Hindmarsh, British Antarctic Survey, UK; Anders Carlson) and Pliocene (R. Ackert, Harvard University, USA), featuring summaries of field data for the 8.2-ka event (Törnqvist and Hijma, 2012) and of late Holocene ice sheet behavior (A. Long, Durham University, UK).

In addition to the scientific themes, workshop participants held discussions with Ben Strauss from Climate Central (climatecentral.org) to identify effective and appropriate public communication pathways on issues related to past sea level position and future sea level behavior.

On behalf of the workshop participants in Madison this year as well as those of previous PALSEA workshops, we would like to take this opportunity to thank Mark Siddall, Bill Thompson (Woods Hole Oceanographic Institution, USA), and Claire Waelbroeck (CNRS, France) for their leadership and vision over the past 5 years. PALSEA has been instrumental in bringing together diverse expertise to address common questions in the study of

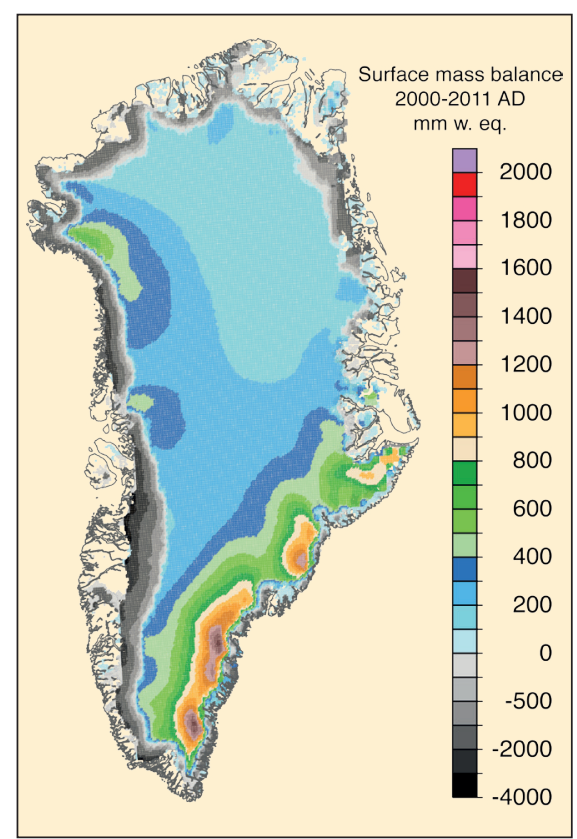

Figure 1: Surface mass balance in $\mathrm{mm}$ water equivalent ( $\mathrm{mm}$ w. eq.) averaged spanning a 12-year period (2000-2011) according to mass accumulation rate simulations. Gray areas indicate the ablation area. Models from the last interglacial period discussed at the workshop identify the southwest region of Greenland as an area of significant retreat similar to present patterns of areas dominated by ablation versus accumulation. Figure from Box et al. (2012).

past ice sheet and sea level behavior with the goal of exploring what this knowledge brings to bear on future sea level change. We look forward to the ongoing multiplier effect of this collaboration throughout our community in the years to come, as Anders Carlson, Andrea Dutton, Antony Long and Glenn Milne (University of Ottawa, Canada) assume leadership.

\section{Acknowledgements}

The organizers thank the following organizations for their support: PAGES, INQUA, the World Universities Network and the Department of Geoscience at the University of Wisconsin.

\section{References}

Box JEetal. (2012) The Cryosphere 6: 821-839 Gregoire L, Payne AJ, Valdes PJ (2012) Nature 487: 219-222

Helsen MM et al. (2011) American Geophysical Union, Fall Meeting 2011, abstract \#C53C-0685

Stone E, Lunt DJ, Annan JD, Hargreaves JC (2012) Climate of the Past 9: 621-639

Törnqvist TE, Hijma MP (2012) Nature Geoscience 5: 601-606 2759-2781 


\title{
Modes of variability in the climate system: Past-Present-
}

\section{Future}

European Science Foundation Conference - Ötztal, Austria, 27 May - 1 June 2012

\author{
Hubertus Fischer ${ }^{1}$ and ERIC W. WolfF ${ }^{2}$ \\ 'Climate and Environmental Physics and Oeschger Centre for Climate Change Research, University of Bern, Switzerland; hubertus.fischer@ \\ climate.unibe.ch \\ ²British Antarctic Survey, Cambridge, UK
}

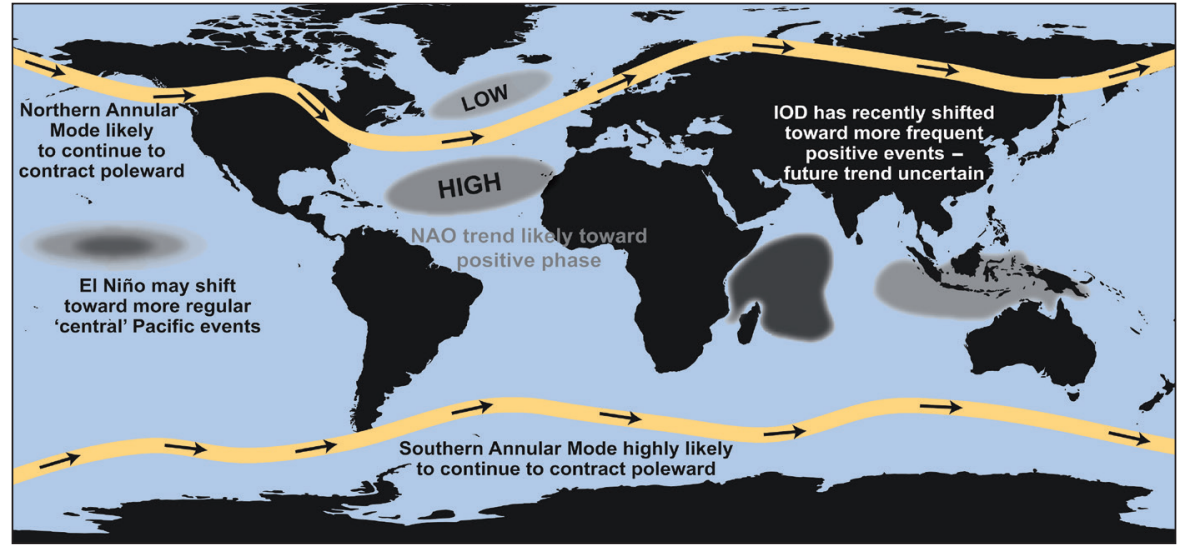

Figure 1: Schematic diagram showing the major modes of climate variability and how they are likely to change in the future. The high-latitude modes have already undergone significant change over the past century. Trends in the tropical modes (ENSO, Indian Ocean Dipole IOD) have been detected in the more recent climatological record (from England 2011).

A ssessing the ongoing climate warming demands a detailed understanding of global and regional climate variations as well as the capacity to forecast future changes using climate models. While greenhouse gas forcing affects climate globally, it is the regional changes that have a direct impact on individual welfare and societies. Moreover, spatially representative climate modes and teleconnection patterns offer the means to contrast rather coarsely-resolved climate models to point-wise paleoclimate data.

Accordingly, modes of climate variability and their biogeochemical impact were the subject of this conference. The first session provided the background on the definition of modes and teleconnection patterns based on observational evidence. Moreover, the physical context of atmospheric and oceanic teleconnections by advection and wave propagation was provided.

Session 2 focussed on tropical climate variability. Latest results show that the ENSO impact is not confined to the tropical Pacific but that hydrological changes and wave propagation transfer energy to other ocean basins. However, representation of ENSO in global climate models is still not satisfactory, hampering progress in making predictions. Past monsoon intensity was another discussion point. It appears to be highly controlled by the Atlantic Meridional Overturning Circulation (AMOC) and concurrent changes in the Intertropical Convergence Zone.
Completely different boundary conditions for modes of climate variability prevailed during the last glacial, which was the topic of session 3. Model studies show that the topography of ice sheets has a strong control on the teleconnection patterns in the North Atlantic and also likely in the Southern Ocean. Moreover the phase relationship between ice sheet retreat, greenhouse gases and ocean circulation shows that climate changes in the Southern Ocean slightly preceded the $\mathrm{CO}_{2}$ increase over the transition, while increasing $\mathrm{CO}_{2}$ accelerated ice sheet loss in the northern hemisphere and led climate changes in the North.

Extratropical teleconnection patterns were the subject of session 4. Reconstructions show that the North Atlantic Oscillation (NAO) also has far-field connections to adjacent regions. The discussion showed that field reconstructions are more desirable for NAO analysis compared to two-point indices. For the Southern Ocean region the Southern Annular Mode (SAM) is the most important teleconnection pattern. Latest results show that both ozone and greenhouse gases can change the location of the southern jet stream and the Southern Ocean westerlies. The lack of a sufficient representation of the stratosphere/troposphere coupling in many models is a major caveat for the model response of the SAM to climate changes.

Session 5 raised the discussion that changes in the ocean circulation modes such as the AMOC and the Antarctic Circumpolar Current can also cause strong changes in inter-hemispheric heat transport and atmospheric $\mathrm{CO}_{2}$ levels. During the glacial, proxy evidence shows that a less-ventilated, carbon enriched water mass prevailed in the Southern Ocean extending into the deep North Atlantic as well as into intermediate waters. Changes in both the southern westerly winds and in the AMOC are able to disrupt this water mass, bringing old $\mathrm{CO}_{2}$ back to the surface. Model studies also show that changes in the AMOC lead to rapid hemispheric responses in climate and the hydrological cycle, which are essentially synchronous with the shut-off of the AMOC.

Changes in the AMOC also have strong impacts on tropical and boreal wetlands and, thus, methane emissions as discussed in session 6. Another influence of changing modes on biogeochemical cycles is the control of the southern westerly wind belt on dust mobilization and transport in the Southern Ocean region, which also strongly affects marine bioproductivity. Ecological studies show that export production can be significantly enhanced by iron fertilization. However, this is not always the case - it depends on complex ecological interaction within the trophic chain and the competition between calcareous and silicious plankton groups.

In addition to invited lectures and poster sessions, several interactive discussions were organized to identify the major gaps and stumbling blocks in research on modes and teleconnection patterns and potential solutions. The conference demonstrated unequivocally that trans- and interdisciplinary research is required to move forward in this field of strong societal importance.

\section{Acknowledgements}

This Conference was co-sponsored by PAGES, the EPICA Descartes Prize, the Oeschger Centre for Climate Change Research (University of Bern, Switzerland), and the German Research Foundation through the project INTERDYNAMIK (University of Bremen, Germany).

\section{Reference}

England MH (2011) In: Richardson K, Steffen W, Liverman D (Eds) Climate Change: Global Risks, Challenges and Decisions, Cambridge University Press, 33-35 


\section{Department of Earth Sciences, University of Cambridge, Cambridge UK, 2-5 July 2012}

Polychronis C. Tzedakis ${ }^{1}$, J.F. McManus ${ }^{2}$, D. Raynaud ${ }^{3}$, D.A. Hodell ${ }^{4}$, L.C. Skinner ${ }^{4}$ and E.W. WolfF ${ }^{5}$

'Department of Geography, University College London, UK; p.c.tzedakis@ucl.ac.uk

'Lamont-Doherty Earth Observatory of Columbia University, New York, USA; ${ }^{2}$ Laboratoire de Glaciologie et Géophysique de l'Environnement, Grenoble, France; ${ }^{4}$ Department of Earth Sciences, University of Cambridge, UK; ${ }^{5}$ British Antarctic Survey, Cambridge, UK

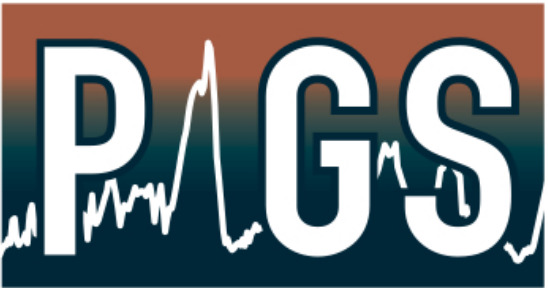

PAST INTERGLACIALS
E amination of the paleoclimate record reveals a large diversity among interglacials in terms of their intensity, duration and internal variability, but a general theory accounting for these differing characteristics remains elusive (Tzedakis et al. 2009). This has provided the impetus to attempt a comprehensive comparison of interglacials of the last $800 \mathrm{ka}$ BP within the context of a PAGES Working Group on Past Interglacials (PIGS).

An initial PIGS workshop held at Bernin, France in October 2008, laid out the themes to be addressed at each of three subsequent workshops. A second workshop, held at the University of the Aegean on the Island of Lesvos, Greece in August 2009, examined intra-interglacial variability and the deglacial onset of interglacials. The third workshop, held at Lamont-Doherty Earth Observatory of Columbia University, USA in October 2010 focused on the duration of interglacials and the ensuing glacial inception. The fourth workshop, held in Cambridge, UK in July 2012, focused on how well we can explain the diversity of interglacials from the forcing and feedbacks. The meeting brought together 35 scientists from 10 countries (including nine postdoctoral investigators and two PhD students), representing the marine, ice core, terrestrial and modeling communities.

The first theme of the workshop was on interglacial intensities, and more specifically, whether the distinction between "cooler" and "warmer" interglacials before and after the socalled Mid-Brunhes Event (MBE) 430 ka BP, respectively, identified in Antarctic temperatures, $\mathrm{CO}_{2}$ concentrations and benthic $\delta^{18} \mathrm{O}$ records (Jouzel et al. 2007; Lüthi et al. 2007; Tzedakis et al. 2009; Fig. 1C-D) was evident in other records. A review of the evidence

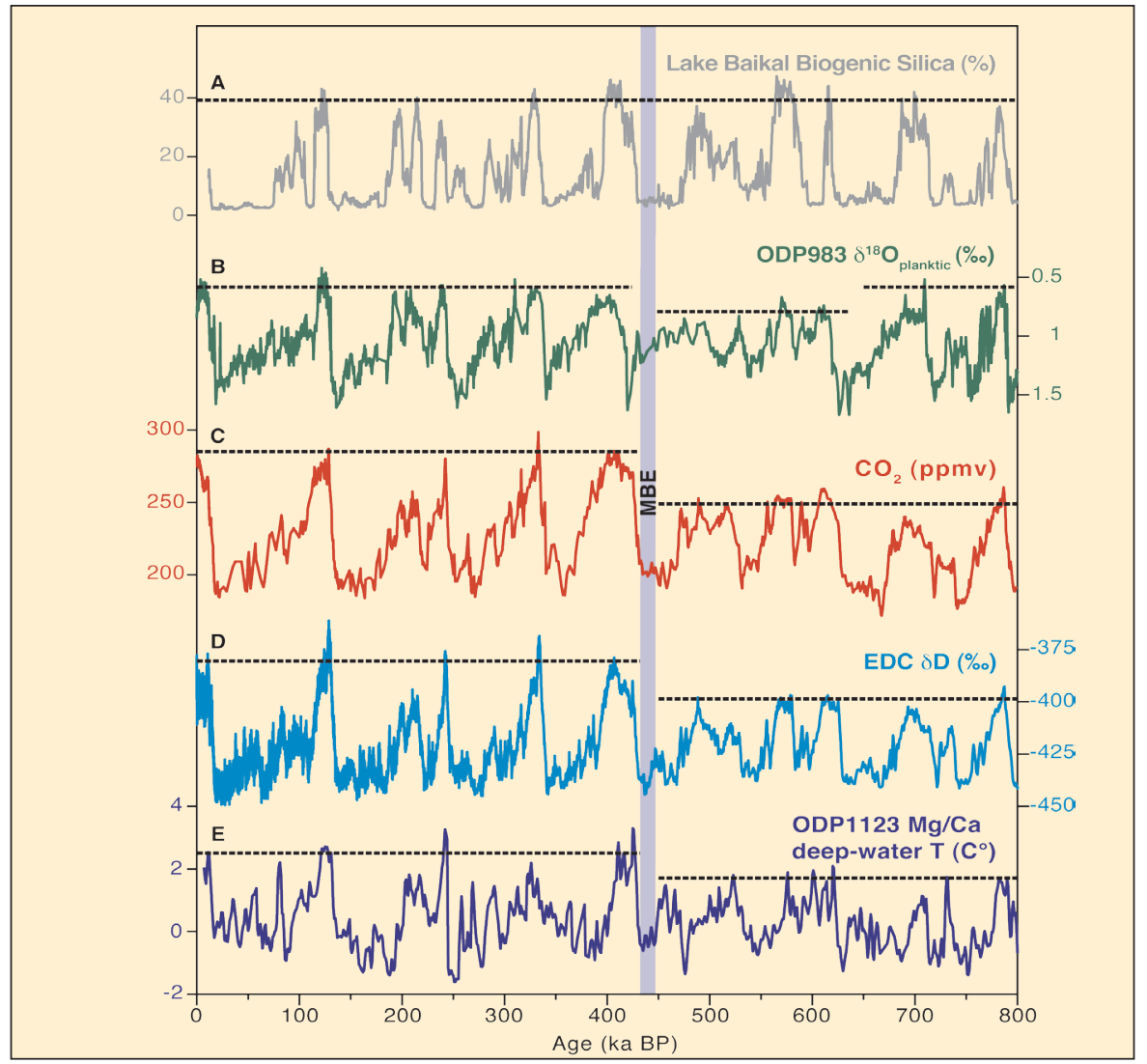

Figure 1: Differences in interglacial intensities in relation to the Mid-Brunhes Event (MBE; $430 \mathrm{ka} B P$ ). A) Percent biogenic silica in composite sequence BDP-96 from Lake Baikal, SE Siberia (Prokopenko et al. 2006); (B) Planktonic $\delta^{18}$ O record from ODP Site 983, North Atlantic (Channell et al. 1998; Channell and Kleiven 2000); (C) Atmospheric $\mathrm{CO}_{2}$ concentration in Antarctic ice cores (Lüthi et al. 2008); (D) $\delta$ D composition of ice in the EDC ice core (Jouzel et al. 2007); (E) Mg/Ca deep-water temperatures from ODP site 1123 on the Chatham Rise, SW Pacific (Elderfield et al. 2012). showed that a pre- and post-MBE distinction was also observed in deep-water temperature reconstructions (Elderfield et al. 2012), but not in some regional marine and terrestrial records, including speleothems, faunal and floral temperature reconstructions and lake sediment records (Fig. 1A-B). This raises questions about the global significance of the MBE and the extent to which Antarctic temperatures are representative of global temperatures during the pre-MBE interglacials.

The second theme of the workshop revolved around the duration of interglacials. More specifically, it examined the sequence of climatic events at glacial terminations and inceptions and considered whether any emerging patterns could be identified. This was followed by a discussion of whether differences in the duration of interglacials can provide insights into climate forcings and feedbacks that are relevant to the onset and end of interglacials. It was proposed that the broad duration of interglacials may be determined by the phasing of precession and obliquity and the history of insolation, rather than the instantaneous forcing strength at inception (Tzedakis et al. 2012).

The third theme considered whether models are capable of "explaining" the diversity of interglacials, and what they imply in terms of rules and processes. Finally, interglacials were placed within the wider context of glacial-interglacial cycles and the extent to which these are deterministic was debated.

The meeting ended with a session summarizing the discussions and planning a community paper that will develop the major themes considered over the course of the project. To this end, a writing-workshop, involving a focus group is taking place in March 2013.

\section{Selected references}

Full reference list online under:

http://www.pages-igbp.org/products/newsletters/ref2013_1.pdf

Elderfield H et al. (2012) Science 337: 704-709

Jouzel J et al. (2007) Science 317: 793-796 Lüthi D et al. (2008) Nature 453: 379-382

Tzedakis PC et al. (2009) Nature Geoscience 2: 751-755

Tzedakis PC et al. (2012) Climate of the Past 8: 1473-1485 


\title{
$1^{\text {st }}$ Sea Ice Proxies (SIP) Working Group workshop, Montréal, Canada, 7-9 March 2012
}

\author{
Anne de Vernal' ${ }^{1}$, E.W. WolfF ${ }^{2}$ and R. Gersonde ${ }^{3}$ \\ 'GEOTOP, Université du Québec à Montréal, Canada; devernal.anne@uqam.ca \\ ${ }^{2}$ British Antarctic Survey, Cambridge, UK; ${ }^{3}$ Alfred-Wegener-Institute for Polar and Marine Research, Bremerhaven, Germany
}

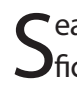
ea ice is a complex parameter that is dificult to reconstruct from indirect observations. While climate scientists often refer to sea ice as a purely physical parameter, geoscientists reconstruct past sea ice assuming it plays a role in the biogeochemistry of seawater, and thus on primary productivity and trophic structure of the planktonic populations (e.g. Meier et al. 2011). Moreover, whereas climatologists and modelers examine sea ice at hemispheric scale, geoscientists make reconstructions from coring sites where smallscale processes may obscure larger-scale sea ice behavior relevant to the climate system. Nevertheless, geoscientists have unique tools to contribute to the understanding of long-term sea ice dynamics by providing pictures of past sea ice states. This is the overarching objective of the PAGES Sea Ice Proxies (SIP) working group, which was created in 2011.

To achieve the objective of documenting sea ice in the paleoclimate system with the best possible coverage and accuracy, an assessment of each proxy and the development of multi-proxy approaches are both necessary. During the first workshop, scientists with physical, chemical, and biological backgrounds met to assess the reliability and use of sea ice indicators recovered in marine sediments and ice cores, and the robustness of calibration with instrumental data. The geographical and temporal ranges of application of the different proxies were also considered.

Sea ice proxies include chemical tracers in ice cores such as methanesulfonic acid and sea salt, which relate to regional circum-icecap sea ice extent (Röthlisberger and Abram 2009). Most sea ice proxies, however, consist of biogenic remains recovered from marine sediment such as diatoms, foraminifers, ostracods and dinocysts, as well as the IP25 biomarker (a C25 mono-unsaturated hydrocarbon). Because productivity in sea ice environments mostly occurs close to the ice edge in spring and summer, most biogenic proxies relate to the occurrence of seasonal sea ice. It is more difficult to quantify the seasonality of the ice extent, although diatom and dinocyst assemblages yield information about the yearly extent of the sea ice cover in the Southern Hemisphere (e.g. Crosta et al. 2004) and Northern Hemisphere (e.g. de Vernal et al. 2008), respectively. IP25 and related biomarker indices offer great promise for reconstruction of sea ice (e.g. Belt et al. 2007; Müller et al. 2011), but large-scale calibrations are still needed and the available data suggest primarily regional relationships. Another difficulty is the identification of multiyear ice because of the extremely low productivity of such environments. However, the occurrence of an ostracod species,

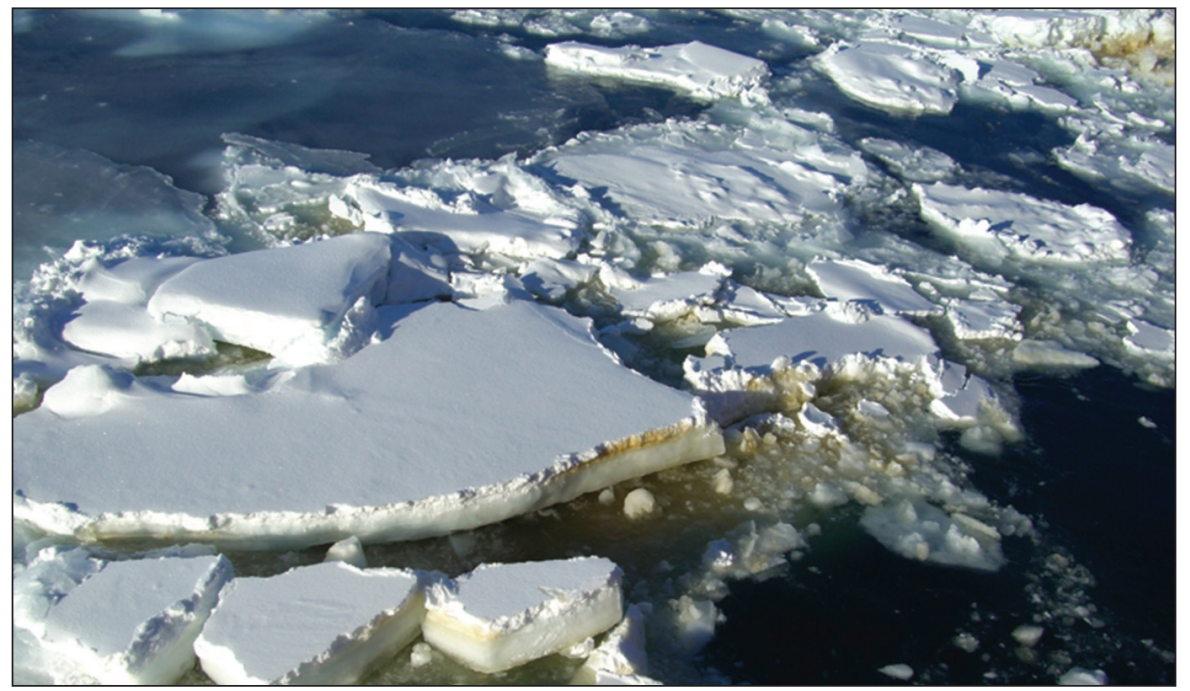

Figure 1: Sea ice edge as a productive environment (photograph from the Southern Ocean and provided by Claire Allen, British Antarctic Survey, UK). parasitic of amphipods living in perennial sea ice environments, may lead to inferences about multiyear ice (Cronin et al. 2010). The shell of Neoquoboquadrina pachyderma, which is the only planktonic foraminifer species found in sea ice environments, may yield an isotopic signature providing clues on sea ice production rates (Hillaire-Marcel and de Vernal 2008).

Each sea ice proxy has limitations and uncertainties. Diatoms have allowed circumAntarctic sea-ice extent reconstructions, but limitations remain where the signal is affected by opal dissolution. Other uncertainties come from the relationship to sea ice that is often indirect, as in the case of dinocyst, foraminifer and ostracod assemblages. In addition, taxonomical heterogeneity of populations in space may be related to endemism or to the development of genotypes having different ecological affinities, which make each biogenic proxy applicable mostly at a regional scale. Hence the Arctic-subarctic and circum-Antarctic have to be considered as distinct sea ice ecosystems with very different biogenic characteristics.

Reconstructing past sea ice is a challenge, which has to be addressed based on proxies offering complementary local to regional information on sea ice occurrence. The SIP Working Group will publish a special issue of Quaternary Science Reviews entitled "Sea ice in the paleoclimate system: modeling challenges and status of proxies" in 2013. The next step is to combine results with their respective uncertainties for multi proxy data integration and hemispheric scale sea ice reconstructions of Holocene and Last Glacial Maximum time slices. This will be the focus of the July 2013 rendezvous of the SIP Working Groupin Cambridge, UK.

\section{References}

Belt ST et al. (2007) Organic Geochemistry 38: 16-27 Cronin TM et al. (2010) Quaternary Science Reviews 29: 3415-3429 Crosta X, Sturm A, Armand L, Pichon JJ (2004) Marine Micropaleontolology 50: 209-223

de Vernal A et al. (2008) In: E. Weaver (Ed) Arctic Sea ice Decline: Observations, Projections, Mechanisms, and Implications, AGU Monograph Series 180: 27-45

Röthlisberger R and Abram N (2009) PAGES news 17(1): 24-26 


\section{Special Section: Investigating past interglacials: An integrative approach}

\section{Editorial:}

- Past4Future - learning from interglacials

\section{Past4Future: Behind the Scenes:}

- Past4Future stakeholder survey

H. Thing

- Lifting the veil on speleothem sampling

S. Verheyden and D. Genty

- Drilling a deep ice core at the NEEM site (Greenland)

J.P. Steffensen

- Sampling marine sediment

R. Gersonde and M.-S. Seidenkrantz

- Insights into paleoclimate modeling

E. J. Stone, P. Bakker, S. Charbit, S.P. Ritz and V. Varma

\section{Science Highlights:}

- Using marine sediment archives to reconstruct past outlet glacier variability

C.S. Andresen, F. Straneo, M.H. Ribergaard, A.A. Bjørk, A. Kuijpers and K.H. Kjær

- Data assimilation to estimate the consistency between proxies and model results

A. Mairesse and H. Goosse

- Increasing fire activity in a warming climate?

N. Kehrwald, P. Zennaro and C. Barbante

- Antarctic interglacial climate and changes in ice sheet topography

V. Masson-Delmotte, E. Capron, H. Goosse, K. Pol, M. Siddall, L. Sime, S. Bradley and B. Stenni

- Land biosphere dynamics during the present and the last interglacials

T. Brücher and V. Brovkin

- Reconstruction of the last interglacial period from the NEEM ice core

D. Dahl-Jensen, P. Gogineni and J.W.C. White

- Speleothem records over the last interglacial

D. Genty, S. Verheyden and K. Wainer

- Dating and synchronizing paleoclimatic records over the last interglacial

E. Capron, A. Landais, P.C. Tzedakis, E. Bard, T. Blunier, D. Dahl-Jensen, T. Dokken, R.

Gersonde, F. Parrenin, M. Schulz, B. Vinther and C. Waelbroeck

- Sea surface temperature controls on water isotopes in Greenland ice cores

L.C. Sime, V. Masson-Delmotte, C. Risi and J. Sjolte

- Reconstruction of past sea ice extent

R. Gersonde and A. de Vernal

- A climate model inter-comparison of last interglacial peak warmth

E. J. Stone, P. Bakker, S. Charbit, S.P. Ritz and V. Varma

- Continuous in-field measurements of gas concentration from ice cores

T. Blunier, J. Chappellaz and E. Brook

- Sea level variations during the last interglacial

M. Siddall, R.C.A. Hindmarsh, W.G. Thompson, A. Dutton, R.E. Kopp and E.J. Stone
PAGES International Project Office

Zähringerstrasse 25

3012 Bern - Switzerland

Tel.: +41316315611

Fax: +41316315606

pages@pages.unibe.ch

www.pages-igbp.org

\section{Workshop Reports:}

- Paleofire workshop

- Sea level changes into MIS 5: From observations to predictions

- Ice sheet climate interactions: Implications for coastal engineering

- Modes of variability in the climate system: Past-Present-Future

- The $4^{\text {th }}$ PAGES past interglacials workshop

- Sea ice in the paleoclimate system

\section{Editors:}

Series Editors:

Lucien von Gunten and Thorsten Kiefer

Guest Editors:

Dorthe Dahl-Jensen, Emilie Capron and Emma Stone

Text Editing: Saadia lqbal

Layout:

Emilie Capron, Emma Stone and Lucien von Gunten

Cover image:

Antarctic iceberg. Image by Emilie Capron

Hardcopy circulation: 2300

\section{ISSN 1811-1602}

Printed on recycled paper by Läderach AG - Bern, Switzerland
The PAGES International Project Office and its publications are supported by the Swiss and US National Science Foundations and NOAA. 